EMBRYARIDDLE
Aeronautical University

SCHOLARLY COMMONS

\section{International Journal of Aviation,} Aeronautics, and Aerospace

8-1-2018

\title{
Determination of Takeoff and Landing Distances Using an iPad Performance Application for the Diamond DA40
}

\author{
Tyler A. Babb
}

Middle Tennessee State University, tyler.babb@mtsu.edu

Christina Hiers

Middle Tennessee State University, christina.hiers@mtsu.edu

Follow this and additional works at: https://commons.erau.edu/ijaaa

Part of the Aviation Safety and Security Commons, Educational Psychology Commons, Management and Operations Commons, Science and Technology Studies Commons, and the Systems Engineering and Multidisciplinary Design Optimization Commons

\section{Scholarly Commons Citation}

Babb, T. A., \& Hiers, C. (2018). Determination of Takeoff and Landing Distances Using an iPad Performance Application for the Diamond DA40. International Journal of Aviation, Aeronautics, and Aerospace, 5(4). https://doi.org/10.15394/ijaaa.2018.1252

This Article is brought to you for free and open access by the Journals at Scholarly Commons. It has been accepted for inclusion in International Journal of Aviation, Aeronautics, and Aerospace by an authorized administrator of Scholarly Commons. For more information, please contact commons@erau.edu. 
Electronic Flight Bags (EFBs) have become standard equipment in both the commercial aviation and aviation training environments. EFBs can provide aeronautical charts, weather information, pilot logbooks, glide advisors, flight plan processing, and many other services. As EFBs gain more capabilities, they are becoming more central to flight operations. For example, cruise performance calculations are now included in some common software (ForeFlight, n.d.). Prior to approving students to use such EFB functions, flight schools should evaluate performance data generated by the EFB to verify accuracy.

At Part 121 air carriers, the hardware and software used to determine aircraft performance parameters are typically evaluated and approved by the appropriate civilian aviation authority. The approval process requires substantial testing, including all parameters and limits as identified by the manufacturer data provided in the Airplane Flight Manual (AFM). Historically, general aviation pilots have determined performance parameters on paper using the manufacturer's information in the approved AFM.

In 2017, a software developer introduced a performance application for general aviation (GA) aircraft, providing an opportunity for GA pilots to use an EFB for fast and accurate aircraft performance calculations. To evaluate this software, guidance from the Federal Aviation Administration (FAA) and the European Aviation Safety Agency (EASA) was tested in a manner as if this software was used by an air carrier. Several civilian aviation authorities around the world have provided guidance to air carriers on how to achieve operational approval for the use of EFBs to calculate takeoff and landing distances. This study applied appropriate regulatory guidance to evaluate this application for accuracy, consistency and recommended human/software interface behaviors.

Research suggests that today's students now use tablet technology on a daily basis for both school and leisure. A recent study found that as many as $86 \%$ of students used tablet computers daily for educational purposes (Cassidy et al., 2014). As for aviation education, this trend may lead to the use of EFBs for more and more functions not only for ease of use but also as a student-preferred method. Effectively, E6B flight computers, sectional charts, and navigation plotters have been replaced by EFBs. If a developer can generate an EFB software that accurately determines performance data, then this could add another usable EFB function for pilots in training. 


\section{Literature Review}

Many companies provide performance data for operators of transport category aircraft. One such company is Aircraft Performance Group (APG), which originally provided dispatch services to air carriers dating back to 1981 (APG, n.d.). After Jeppesen acquired APG in 1995, the company expanded services to offer performance calculations for more than 5,000 general aviation aircraft worldwide (APG, n.d.). Software developers design performance software to satisfy regulatory requirements meet the unique needs of each of their customers. As for air carriers, it is their responsibility to evaluate the software to secure operational approval for specific EFB functions from their appropriate FAA regulatory office.

The newly burgeoning market of general aviation EFB applications is also expanding to performance calculations. ForeFlight Mobile is a very popular EFB application for GA pilots and has been found to have the most usable software design when compared with competitors (Schwartzentruber, 2017). Software such as Foreflight was first used to replace sectional charts and low enroute IFR charts, but the capabilities of these EFB applications are growing. ForeFlight introduced performance calculations in 2017 (ForeFlight, 2017). The pilot can now choose a performance profile, and then the software calculates fuel burn inflight using a manufacturer's recommended power setting (Foreflight, 2017). However, ForeFlight Mobile does not yet support detailed performance parameters such as takeoff and landing distance.

Takeoff and landing performance calculations are essential skills even for student pilots. The FAA's Private Pilot Airmen Certification Standards (ACS) require that a private pilot applicant exhibit satisfactory knowledge and skills associated with operating an aircraft safely within performance limitations and manage the risk of inaccurate use of performance charts (FAA, 2017). Basic aircraft performance parameters are discussed in the FAA's Pilot's Handbook of Aeronautical Knowledge. This text provides pilots with instructions on how to determine takeoff distance using charts very similar to the charts used in this study. 


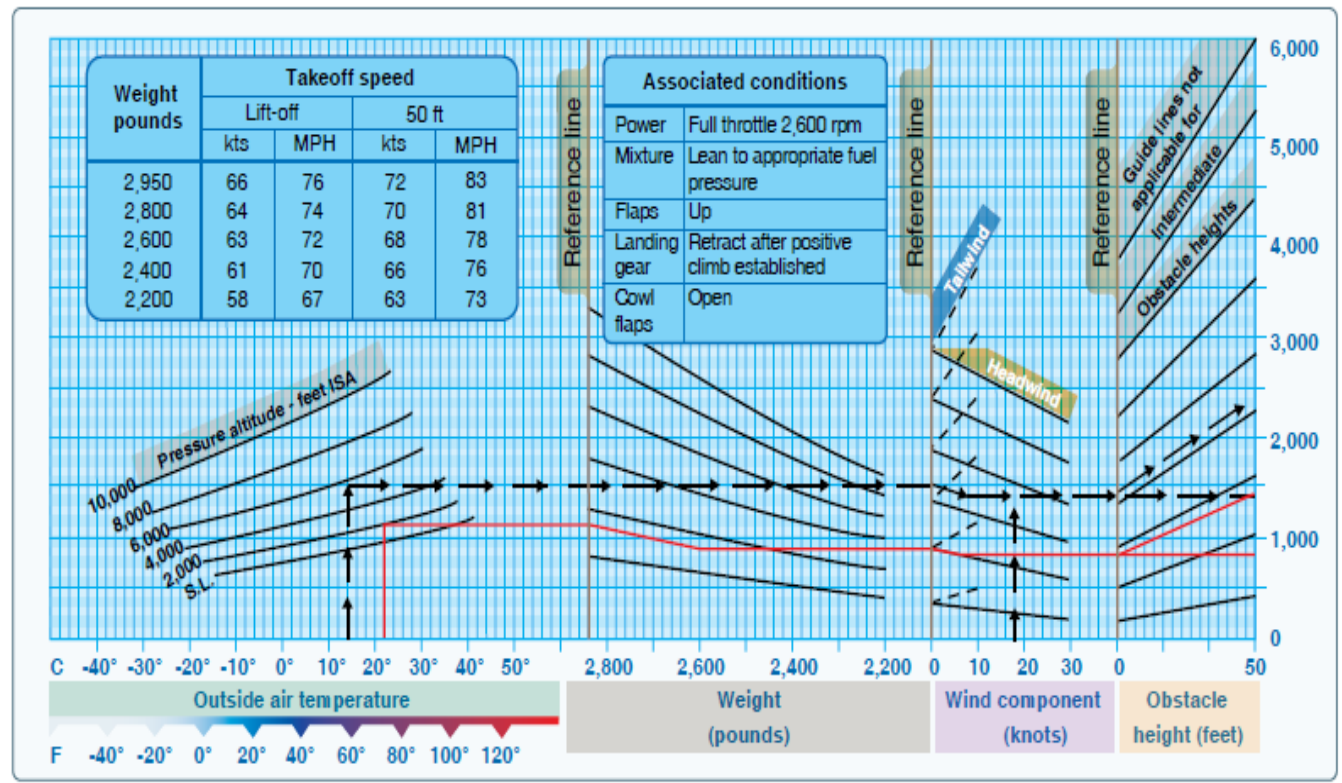

Figure 1. FAA Instructions on How to Determine Takeoff Distance (Pilot's Handbook of Aeronautical Knowledge, 2017)

When pilots calculate takeoff and landing distance, they must account for several variables. These variables include, but are not limited to temperature, pressure altitude, aircraft weight, and winds. Most data provided by manufacturers assume that for takeoff and landing distances, the runway surface is smooth, ungrooved, and dry (FAA, 2017). If the runway condition is contaminated, then these factors affect both the acceleration and deceleration capabilities of the airplane, greatly increasing distances required (FAA, 2017).

The FAA provides both the regulatory requirements and guidance on how to determine aircraft performance parameters in the United States. Federal Aviation Regulation (FAR) 91.103, titled "Preflight Action," requires pilots to determine takeoff and landing distances, as well as the runway distances available for each flight (FAA, 2018). This guidance is broad but applies to all flight operations. This requirement is directly related to safety. A pilot must ensure that there is enough runway available to takeoff or land.

The FAA provides guidance to for EFB operational approval in Advisory Circular (AC) 120.76D. The AC is intended for use by air carriers such as airlines and air charter companies. The primary purpose of this document is to assist air carriers in securing operational approval to use EFBs for specific functions. The document outlines limitations as they relate to performance calculations 
accomplished by an EFB. Performance calculation software types are categorized by AC 120-76D. Type B software essentially replaces a paper AFM performance chart and requires specific authorization by the FAA prior to being used for performance determinations for an air carrier operation. This software essentially duplicates the manufacturer's performance information from the respective FAAapproved AFM by using the same input data with algorithms (FAA, 2017).

According to AC $120.76 \mathrm{D}$, operational approval requires type $\mathrm{B}$ performance software to (1) adhere to existing approved data and be validated for accuracy within the entire aircraft operating envelope, (2) interpolate data, but not extrapolate data, and (3) be based upon existing published data found in the FAAapproved AFM, POH, or performance manual for an aircraft (FAA, 2017). The document also states that "applications are suitable only insofar as they accurately reproduce the AFM data" (FAA, 2017, p. 17). In the United States, air carriers, operators must go through at least a six-month demonstration period using EFBs to receive operational approval for (FAA, 2017).

An aviation software developer named Gyronimo has released several versions of their Performance Pad application. Unique versions of the Performance Pad are available for several small aircraft, many of which are used primarily for flight training. Gyronimo offers five types of performance planning for the Diamond DA 40, including weight and balance, takeoff, climb, cruise and landing performance. In many cases, the application provides more information than the AFM charts, essentially adding E6B flight planning capabilities. For this study, only the takeoff and landing performance data that could be verified with AFM charts was evaluated. Any additional information provided by Gyronimo would need to be investigated separately for validation.

When the Gyronimo Performance Pad application is first opened, it states "Please note: The Gyronimo Performance Pad is a student, professional pilot, and flight instructor assistance tool for plausibility checks and flight training only. All graphics and data provided in this application are used as examples. For flight planning, the original Pilot's Operating Handbook must be used!" (Gyronimo, 2017). However, if the Gyronimo application generates acceptable data, then it could potentially be approved and used in a flight training environment.

When using a computer to generate performance data, errors can occur. The human/software interface can have negative impacts upon accurate performance calculations. Data entry errors are the most common reason that software generates incorrect performance data (Australian Transport Safety Bureau, 2011). By design, the software should manage incorrect and/or inaccurate data entry. A recent study 
investigated these types of errors and found that the primary human/machine interface concerns were data entry, reading, and selection errors (Joslin, 2013). If a pilot provides the software with incorrect input, the output will be incorrect. Not only does the software require correct input, but the assumptions made by the software must also reflect the data provided by the manufacturer (Bos, 2009).

Using a computer to determine performance parameters may simplify and shorten the process, but even professional pilots have made data entry errors, and these errors have caused accidents. In 2014, the Australian Transport Safety Bureau released a research report documenting how erroneous pilot input can cause performance planning errors which directly affected aviation safety. Their research investigated 31 international accidents and incidents in which data entry errors were a factor (ATSB, 2014). Each of these cases involved air carriers with experienced and trained flight crews. Despite all the training and certification requirements for both flight crews and EFB software, the human/machine interface and data entry errors are a major concern in aviation safety.

FAA Order 8900.1 provides many details for the evaluation of the software from a human factors perspective. The document includes a checklist to evaluate data entry issues. Specifically, the document addresses incorrect data entry and software behavior when the data entered is out of the operating envelope. For example, if a maximum gross takeoff weight is 2,646 pounds, but a user inputs 2,800 pounds, the software should recognize the incorrect data and generate an error message. Other suggested evaluation questions applicable to the software are included in Table 1.

\section{Method}

Takeoff and landing distances were calculated using AFM paper charts and then the Gyronimo application. The paper performance charts were retrieved from a Diamond DA40 Approved Airplane Flight Manual, Revision 8 (Diamond 2010). Twenty-five takeoff performance calculations and 24 landing performance calculations were generated based upon FAA and EASA guidance, effectively duplicating the typical EFB approval process for an air carrier. For each performance determination, all potential variables were manipulated to ensure a thorough evaluation. The first tests for takeoff and landing distances used the default variables described in the AFM. Subsequent tests then changed individual variables from their minimum to maximum value, and all other variables were consistent from the first test. Table 2 displays the specific test conditions for takeoff and landing distance. The landing distance with a tailwind was not included, as the AFM did not provide that data. 
Table 1

FAA Order 8900.1: Checklist Items for Performance Calculations from the Electronic Flight Bag Program Evaluation and Authorization (FAA, 2017)

\begin{tabular}{c|l}
$\begin{array}{c}\text { Question } \\
\text { Number }\end{array}$ & \multicolumn{1}{c}{ Human/Machine Interface Questions } \\
\hline 1 & $\begin{array}{l}\text { Does the device identify entries having an incorrect format or type and } \\
\text { does it generate an appropriate error message? }\end{array}$ \\
\hline 2 & Does the error message clarify the type and range of data expected? \\
\hline 3 & Are units for performance data clearly labeled? \\
\hline 4 & $\begin{array}{l}\text { Do the labels used in the EFB match the language of the operator } \\
\text { document? }\end{array}$ \\
\hline 5 & $\begin{array}{l}\text { Is all the information for a given task presented together or easily } \\
\text { accessible? }\end{array}$ \\
\hline 7 & $\begin{array}{l}\text { Can the crews modify performance calculations easily, especially when } \\
\text { making last-minute changes? }\end{array}$ \\
\hline 8 & $\begin{array}{l}\text { Are outdated results of performance calculations deleted when } \\
\text { modifications are entered? }\end{array}$ \\
\hline 9 & $\begin{array}{l}\text { Does the display and/or crew training provide information to the crew on } \\
\text { the assumptions on which the calculations are based? }\end{array}$ \\
\hline $\begin{array}{l}\text { Are the assumptions made about any calculation as clear to pilots as } \\
\text { similar information would be on a tabular chart? }\end{array}$
\end{tabular}

The European Aviation Safety Agency (EASA) is the civilian aviation authority for all European Union nations plus Switzerland, Norway, Iceland, and Liechtenstein (EASA, n.d.). In response to the growing number of applications for EFB approval, EASA performed research on how to improve the EFB operational approval process by surveying eleven different aviation authorities. Their findings recommend specific test points for performance scenarios, and each was used for the takeoff and landing performance calculations in this study. The recommended test points were as follows: (1) hot and high test condition, (2) standard atmosphere test condition, and (3) adverse weather/low-temperature condition (EASA, 2017). The report from EASA also recommended gathering data from other operatorspecific test conditions. 
Table 2

Specific Test Conditions

\begin{tabular}{l|l} 
Test \# & \multicolumn{1}{|c}{ Specific Condition } \\
\hline 1 AFM & All AFM Default \\
\hline 2 AFM & Max Gross Weight \\
\hline 3 AFM & Maximum tailwind (10 Knots) \\
\hline 4 AFM & Maximum Pressure Altitude \\
\hline 5 AFM & Maximum Outside Air Temperature \\
\hline 6 AFM & $2 \%$ Positive Runway Slope \\
\hline 7 AFM & Wet Grass (2-4 inches) \\
\hline 8 AFM & Hot, High (Pressure Altitude 9,000 feet and 30 \\
\hline 9 AFM & ISA Condition (MSL) with no Wind \\
\hline 10 AFM & ISA Condition (MSL) with 20 knot Headwind \\
\hline 11 AFM & ISA Condition (5,000 feet) with no Wind \\
\hline 12 AFM & $\begin{array}{l}\text { ISA Condition (5,000 feet) with 20 Knot } \\
\text { Headwind }\end{array}$ \\
\hline 13 AFM & Extreme Low Temperature (Pressure Altitude \\
\hline 14 AFM & Temperature - 5 C \\
\hline 15 AFM & Temperature 15 C \\
\hline 16 AFM & Temperature 30 C \\
\hline 17 AFM & Pressure Altitude 1,000 feet \\
\hline 18 AFM & Pressure Altitude 4,000 feet \\
\hline 19 AFM & Pressure Altitude 8,000 feet \\
\hline 20 AFM & Weight 2,000 Pounds \\
\hline 21 AFM & Weight 2,400 Pounds \\
\hline 22 AFM & Weight 2,600 Pounds \\
\hline 23 AFM & 7 Knot Headwind \\
\hline 24 AFM & 14 Knot Headwind \\
\hline 25 AFM & 20 Knot Headwind \\
\hline 100
\end{tabular}

First, takeoff and landing distances were generated using AFM charts. These charts provide example data for users. Both the takeoff and landing charts include the following four variables: outside air temperature (OAT), pressure altitude, airplane weight, and headwind component. These charts generate two distances for takeoff and landing. The ground roll is the distance the airplane travels on the runway, and the distances over a 50-foot obstacle provide the lateral distance required to either (1) climb to 50 feet AGL during takeoff or (2) descend and land from 50 feet AGL during landing. Examples of the AFM charts are provided in Figures 2 and 3. 
The same data was then provided to the Gyronimo software for performance calculations. The software has two pages available for both takeoff and landing. The first page is the default page and displays all applicable variables and visually shows the ground roll and distance over a 50-foot obstacle. On the right side of the default page, the application provides specific takeoff data (accurate to the nearest whole foot). The application also allows for users to view the original AFM chart and shows (with circles) how each variable is placed into the calculation. These application pages are shown in Figures 4 and 5.

One challenge when comparing the distances generated by the two different methods was associated with the numbers themselves. The AFM charts are inherently less accurate than the numbers generated by Gyronimo. The pilot must properly use and interpret the chart. The method used to generate distances with the paper charts included a line that was about 10 feet thick on the paper chart. For this study, each AFM distance calculation was rounded to the nearest unit of 10 (i.e. 930 feet). An example of the AFM chart determination is shown in Figure 6. However, the distances generated by the Gyronimo application show the distance to the nearest foot (i.e., 943 feet).

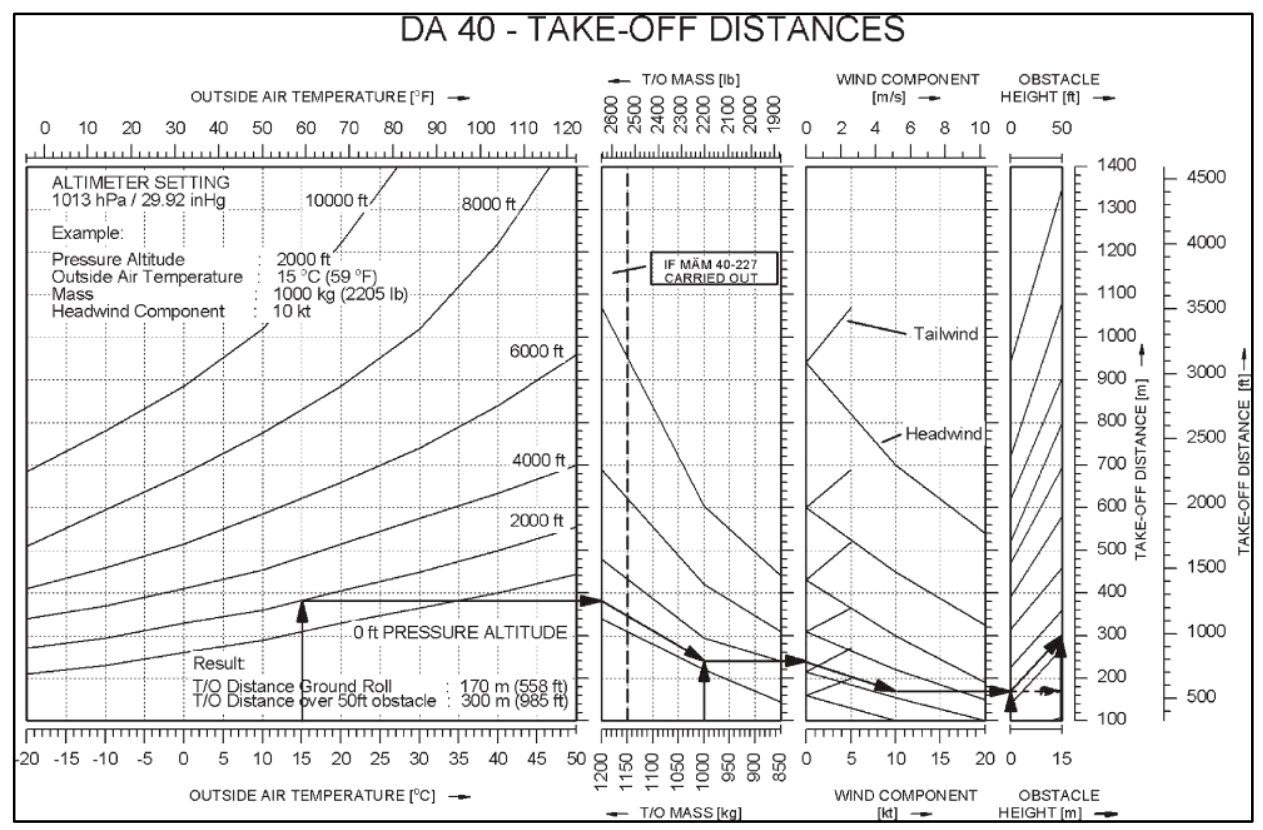

Figure 2. Default Conditions Provided on DA40 AFM Takeoff Distance Chart. 


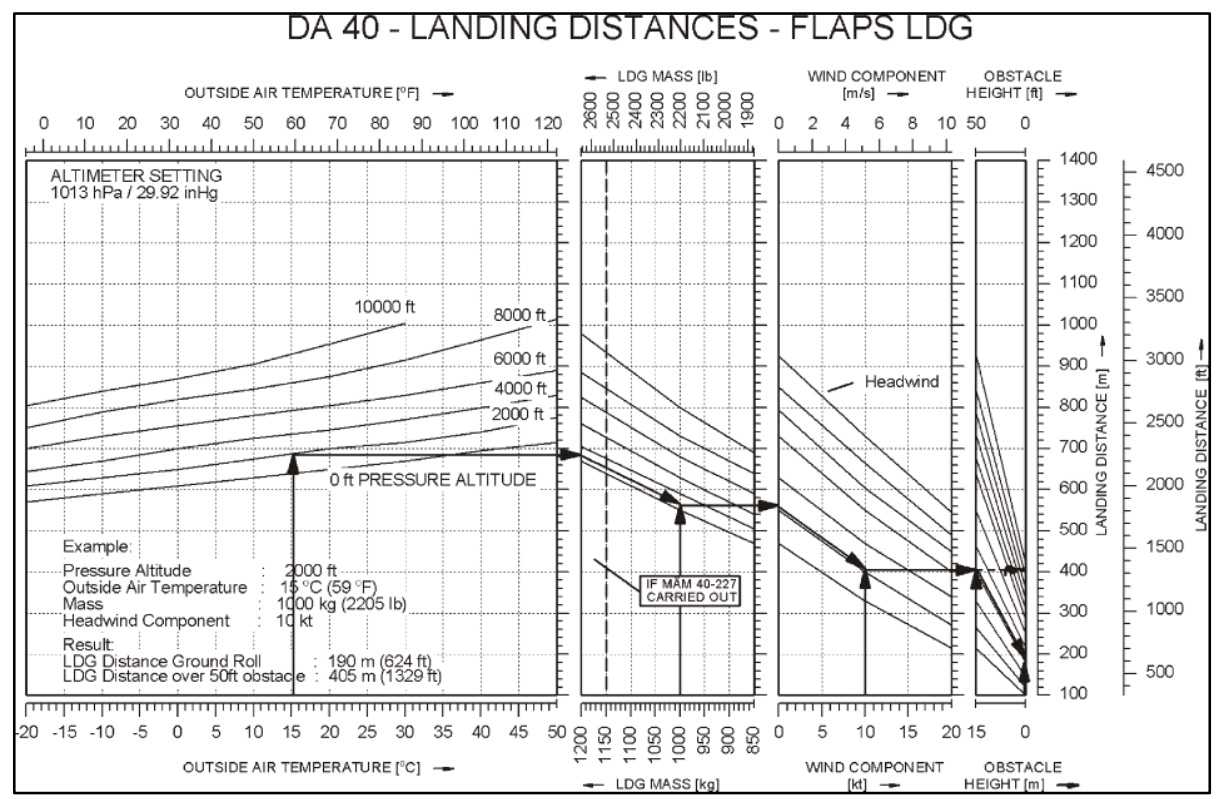

Figure 3. Default Conditions Provided on DA40 AFM Landing Distance Chart.

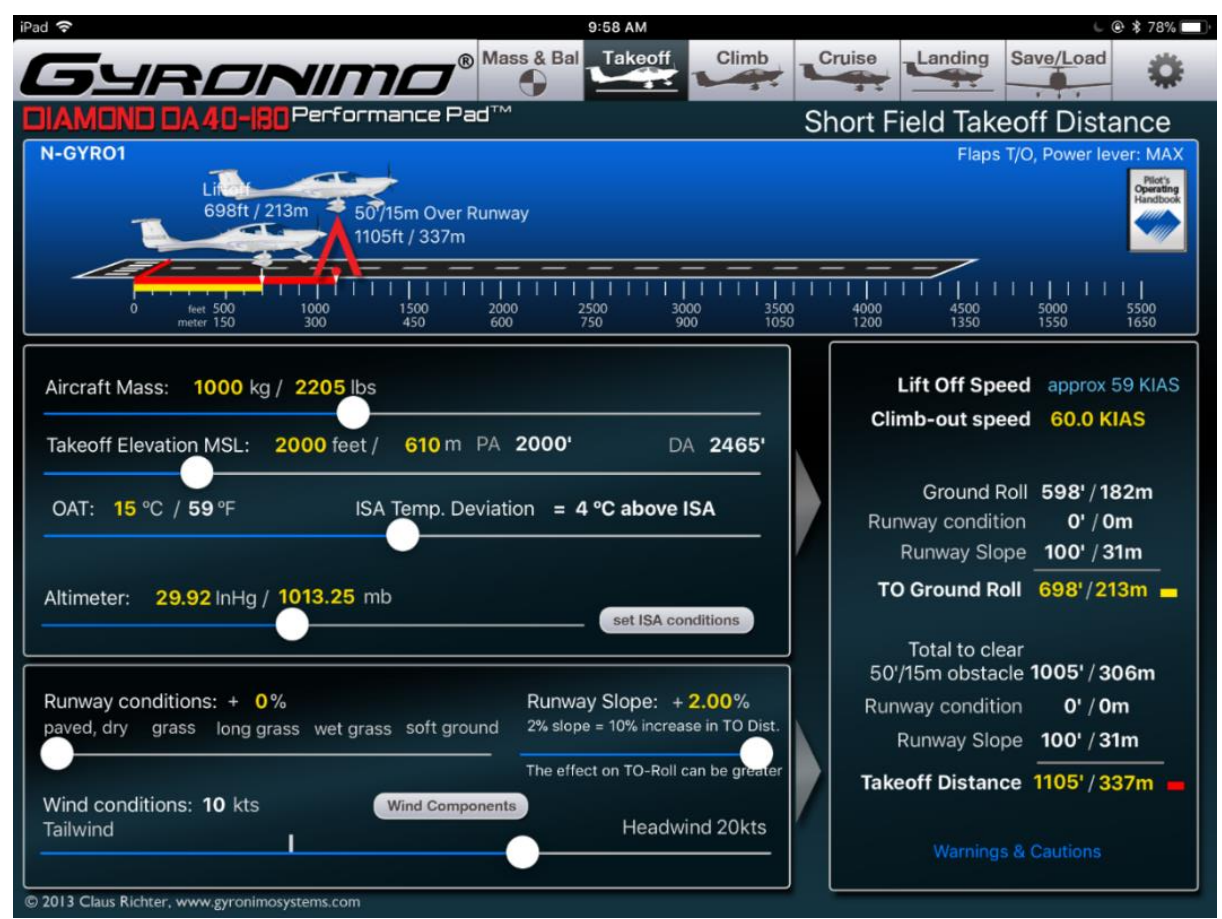

Figure 4. Gyronimo Performance Pad Takeoff Distance Default Page 
International Journal of Aviation, Aeronautics, and Aerospace, Vol. 5 [2018], Iss. 4, Art. 1

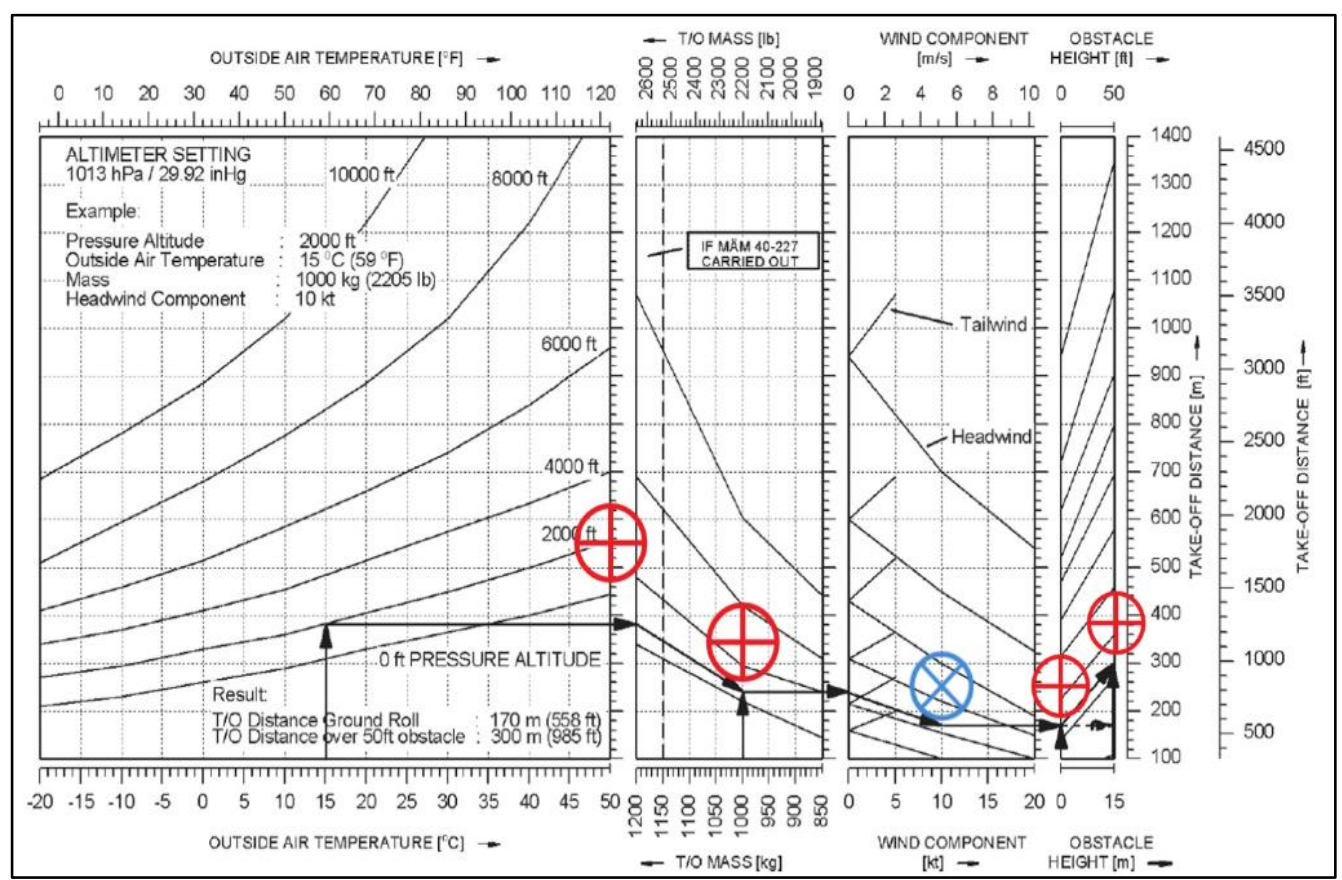

Figure 5. Gyronimo Performance Pad Takeoff Distance AFM Page.

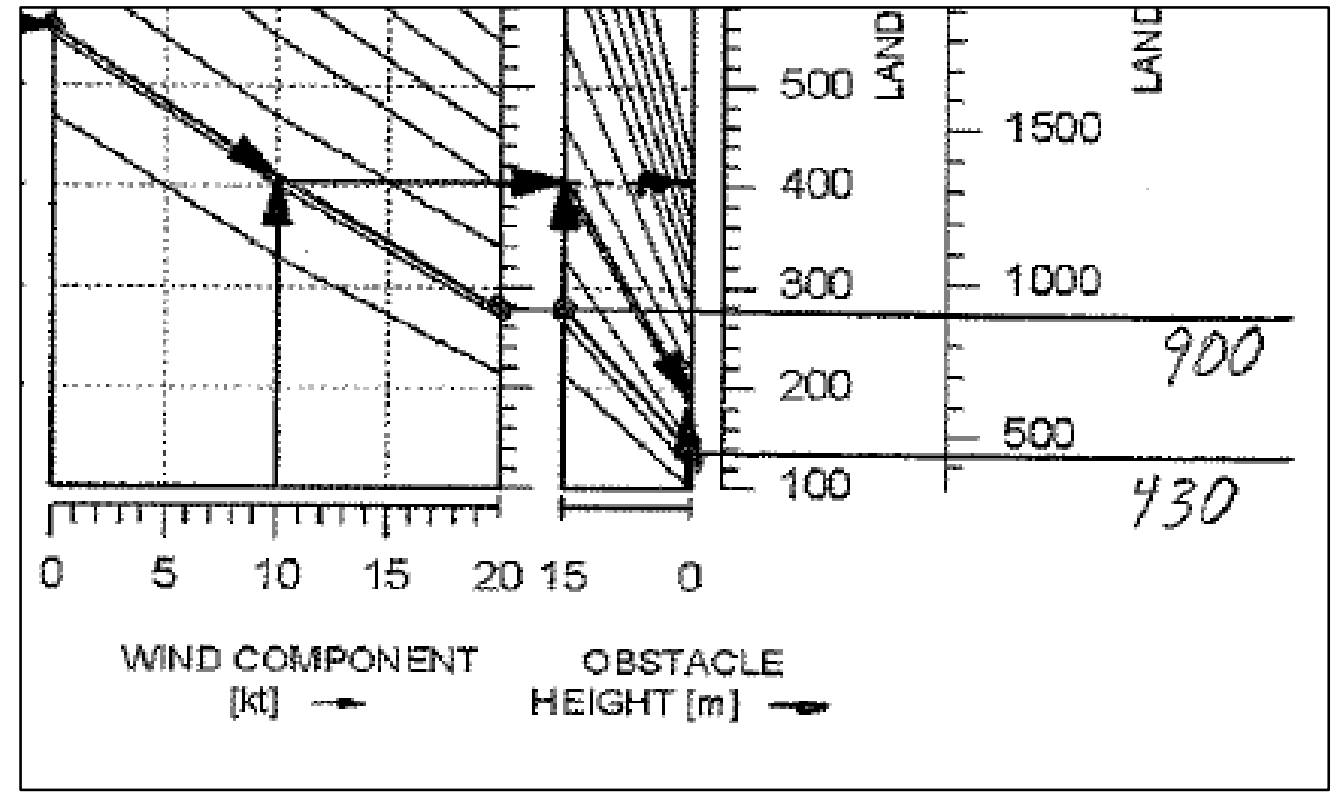

Figure 6. AFM Landing Distance Excerpt Showing Human Interpretation of Landing Ground Roll Distance and Landing Distance Over a 50-Foot Obstacle. 


\section{Results}

In general, the Gyronimo application provided similar performance data as the AFM. The human/software interface had a few deviations from suggested behavior, but otherwise satisfied FAA recommendations. More importantly, the actual distances generated by Gyronimo were similar to data generated from the AFM. This results section first discusses the human/software interface issues and then provides the evaluation of the performance data generated by Gyronimo.

FAA guidance emphasizes that Type B performance applications may interpolate data, but must not extrapolate data. Prior to beginning calculations, the limits of takeoff and landing variables were compared. With some variables, the limits did not match. For example, the minimum and maximum pressure altitudes were slightly different. When calculating takeoff distance, the AFM charts allowed for a maximum tailwind of 20 knots, while the Gyronimo application had a tailwind limit of 10 knots. For landing calculations, the AFM charts provided no data for tailwinds, while the Gyronimo application allowed for up to 10 knots of tailwind. In this case, the application extrapolates data, which conflicts with FAA guidance. Tables 3 and 4 summarize the limits of specific variables for takeoff and landing performance when using both methods.

The human/software analysis of the Gyronimo software revealed that when data was entered incorrectly, the software did not generate a warning, and in many cases defaulted to a specific value. For example, when determining takeoff performance, the available weight range should be between 1,874 and 2,646 pounds. If a pilot manually enters 10 pounds, the software defaults to the lowest possible weight (1,874 pounds). Conversely, if a pilot enters a weight above the airplane's maximum gross takeoff weight, the software defaults to the maximum gross takeoff weight. It is important to note that in the Gyronimo software, all these values can be entered with sliders, but manual entry is also an option. Manual entry of intentionally incorrect data was used for this study. This process could not be accomplished when entering a pressure altitude or headwind, as those values were automatically generated by the software after the pilot enters other data. Table 5 summarizes incorrect data entry responses for two takeoff and landing performance variables.

Additional user interface issues were investigated using the FAA's software checklist from FAA Order 8900.1. The Gyronimo software satisfied several FAA requirements for interface items from the checklist. The units for performance calculations were clearly labeled, pilots could easily modify the input quickly, previous calculations were deleted once new data was entered, and the information 
was presented just as clearly as it would be on the paper AFM charts. In addition, the "notes" section of the AFM is easily accessible inside the software, which provides assumptions for output data. Most of the language of the AFM and Gyronimo matched. A summary of these items can be found in Table 6 .

Table 3

Summary of Variable Limitations with AFM and Gyronimo Takeoff Distance Calculation

\begin{tabular}{l|c|c} 
Variable & AFM Limits & Gyronimo Limits \\
\hline OAT & $-20^{\circ} \mathrm{C}$ to $50^{\circ} \mathrm{C}$ & $-20^{\circ} \mathrm{C}$ to $50^{\circ} \mathrm{C}$ \\
\hline Pressure Altitude & $-3,000$ feet to 10,000 feet & $-1,080$ feet to 10,920 feet \\
\hline Airplane Weight & $1,874 \mathrm{lbs}$ to $2,646 \mathrm{lbs}$ & $1,874 \mathrm{lbs}$ to $2,646 \mathrm{lbs}$ \\
\hline Headwind & 20 knot maximum & 20 knot maximum \\
\hline Tailwind & 20 knot maximum & 10 knot maximum \\
\hline Obstacle height & 0 feet to 50 feet & 0 feet OR 50 feet \\
\hline Runway Gradient/Slope $\%$ & Positive (no limit) & Up to $+2 \%$
\end{tabular}

Table 4

Summary of Variable Limitations with AFM and Gyronimo Landing Distance Calculation

\begin{tabular}{l|c|c} 
Variable & AFM Limits & Gyronimo Limits \\
\hline OAT & $-20^{\circ} \mathrm{C}$ to $50^{\circ} \mathrm{C}$ & $-20^{\circ} \mathrm{C}$ to $50^{\circ} \mathrm{C}$ \\
\hline Pressure Altitude & $-2,000$ feet to 10,000 feet & $-1,080$ feet to 10,920 feet \\
\hline Airplane Weight & $1,874 \mathrm{lbs}$ to $2,646 \mathrm{lbs}$ & $1,874 \mathrm{lbs}$ to $2,646 \mathrm{lbs}$ \\
\hline Headwind & 20 knot maximum & 20 knot maximum \\
\hline Tailwind & No data & 10 knot maximum \\
\hline Obstacle height & 0 feet to 50 feet & 0 feet OR 50 feet \\
\hline Runway Slope $\%$ & Negative (no limit) & Up to $-2 \%$
\end{tabular}

Table 5

Software Responses to Incorrect Data Entry

\begin{tabular}{l|l|l|l|l} 
Variable & $\begin{array}{l}\text { Data value } \\
\text { too low }\end{array}$ & $\begin{array}{l}\text { Data value } \\
\text { too high }\end{array}$ & $\begin{array}{l}\text { Incorrectly } \\
\text { formatted } \\
\text { data (i.e. } \\
\text { letters) }\end{array}$ & $\begin{array}{l}\text { Did software } \\
\text { generate } \\
\text { error } \\
\text { message? }\end{array}$ \\
\hline Temperature & $\begin{array}{c}\text { Defaults to } \\
\text { negative limit }\end{array}$ & $\begin{array}{c}\text { Defaults to } \\
\text { positive limit }\end{array}$ & $\begin{array}{l}\text { Defaults to 0 } \\
\text { degrees C }\end{array}$ & No \\
\hline Weight & $\begin{array}{c}\text { Defaults to } \\
\text { negative limit }\end{array}$ & $\begin{array}{c}\text { Defaults to } \\
\text { positive limit }\end{array}$ & $\begin{array}{c}\text { Defaults to } \\
\text { negative limit }\end{array}$ & No
\end{tabular}


Table 6

Summary of FAA Order 8900.1 EFB Software Checklist Items

\begin{tabular}{|c|c|c|}
\hline $\begin{array}{l}\text { Question } \\
\text { Number }\end{array}$ & $\begin{array}{c}\text { Human/Machine Interface } \\
\text { Questions }\end{array}$ & Gyronimo Behavior/Response \\
\hline 1 & $\begin{array}{l}\text { Does the device identify entries } \\
\text { having an incorrect format or type } \\
\text { and does it generate an appropriate } \\
\text { error message? }\end{array}$ & $\begin{array}{l}\text { No, the software defaults to largest } \\
\text { or smallest possible value. There is } \\
\text { no error message generated }\end{array}$ \\
\hline 2 & $\begin{array}{l}\text { Does the error message clarify the } \\
\text { type and range of data expected? }\end{array}$ & $\mathrm{N} / \mathrm{A}$ \\
\hline 3 & $\begin{array}{l}\text { Are units for performance data } \\
\text { clearly labeled? }\end{array}$ & Yes \\
\hline 4 & $\begin{array}{l}\text { Do the labels used in the EFB } \\
\text { match the language of the operator } \\
\text { document? }\end{array}$ & Yes \\
\hline 5 & $\begin{array}{l}\text { Is all the information for a given } \\
\text { task presented together or easily } \\
\text { accessible? }\end{array}$ & Yes \\
\hline 6 & $\begin{array}{l}\text { Can the crews modify performance } \\
\text { calculations easily, especially when }\end{array}$ & Yes \\
\hline 7 & $\begin{array}{l}\text { Are outdated results of performance } \\
\text { calculations deleted when }\end{array}$ & Yes \\
\hline 8 & $\begin{array}{l}\text { Does the display and/or crew } \\
\text { training provide information to the } \\
\text { crew on the assumptions on which } \\
\text { the calculations are based? }\end{array}$ & Yes \\
\hline 9 & $\begin{array}{l}\text { Are the assumptions made about } \\
\text { any calculation as clear to pilots as } \\
\text { similar information would be on a } \\
\text { tabular chart? }\end{array}$ & Yes \\
\hline
\end{tabular}

The AFM notes for takeoff distance adjustments if the takeoff is from a grass runway are displayed in Figure 7. The AFM indicates that the takeoff roll will increase by certain percentages based upon the length of the grass. In addition, the note states that on wet grass, an additional 10\% increase should be included in the takeoff roll. As for Gyronimo, the software has a slider bar which increases both the ground roll and takeoff distance progressively from a paved and dry runway, to grass, to long grass, then wet grass, and finally "soft ground." These adjustments are displayed in Figure 8. 


\section{NOTE}

For take-off from dry, short-cut grass covered runways, the following corrections must be taken into account, compared to paved runways (typical values, see CAUTION above):

- Grass up to $5 \mathrm{~cm}(2$ in) long: $10 \%$ increase in take-off roll.

- Grass 5 to $10 \mathrm{~cm}$ (2 to 4 in) long: $15 \%$ increase in take-off roll.

- Grass longer than $10 \mathrm{~cm} \mathrm{(4} \mathrm{in):} \mathrm{at} \mathrm{least} 25 \%$ increase in take-off roll.

- Grass longer than $25 \mathrm{~cm}$ (10 in): take-off should not be attempted.

\section{NOTE}

On wet grass, a further $10 \%$ increase in take-off roll must be expected.

Figure 7. AFM Notes on takeoff distance for grass runways.
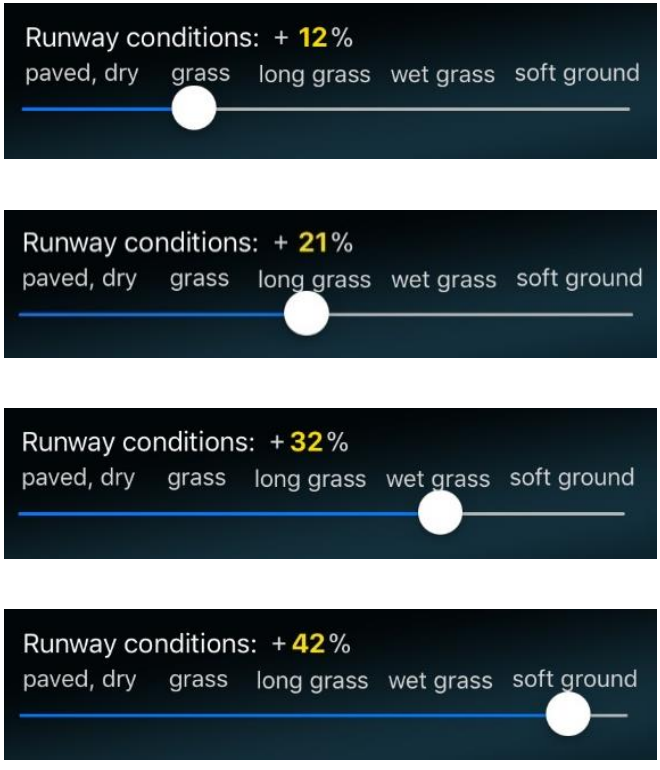

Figure 8. Gyronimo Adjustments on takeoff distance for grass runways. 
The takeoff and landing distances generated for grass runways generated similar discrepancies. The AFM once again provides an increase in the landing roll based upon the height of the grass and then adds $10 \%$ more distance for wet grass. The Gyronimo landing page allows for a paved/dry runway, grass, long grass, and then finally long/wet grass. As the slider progresses through these conditions, only the ground roll is changed. Figures 9 and 10 display the landing distance adjustments for grass runways.

\section{NOTE}

For landings on dry, short-cut grass covered runways, the following corrections must be taken into account, compared to paved runways (typical values, see CAUTION above):

- Grass up to $5 \mathrm{~cm}(2$ in) long: $5 \%$ increase in landing roll.

- Grass 5 to $10 \mathrm{~cm}$ ( 2 to 4 in) long: $15 \%$ increase in landing roll.

- Grass longer than $10 \mathrm{~cm} \mathrm{(4} \mathrm{in):} \mathrm{at} \mathrm{least} 25 \%$ increase in landing roll.

\section{NOTE}

On wet grass, a further $10 \%$ increase in landing roll must be expected.

Figure 9. AFM Notes on landing distance for grass runways.

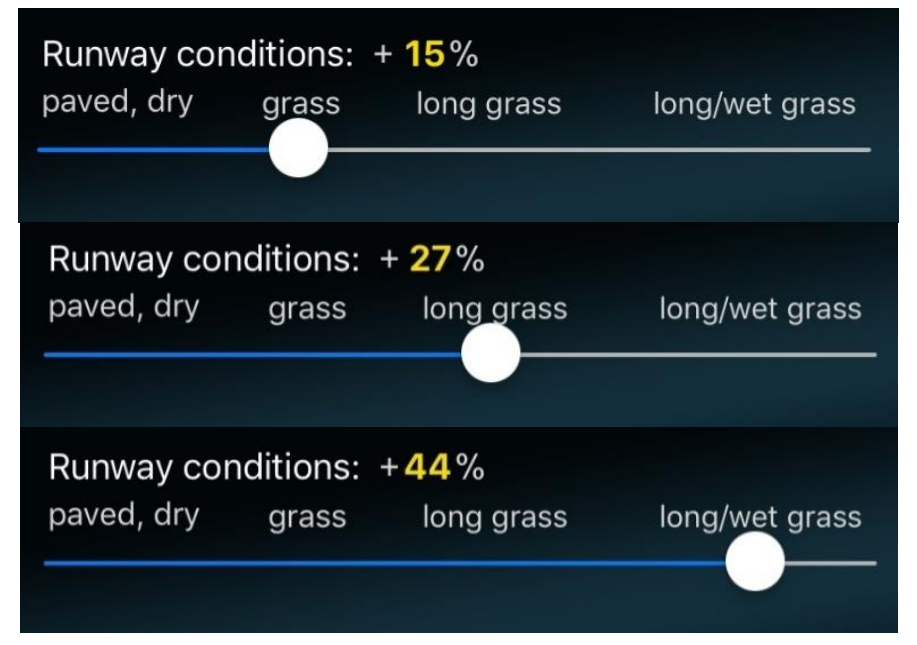

Figure 10. Gyronimo Adjustments on Landing Distance for Grass Runways. 
Results indicated that the Gyronimo software provides accurate data when compared to the AFM charts. The takeoff performance comparison included 25 calculations, and the average variance between the AFM and Gyronimo distances were +/- 54 feet for ground roll, and +/- 56 feet for the takeoff distance over a 50foot obstacle. The average ground roll was 752 feet and the average takeoff distance over a 50-foot obstacle was 1,210 feet. The landing performance comparison included 24 calculations, and the average variance between the AFM and Gyronimo distances were $+/-54$ feet for ground roll, and +/- 76 feet for the landing distance over a 50-foot obstacle. The average landing ground roll was $688 \mathrm{feet}$, and the average landing distance over a 50-foot obstacle was 1,466 feet. The takeoff and landing performance data is summarized in Tables 7 and 8 .

Table 7

\section{Takeoff Distance Calculations and Variances}

\begin{tabular}{|c|c|c|c|c|c|}
\hline Test \# & Specific Condition & Ground Roll (ft) & $\begin{array}{c}\text { Distance } \\
\text { over 50-Foot } \\
\text { Obstacle (ft) }\end{array}$ & $\begin{array}{c}\text { Ground } \\
\text { Roll } \\
\text { Variance } \\
\end{array}$ & $\begin{array}{c}50-\mathrm{ft} \\
\text { Obstacle } \\
\text { Variance } \\
\end{array}$ \\
\hline $1 \mathrm{AFM}$ & \multirow[t]{2}{*}{ All AFM Default } & 558 & 985 & \multirow[t]{2}{*}{40} & \multirow[t]{2}{*}{20} \\
\hline $1 \mathrm{GYR}$ & & 598 & 1,005 & & \\
\hline $2 \mathrm{AFM}$ & \multirow[t]{2}{*}{ Max Gross Weight } & 850 & 1,260 & \multirow[t]{2}{*}{58} & \multirow{2}{*}{93} \\
\hline 2 GYR & & 908 & 1,353 & & \\
\hline $3 \mathrm{AFM}$ & \multirow[t]{2}{*}{ Maximum Tailwind (10 Knots) } & 1,110 & 1,610 & \multirow[t]{2}{*}{73} & \multirow[t]{2}{*}{107} \\
\hline 3 GYR & & 1,183 & 1,717 & & \\
\hline $4 \mathrm{AFM}$ & 10,000 Feet Pressure Altitude & 1,710 & 2,500 & \multirow{2}{*}{186} & \multirow{2}{*}{289} \\
\hline $4 \mathrm{GYR}$ & & 1,524 & 2,211 & & \\
\hline $5 \mathrm{AFM}$ & $\begin{array}{l}\text { Maximum Outside Air } \\
\text { Temperature }(50 \mathrm{C})\end{array}$ & 820 & 1,300 & \multirow[t]{2}{*}{1} & \multirow{2}{*}{47} \\
\hline $5 \mathrm{GYR}$ & & 819 & 1,253 & & \\
\hline $6 \mathrm{AFM}$ & $2 \%$ Positive Runway Slope & 613 & 1,083 & \multirow{2}{*}{85} & \multirow{2}{*}{22} \\
\hline $6 \mathrm{GYR}$ & & 698 & 1,105 & & \\
\hline $7 \mathrm{AFM}$ & Wet Grass (2-4 inches) & 698 & 1,125 & \multirow[t]{2}{*}{211} & \multirow{2}{*}{191} \\
\hline 7 GYR & & 909 & 1,316 & & \\
\hline $8 \mathrm{AFM}$ & $\begin{array}{l}\text { Hot, High (Pressure Altitude } \\
9,000 \text { feet and } 30 \mathrm{C} \text { ) }\end{array}$ & 1,870 & 2,710 & \multirow{2}{*}{116} & \multirow{2}{*}{165} \\
\hline 8 GYR & & 1,754 & 2,545 & & \\
\hline 9 AFM & $\begin{array}{l}\text { ISA Condition (MSL) with no } \\
\text { Wind }\end{array}$ & 640 & 1,090 & \multirow{2}{*}{48} & \multirow{2}{*}{16} \\
\hline $9 \mathrm{GYR}$ & & 688 & 1,106 & & \\
\hline $10 \mathrm{AFM}$ & $\begin{array}{l}\text { ISA Condition (MSL) with } 20 \\
\text { knot Headwind }\end{array}$ & 290 & 710 & \multirow[t]{2}{*}{37} & \multirow[t]{2}{*}{1} \\
\hline $10 \mathrm{GYR}$ & & 327 & 709 & & \\
\hline $11 \mathrm{AFM}$ & $\begin{array}{l}\text { ISA Condition (5,000 feet) with } \\
\text { no Wind }\end{array}$ & 1,010 & 1,440 & \multirow{2}{*}{13} & \multirow{2}{*}{14} \\
\hline $11 \mathrm{GYR}$ & & 997 & 1,454 & & \\
\hline 12 AFM & $\begin{array}{l}\text { ISA Condition }(5,000 \text { feet }) \text { with } \\
20 \text { Knot Headwind }\end{array}$ & 420 & 890 & \multirow[t]{2}{*}{47} & \multirow[t]{2}{*}{34} \\
\hline 12 GYR & & 467 & 856 & & \\
\hline
\end{tabular}


Table 7 Continued

\begin{tabular}{|c|c|c|c|c|c|}
\hline Test \# & Specific Condition & Ground Roll (ft) & $\begin{array}{c}\text { Distance } \\
\text { over 50-Foot } \\
\text { Obstacle (ft) }\end{array}$ & $\begin{array}{c}\text { Ground } \\
\text { Roll } \\
\text { Variance } \\
\end{array}$ & $\begin{array}{c}50-\mathrm{ft} \\
\text { Obstacle } \\
\text { Variance } \\
\end{array}$ \\
\hline 13 AFM & $\begin{array}{l}\text { Extreme Low Temperature } \\
\text { (Pressure Altitude } 1,000)\end{array}$ & 300 & 720 & \multirow{2}{*}{59} & \multirow{2}{*}{6} \\
\hline 13 GYR & & 359 & 726 & & \\
\hline $14 \mathrm{AFM}$ & Temperature - $5 \mathrm{C}$ & 490 & 910 & \multirow[t]{2}{*}{22} & \multirow[t]{2}{*}{2} \\
\hline 14 GYR & & 512 & 908 & & \\
\hline $15 \mathrm{AFM}$ & Temperature $15 \mathrm{C}$ & 558 & 985 & \multirow[t]{2}{*}{40} & \multirow[t]{2}{*}{20} \\
\hline 15 GYR & & 598 & 1,005 & & \\
\hline 16 AFM & Temperature $30 \mathrm{C}$ & 600 & 1,040 & \multirow[t]{2}{*}{79} & \multirow{2}{*}{56} \\
\hline 16 GYR & & 679 & 1,096 & & \\
\hline $17 \mathrm{AFM}$ & Pressure Altitude 1,000 feet & 520 & 1,000 & \multirow[t]{2}{*}{33} & \multirow[t]{2}{*}{46} \\
\hline 17 GYR & & 553 & 954 & & \\
\hline $18 \mathrm{AFM}$ & Pressure Altitude 4,000 feet & 690 & 1,120 & \multirow{2}{*}{32} & \multirow{2}{*}{24} \\
\hline 18 GYR & & 722 & 1,144 & & \\
\hline 19 AFM & Pressure Altitude 8,000 feet & 1,190 & 1,690 & \multirow[t]{2}{*}{6} & \multirow{2}{*}{45} \\
\hline 19 GYR & & 1,196 & 1,735 & & \\
\hline $20 \mathrm{AFM}$ & Weight 2,000 Pounds & 440 & 890 & \multirow[t]{2}{*}{46} & \multirow[t]{2}{*}{12} \\
\hline 20 GYR & & 486 & 878 & & \\
\hline 21 AFM & Weight 2,400 Pounds & 700 & 1,100 & \multirow{2}{*}{39} & \multirow{2}{*}{64} \\
\hline $21 \mathrm{GYR}$ & & 739 & 1,164 & & \\
\hline 22 AFM & Weight 2,600 Pounds & 870 & 1,310 & \multirow{2}{*}{7} & \multirow{2}{*}{8} \\
\hline 22 GYR & & 877 & 1,318 & & \\
\hline $23 \mathrm{AFM}$ & 7 Knot Headwind & 610 & 1,010 & \multirow[t]{2}{*}{52} & \multirow[t]{2}{*}{67} \\
\hline 23 GYR & & 662 & 1,077 & & \\
\hline 24 AFM & 14 Knot Headwind & 490 & 920 & \multirow{2}{*}{22} & \multirow{2}{*}{12} \\
\hline 24 GYR & & 512 & 908 & & \\
\hline 25 AFM & 20 Knot Headwind & 390 & 790 & \multirow{2}{*}{6} & \multirow{2}{*}{34} \\
\hline 25 GYR & & 384 & 756 & & \\
\hline
\end{tabular}


Table 8

Landing Distance Calculations and Variances

\begin{tabular}{|c|c|c|c|c|c|}
\hline Test \# & Specific Condition & $\begin{array}{l}\text { Ground Roll } \\
\text { (ft) }\end{array}$ & $\begin{array}{c}\text { Distance over } \\
50 \text { foot } \\
\text { obstacle }(\mathrm{ft})\end{array}$ & $\begin{array}{c}\text { Ground } \\
\text { Roll } \\
\text { Variance }\end{array}$ & $\begin{array}{l}\text { 50-ft Obstacle } \\
\text { Variance }\end{array}$ \\
\hline $1 \mathrm{AFM}$ & All AFM Default & 624 & 1,329 & \multirow{2}{*}{27} & \multirow{2}{*}{72} \\
\hline GYR & & 651 & 1,401 & & \\
\hline 2 AFM & Max Gross Weight & 710 & 1,690 & \multirow{2}{*}{157} & \multirow{2}{*}{149} \\
\hline GYR & & 867 & 1,839 & & \\
\hline 3 AFM & 10,000 Feet Pressure Altitude & 870 & 1,900 & \multirow{2}{*}{73} & \multirow{2}{*}{84} \\
\hline GYR & & 943 & 1,984 & & \\
\hline 4 AFM & OAT 50 Degrees C & 790 & 1,580 & \multirow{2}{*}{27} & \multirow{2}{*}{44} \\
\hline GYR & & 763 & 1,624 & & \\
\hline 5 AFM & \multirow{2}{*}{$\begin{array}{l}\text { Hot, High (Pressure Altitude } \\
9,000 \text { feet and } 30 \mathrm{C} \text { ) }\end{array}$} & 880 & 1,910 & \multirow{2}{*}{95} & \multirow{2}{*}{138} \\
\hline GYR & & 975 & 2,048 & & \\
\hline 6 AFM & ISA (MSL) No Wind & 790 & 1,730 & \multirow{2}{*}{22} & \multirow{2}{*}{8} \\
\hline GYR & & 812 & 1,722 & & \\
\hline 7 AFM & ISA (MSL) 20 knot Headwind & 360 & 780 & \multirow{2}{*}{48} & \multirow{2}{*}{50} \\
\hline GYR & & 408 & 830 & & \\
\hline 8 AFM & \multirow{2}{*}{$\begin{array}{l}\text { ISA Condition }(5,000 \text { feet }) \text { with } \\
\text { no Wind }\end{array}$} & 900 & 2,000 & \multirow{2}{*}{65} & \multirow{2}{*}{28} \\
\hline GYR & & 965 & 2,028 & & \\
\hline 9 AFM & \multirow{2}{*}{$\begin{array}{l}\text { ISA Condition (5,000 feet) with } \\
20 \text { Knot Headwind }\end{array}$} & 430 & 1,030 & \multirow{2}{*}{75} & \multirow{2}{*}{48} \\
\hline GYR & & 505 & 1,078 & & \\
\hline $10 \mathrm{AFM}$ & \multirow{2}{*}{$\begin{array}{l}\text { Extreme Low Temperature } \\
\text { (Pressure Altitude 1,000 feet) }\end{array}$} & 490 & 1,090 & \multirow{2}{*}{59} & \multirow{2}{*}{88} \\
\hline GYR & & 549 & 1,178 & & \\
\hline $11 \mathrm{AFM}$ & Temperature - $5 \mathrm{C}$ & 540 & 1,210 & \multirow{2}{*}{54} & \multirow{2}{*}{68} \\
\hline GYR & & 594 & 1,278 & & \\
\hline 12 AFM & Temperature $15 \mathrm{C}$ & 624 & 1,329 & \multirow{2}{*}{27} & \multirow{2}{*}{72} \\
\hline GYR & & 651 & 1,401 & & \\
\hline 13 AFM & Temperature $30 \mathrm{C}$ & 690 & 1,420 & \multirow{2}{*}{10} & \\
\hline GYR & & 700 & 1,498 & & 18 \\
\hline 14 AFM & Pressure Altitude 1,000 feet & 590 & 1,280 & 20 & 56 \\
\hline GYR & & 619 & 1,336 & 29 & 50 \\
\hline 15 AFM & Pressure Altitude 4,000 feet & 650 & 1,450 & & \\
\hline GYR & & 722 & 1,543 & 72 & 93 \\
\hline 16 AFM & Pressure Altitude 8,000 feet & 740 & 1,700 & & \\
\hline GYR & & 862 & 1,822 & 122 & 122 \\
\hline 17 AFM & Weight 2,000 lbs & 520 & 1,180 & & \\
\hline GYR & & 584 & 1,256 & 64 & 76 \\
\hline
\end{tabular}


Table 8 Continued

\begin{tabular}{|c|c|c|c|c|c|}
\hline Test \# & Specific Condition & $\begin{array}{l}\text { Ground } \\
\text { Roll (ft) }\end{array}$ & $\begin{array}{c}\text { Distance } \\
\text { over } 50 \\
\text { foot } \\
\text { obstacle } \\
\end{array}$ & $\begin{array}{c}\text { Groun } \\
\text { d Roll } \\
\text { Varia } \\
\text { nce }\end{array}$ & $\begin{array}{c}50-\mathrm{ft} \\
\text { Obstacle } \\
\text { Variance }\end{array}$ \\
\hline $18 \mathrm{AFM}$ & Weight 2,400 lbs & 730 & 1,490 & \multirow{2}{*}{2} & \multirow{2}{*}{73} \\
\hline GYR & & 732 & 1,563 & & \\
\hline 19 AFM & Weight 2,600 lbs & 790 & 1,630 & \multirow{2}{*}{61} & \multirow{2}{*}{176} \\
\hline GYR & & 851 & 1,806 & & \\
\hline 20 AFM & 7 Knot Headwind & 710 & 1,520 & \multirow{2}{*}{12} & \multirow{2}{*}{22} \\
\hline GYR & & 722 & 1,542 & & \\
\hline 21 AFM & 14 Knot Headwind & 570 & 1,180 & \multirow{2}{*}{6} & \multirow{2}{*}{32} \\
\hline GYR & & 564 & 1,212 & & \\
\hline 22 AFM & 20 Knot Headwind & 430 & 900 & \multirow{2}{*}{14} & \multirow{2}{*}{29} \\
\hline GYR & & 444 & 929 & & \\
\hline 23 AFM & Wet Grass (2-4 inches) & 780 & 1,485 & \multirow[b]{2}{*}{158} & \multirow[b]{2}{*}{202} \\
\hline GYR & & 938 & 1,687 & & \\
\hline 24 AFM & 2\% Negative Runway Slope & 686 & 1,462 & \multirow[b]{2}{*}{30} & \multirow[b]{2}{*}{4} \\
\hline GYR & & 716 & 1,466 & & \\
\hline
\end{tabular}

Discussion

In this study, the Gyronimo Performance Pad application was evaluated as if it were a Type B EFB application proposed for performance calculations with an air carrier. The high standards set forth by the FAA and EASA in terms of software interface and calculation accuracy are required for air carriers, but this software was not developed with these standards in mind. However, the software did meet several interface standards and also generated reliable performance data.

The largest discrepancies in terms of the human/software interface were the lack of error messages when incorrect data was entered and the variable limitations. A major concern with the human/software interface was the potential of incorrect data entry. As previously discussed, the application does not generate error messages when data is entered that exceeds limitations or if the data is entered with an incorrect format. Instead, the software defaults to either the lowest or highest value. When the format of the data is incorrect (i.e., entering letters instead of numbers), the software then defaults to the lowest value. This is of concern, as data entry errors have been identified as the most common factor in EFB - related accidents (EASA, 2017). 
For takeoff performance, the AFM data allows for up to 20 knots of tailwind, and the Gyronimo software only allows for tailwinds of up to 10 knots. In this case, the software does not extrapolate data, but it does not provide all the data provided by the AFM charts. Also, for landing distance, the AFM charts do not provide any data for landing with a tailwind, while the Gyronimo application allows for up to 10 knots of tailwind. In this case, the software is extrapolating data not provided by the AFM. These discrepancies in the allowance of performance variables should be noted by flight schools that plan to use the software, and perhaps policies could be generated to prohibit Gyronimo calculations when extrapolation is possible (i.e. tailwind for landing distance). These variable limitations were investigated as suggested by the FAA.

The performance calculations generated by the two methods were fairly consistent. The average variance between output never exceeded 76 feet, which reflects accuracy when measuring distances that average 688 feet and 1,466 feet, respectively. Although these average variations were noted, it was apparent that some conditions caused greater variance. For example, the "hot and high" test condition (as recommended by EASA) and "wet grass" condition generated larger than average variances for both the takeoff and landing distances generated by Gyronimo. These conditions typically do not occur during primary flight training, but this discrepancy is worth noting because the issue was found for both takeoff and landing distances with Gyronimo.

During the landing distance calculations, with all three pressure altitude tests, as pressure altitude increased, the variance between the AFM and Gyronimo calculations increased. This is the type of information that an air carrier or flight school would carefully test, and if these variances are found to be too great, then the use of the application may be limited based upon pressure altitude. Similar pressure altitude tests used for the takeoff distance calculation did not produce the same pattern.

Airplane Flight Manuals are constantly updated with revisions from the manufacturer, and sometimes these revisions make adjustments to performance charts. This is certainly the case with the Diamond DA40 AFM used in this research. Previously, it was specifically stated that the AFM used in this study was current through revision 9. Prior versions of the DA40 AFM did not provide the specific grass length data found in the current version of the document. For practical purposes, any operator planning to use a performance software must refer to a current AFM for comparisons. 


\section{Limitations}

This study had several limitations. One specific software was tested against one specific AFM revision. Also, that application was developed for one aircraft type. Only two of the five available Gyronimo performance calculations were tested. The biggest potential limitation was the AFM data generated by the AFM charts and the increments in which the data was recorded (increments of 10 feet). The PI, while experienced with these paper charts, could have made errors when generating the AFM performance calculations. These results must not be extrapolated for other Gyronimo products on other aircraft, and are limited to the takeoff and landing performance data for a Diamond DA40.

\section{Suggested Additional Research}

Errors in performance calculations were briefly mentioned in the literature review, but this issue could create unsafe conditions and even lead to accidents. Incorrectly calculated takeoff and landing data can lead to tail strikes, the inability to take off, or similar complications upon landing. It is suggested that pilots perform these calculations using AFM and application data, and then to investigate potential data input errors when using both.

In an industry that is constantly introducing new forms of automation, this data may encourage flight schools to allow student pilots to use similar software for performance calculations. Flight schools, if interested in this technology, must also consider when to introduce it in the curriculum. Pilots could use it when training at the private, instrument or commercial level. This should be investigated to streamline training and better prepare pilots for industry. However, automation can reduce skills, and if performance calculations are also automated, a pilot may be able to use software to do calculations but may not fully understand performance factors. Software such as Gyronimo could be used to investigate potential negative outcomes of automating performance planning.

\section{Conclusion}

During primary flight training, pilots are increasingly using EFBs for aeronautical charts, checklists, weather information, and many other functions. If pilots in training can use EFB software to determine accurate performance data, then they could benefit from using such technology. The Gyronimo Performance Pad for the Diamond DA40 is a reliable source of takeoff and landing performance for typical conditions. If reviewed and implemented by a flight school, this application could provide flight instructors and students the opportunity to use a 
software for essential performance planning during flight training. This may better prepare pilots in training because pilots in industry routinely perform performance calculations using EFBs. If flight schools are interested in using performance software such as Gyronimo, then the software should be tested with the current version of the specific aircraft AFMs.

For software developers such as Gyronimo, there may be a new market in which software such as this can be used on a large-scale basis at flight schools across the globe. These companies must be careful to accurately present this data, as it is directly related to flight safety. Gyronimo took such precaution when it warned users of the advisory nature of their software when the application is first opened. However, if the application meets the aviation authority's standards for air carriers, and is thoroughly tested and verified, then EFB software such as Gyronimo could be used for commercial operations and primary flight training. 


\section{References}

Aircraft Performance Group. (n.d.). Building on a legacy of engineering experience and excellence. Retrieved from https://www.flyapg.com/history/

Australian Transport Safety Bureau (ATSB). (2011). Take-off performance calculation and entry errors: A global perspective. Retrieved from https://www.atsb.gov.au/media/2229778/ar2009052.pdf

Trump, R.S., Van Es, G.W.H., Karwal, A.K., \& Verbeek, M.J. (2014). Best practices for approval of performance and MB applications on EFBs. Australian Transport Safety Bureau. Retrieved from https://www.easa.europa.eu/sites/default/files/dfu/EASA-Research-Rep2014-1.pdf

Bos, T. (2009). Takeoff performance margins. Dutch Airline Pilots Association. Retrieved from https://www.vnv.nl/publications/takeoff-performancemargins

Cassidy, E. D., Colmenares, A., Jones, G., Manolovitz, T., Shen, L., \& Viera, S. (2014). Higher education and emerging technologies: Shifting trends in student usage. The Journal of Academic Librarianship, 40(2), 124-133

Diamond Aircraft. (2010). FAA approved airplane flight manual. Retrieved from http://support.diamond-air.at/fileadmin/uploads/files/after_sales_support/ DA40-180/Airplane_Flight_Manual/Basic_Manual/60101e-r9complete.pdf

European Aviation Safety Agency. (n.d.). The agency: Facts and figures. Retrieved from https://www.easa.europa.eu/the-agency/the-agency

European Aviation Safety Agency, (2015). Final report: Electronic flight bag; Aircraft performance calculations and mass \& balance. Best practices for evaluation and use of EFB. Retrieved from https://www.easa.europa.eu/sites/default/files/dfu/EASA-Research-Rep$\underline{\text { 2014-1.pdf }}$

Federal Aviation Administration. (2017). Electronic flight bag program evaluation and authorization. Retrieved from http://fsims.faa.gov/wdocs/ 
8900.1/v04\%20ac\%20equip\%20\&\%20auth/chapter\%2015/04_015_001_c hg_260a.htm

Federal Aviation Administration. (2017). Landing distance assessment at time of arrival. Retrieved from https://www.faa.gov/about/initiatives/talpa/ media/order-8900-1-vol4-chap3-section1-par503-2017.pdf

Federal Aviation Administration (2017). Advisory Circular 120.76D: Authorization for use of electronic flight bags. Retrieved from https://www.faa.gov/documentLibrary/media/Advisory_Circular/AC_12076D.pdf

Federal Aviation Administration. (2018). Electronic code of federal regulations 91.103: Preflight action. Retrieved from https://www.ecfr.gov/cgibin/text-idx?SID=1 ec519dc9ba983736d762befddd64aa1\&mc= true\&node=se14.2.91_1103\&rgn=div8

Federal Aviation Administration. (2017). Private pilot-airplane airman certification standards. Retrieved from https://www.faa.gov/training_testing/testing/acs/media/private_airplane_a cs_6A.pdf

ForeFlight Mobile. (n.d.). ForeFlight performance profiles. Retrieved from https://www.foreflight.com/products/performancedirectory/\#/Diamond\%2 0Aircraft/?_k=zy3bpl

Joslin, R. (2013). Human factors hazards of iPads in general aviation cockpits. Proceedings of the Human Factors and Ergonomics Society $57^{\text {th }}$ Annual Meeting.

Schwartzentruber, J. (2017). A usability study for electronic flight bag (EFB) flight planning applications on tablet devices for ab-initio pilots. The International Journal of Aviation, Aeronautics, and Aerospace, 4(2). doi:https://doi.org/10.15394/ijaa.2017.1162 


\section{Appendix A: Takeoff Performance Chart Comparisons}

\section{Takeoff Comparison 1: AFM Default Information}

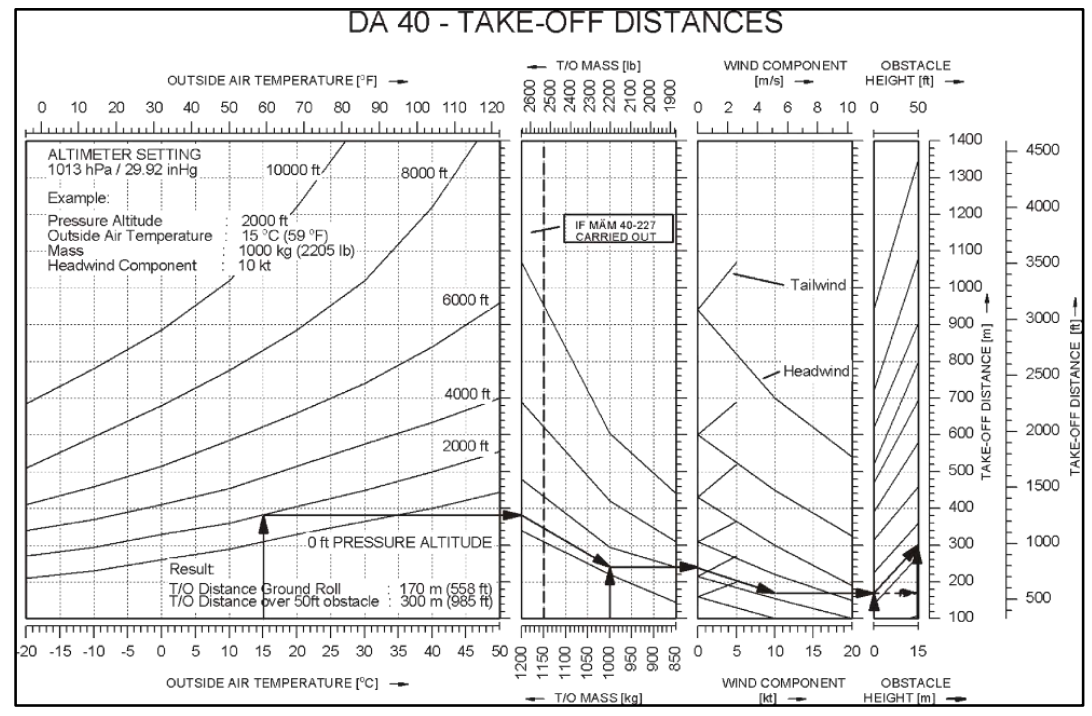

Figure 1. AFM Default Variables Takeoff Determination 
International Journal of Aviation, Aeronautics, and Aerospace, Vol. 5 [2018], Iss. 4, Art. 1

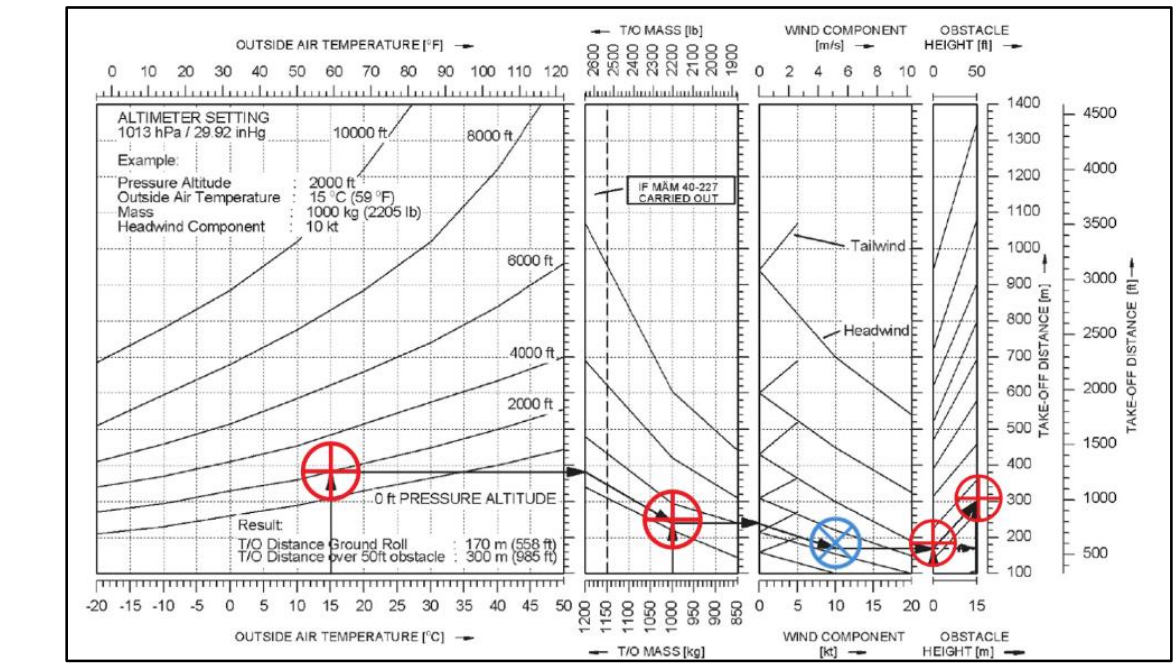

Lift Off Speed approx 59 KIAS

Climb-out speed $60.0 \mathrm{KIAS}$

Ground Roll $598^{\prime} / 182 m$

Runway condition $\quad \mathbf{O}^{\prime} / 0 \mathrm{~m}$

Runway Slope $\quad 0^{\prime} / 0 \mathrm{~m}$

TO Ground Roll $\overline{598^{\prime} / 182 m}$.

Total to clear

50'/15m obstacle $1005^{\prime} / 306 \mathrm{~m}$

Runway condition $\quad \mathbf{0}^{\prime} / \mathrm{Om}$

Runway Slope $\quad \mathbf{0}^{\prime} / \mathrm{Om}$

Takeoff Distance $1005^{\prime}$ / $306 \mathrm{~m}$

Figure 2. Gyronimo Default Variables Takeoff Determination

\section{Takeoff Comparison 2: Maximum Gross Weight}




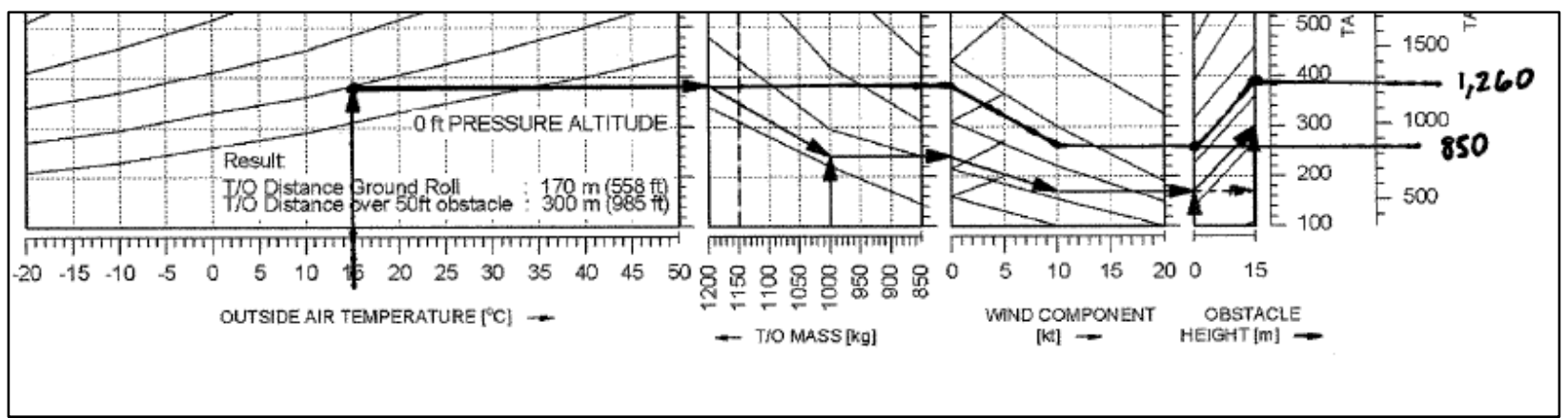

Figure 3. AFM Maximum Gross Weight with Default Variables Takeoff Determination
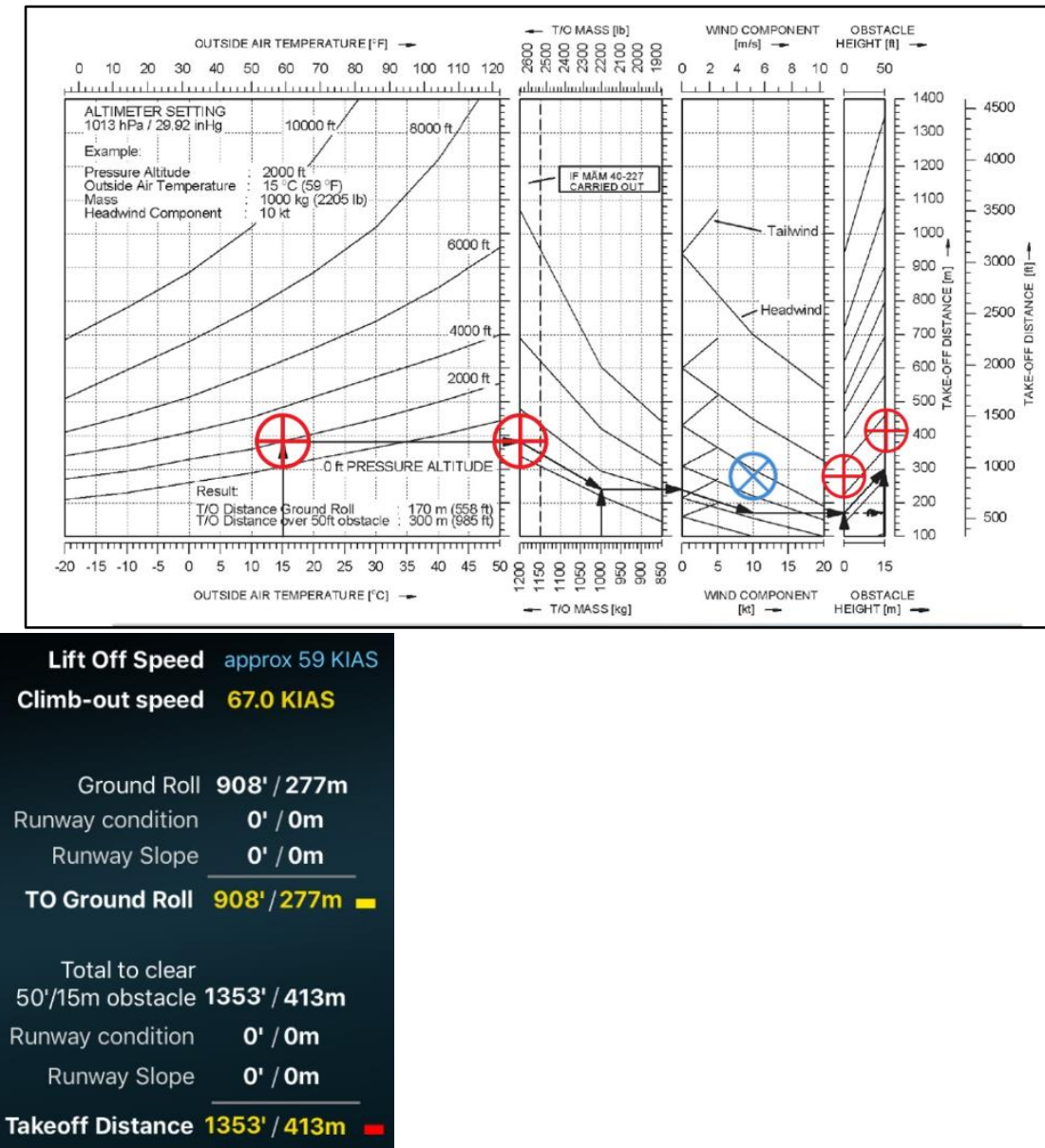

Figure 4. Gyronimo Maximum Gross Weight with Default Variables Takeoff Determination 


\section{Takeoff Comparison 3: Maximum Tailwind (10 knots)}

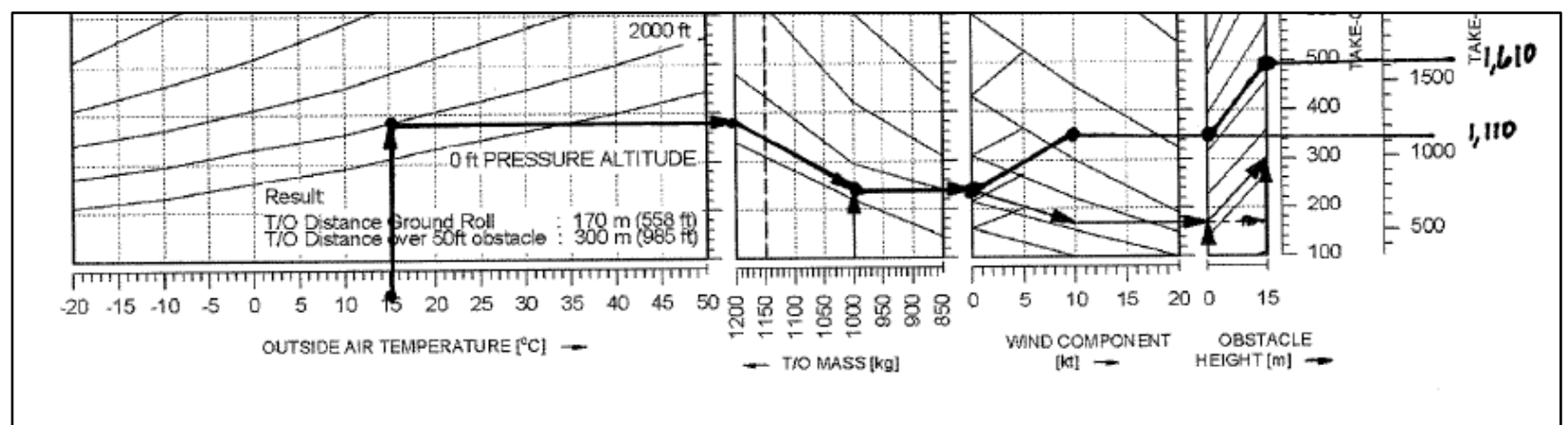

Figure 5. AFM Maximum Tailwind with Default Variables Takeoff Determination 


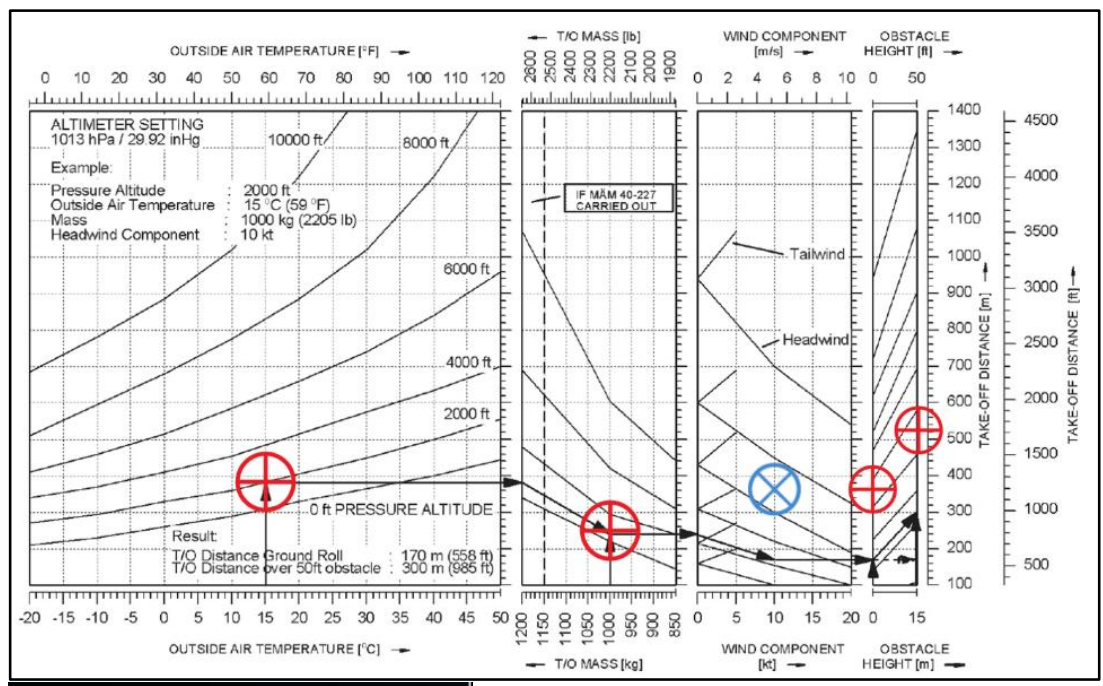

Lift Off Speed approx 59 KIAS

Climb-out speed $60.0 \mathrm{KIAS}$

Ground Roll 1183' / 361m

Runway condition $\quad \mathrm{O}^{\prime} / \mathrm{Om}$

Runway Slope $\quad \mathbf{0}^{\prime} / \mathbf{O m}$

TO Ground Roll $\overline{1183^{1} / 361 \mathrm{~m}}$ -

Total to clear

$50^{\prime} / 15 \mathrm{~m}$ obstacle $1717^{\prime} / \mathbf{5 2 3 m}$

Runway condition $\quad \mathbf{O}^{\prime} / 0 \mathrm{~m}$

Runway Slope $\quad \mathbf{0}^{\prime} / \mathbf{O m}$

Takeoff Distance $1717^{\prime} / 523 m$

Figure 6. Gyronimo Maximum Tailwind with Default Variables Takeoff Determination 


\section{Takeoff Comparison 4: Maximum Pressure Altitude (10,000 feet)}

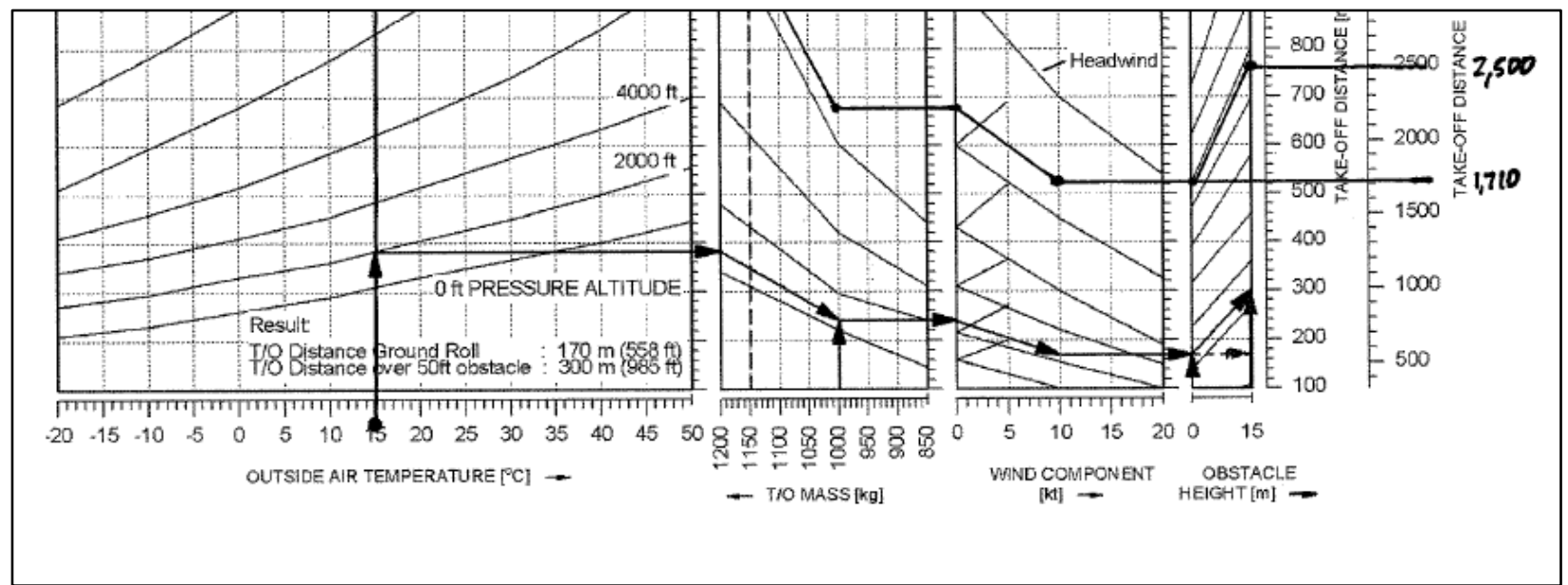

Figure 7. AFM Maximum Pressure Altitude with Default Variables Takeoff Determination 

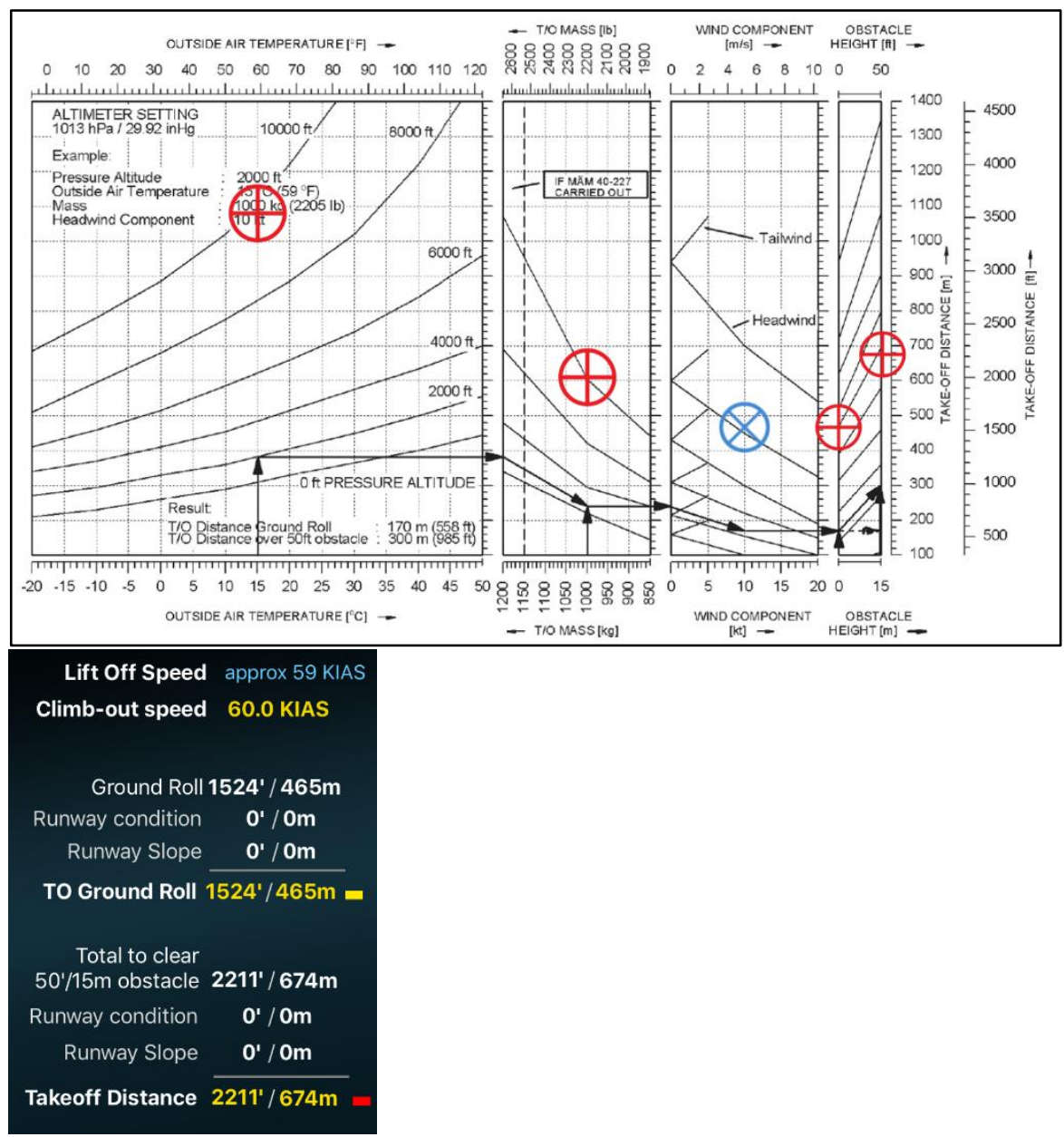

Figure 8. Gyronimo Maximum Pressure Altitude with Default Variables Takeoff Determination

\section{Takeoff Comparison 5: Maximum Temperature (50C)}




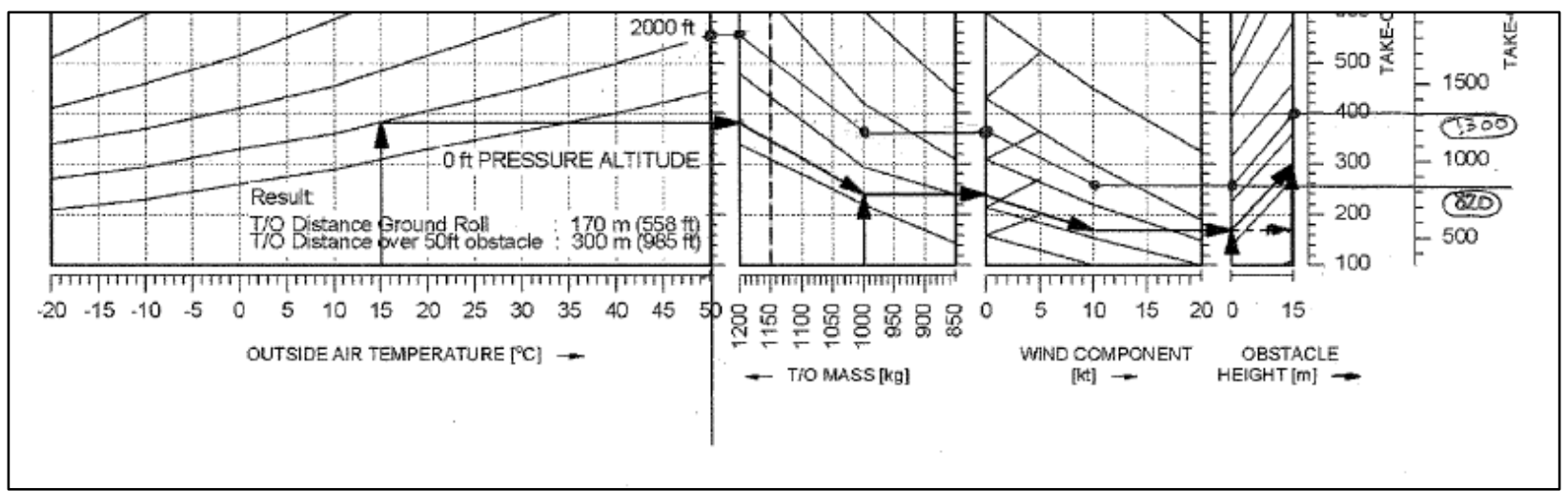

Figure 9. AFM Maximum Temperature with Default Variables Takeoff Determination

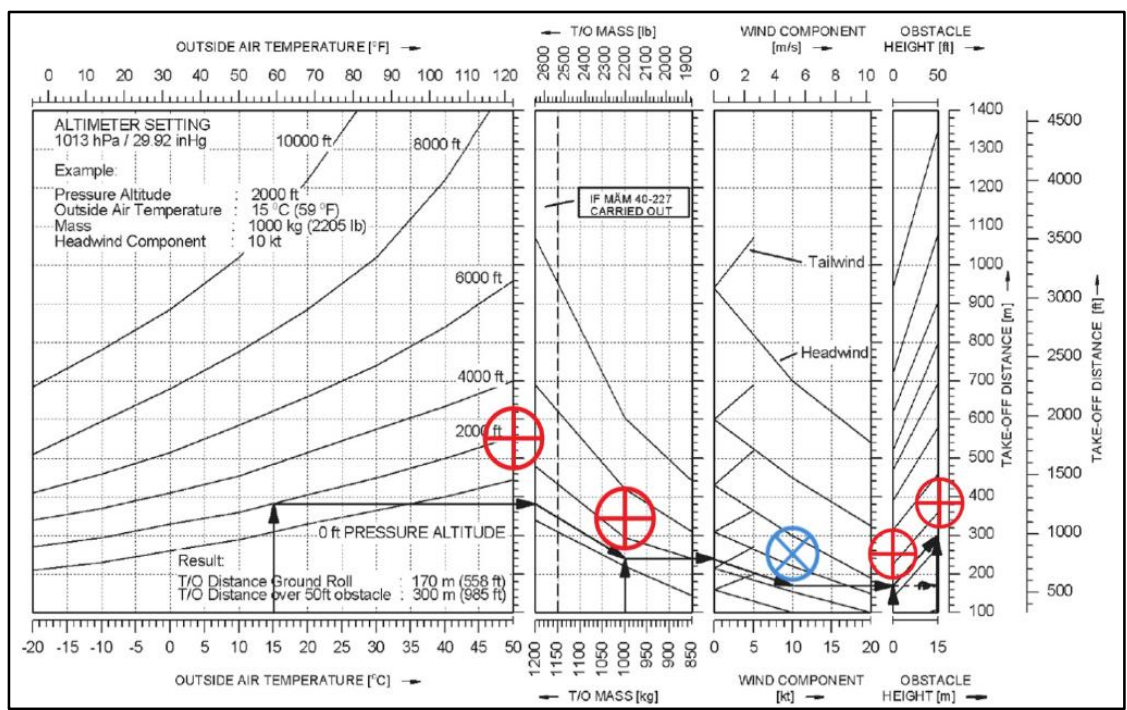

Lift Off Speed approx 59 KIAS

Climb-out speed 60.0 KIAS

Ground Roll $819^{\prime} / 250 m$

Runway condition $\quad \mathbf{O}^{\prime} / \mathrm{Om}$

Runway Slope $\quad \mathbf{O}^{\prime} / \mathrm{Om}$

TO Ground Roll $\overline{819^{\prime} / 250 \mathrm{~m}}$.

Total to clear

$50^{\prime} / 15 \mathrm{~m}$ obstacle $1253^{\prime} / 382 \mathrm{~m}$

Runway condition $\quad \mathbf{O}^{\prime} / \mathrm{Om}$

Runway Slope $\quad \mathbf{0}^{\prime} / \mathbf{O m}$

Takeoff Distance $1253^{\prime} / 382 m$ 
Figure 10. Gyronimo Maximum Temperature with Default Variables Takeoff Determination

\section{Takeoff Comparison 6: 2\% Positive Runway slope}

With default conditions, the AFM yielded a Ground Roll of 558 feet and a distance over a 50 foot obstacle of 985 feet.

The AFM take off notes state that a $2 \%$ positive slope would increase the takeoff distance by approximately $10 \%$. It did not provide for negative runway slope takeoff variables. Thus, with a positive $2 \%$ runway slope, the increase would be + $10 \%$, yielding a ground roll of 613 feet and a takeoff distance over a 50 foot obstacle of 1,083 feet. 


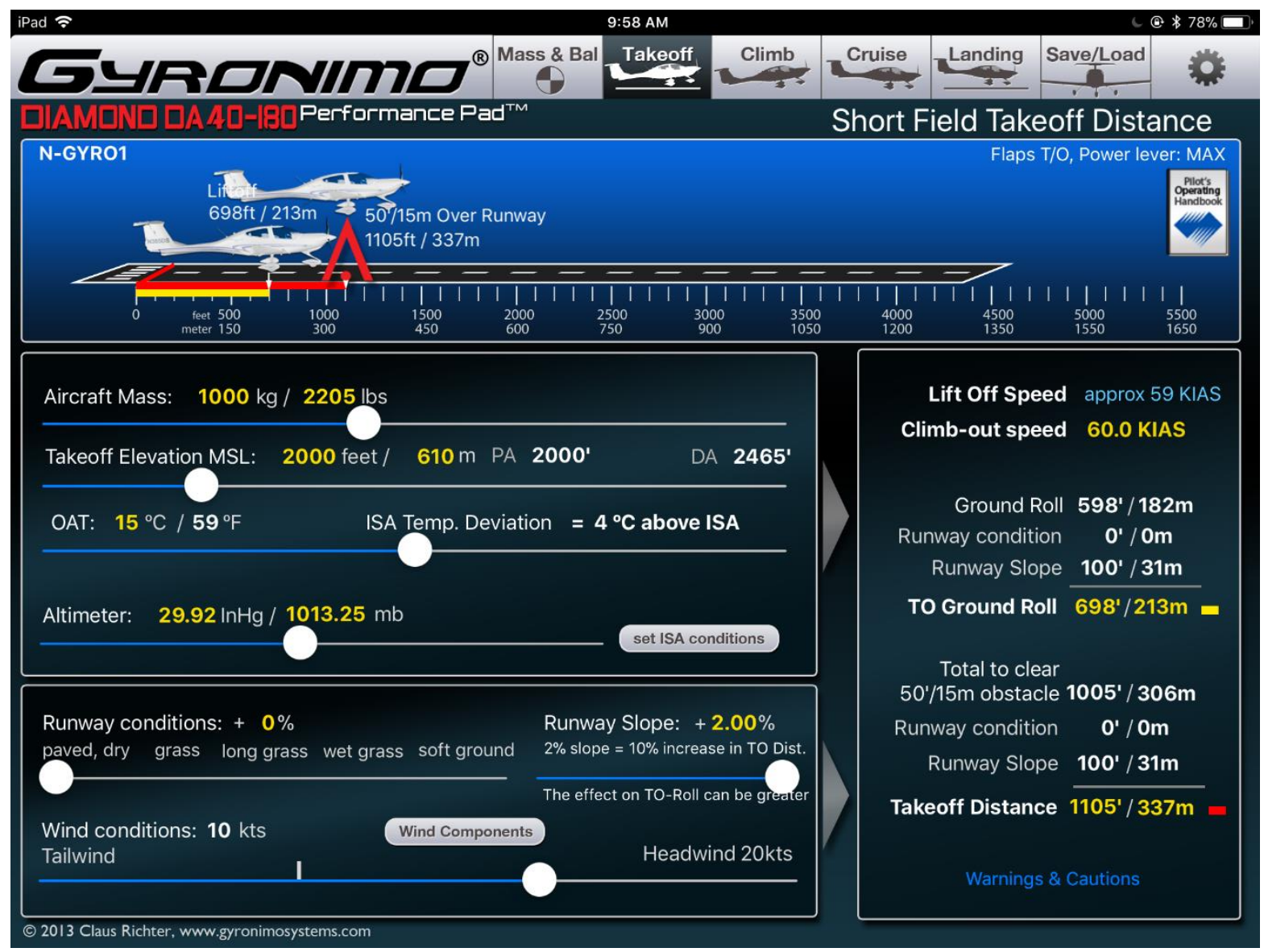

Figure 11. Gyronimo Takeoff Determination with $+2 \%$ Runway Slope

\section{Takeoff Comparison 7: Default Variables on Wet Grass}

With default conditions, the AFM yielded a Ground Roll of 558 feet and a distance over a 50 foot obstacle of 985 feet.

The AFM states that grass from two to four inches high will add $15 \%$ to the takeoff ground roll, and that wet grass would add an additional 10\%. Thus, the 
AFM produced a wet grass ground roll of 698 feet and a distance over a 50-foot obstacle of 1,125 feet.

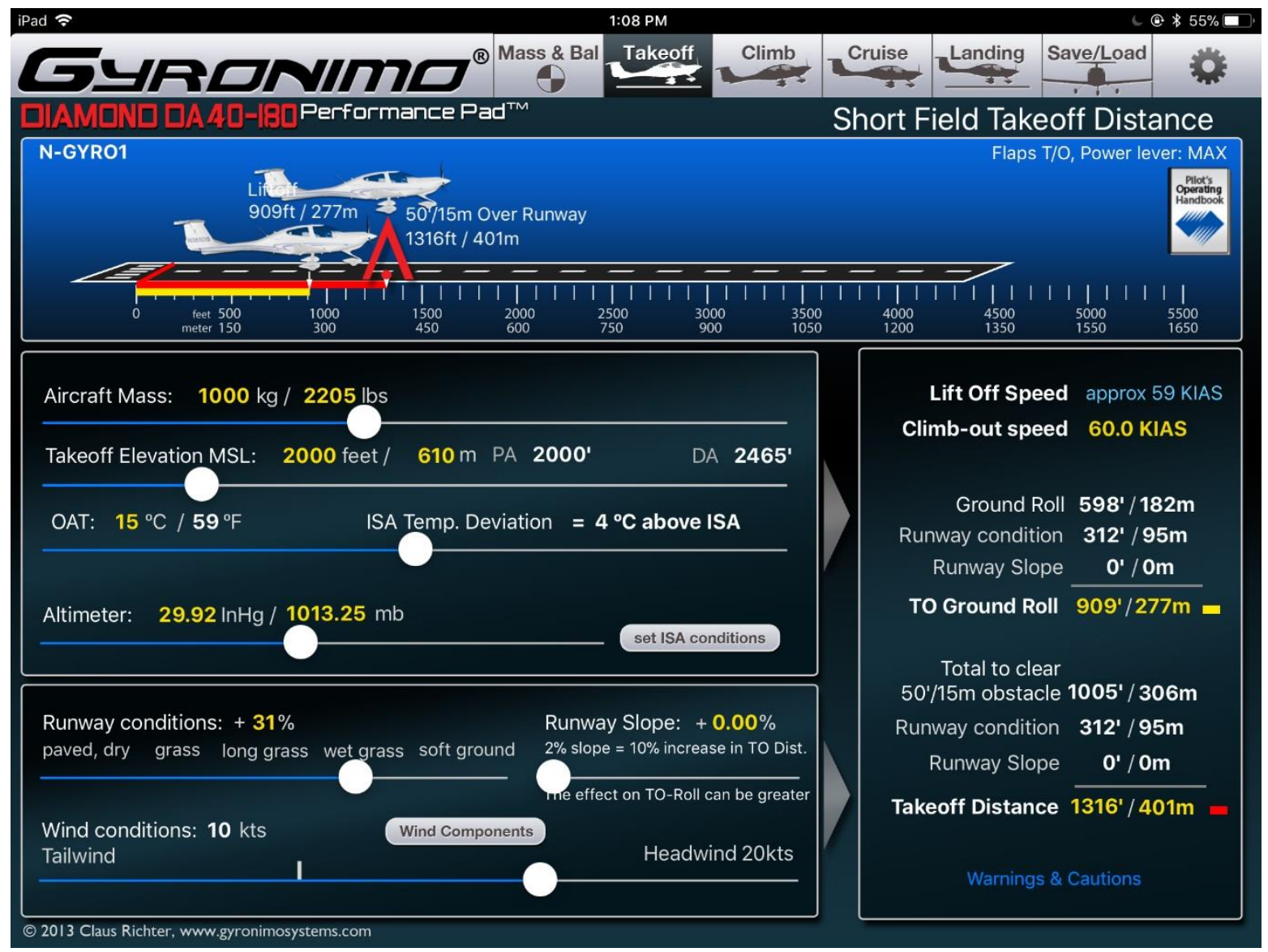

Figure 12. Gyronimo Default Takeoff Variables with Wet Grass 


\section{Takeoff Comparison 8: Hot and High Condition (EASA)}

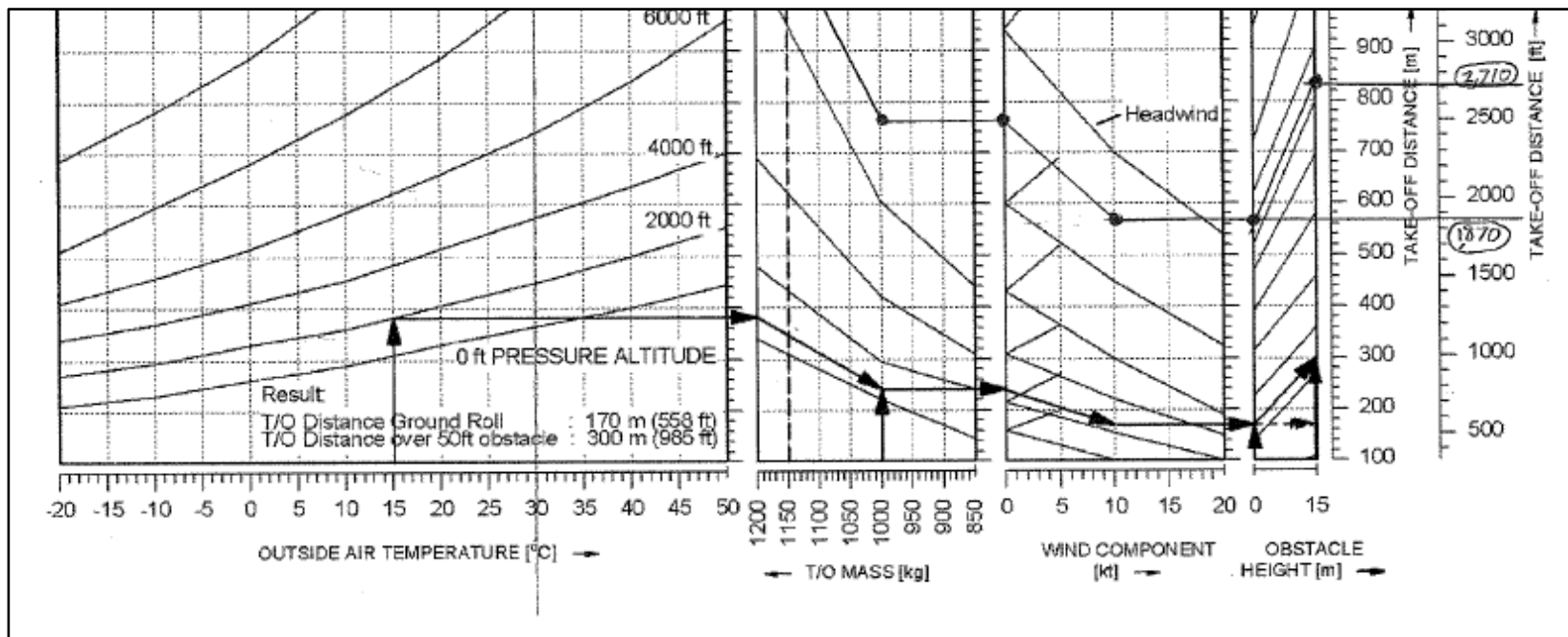

Figure 13. AFM Hot and High Takeoff Determination 

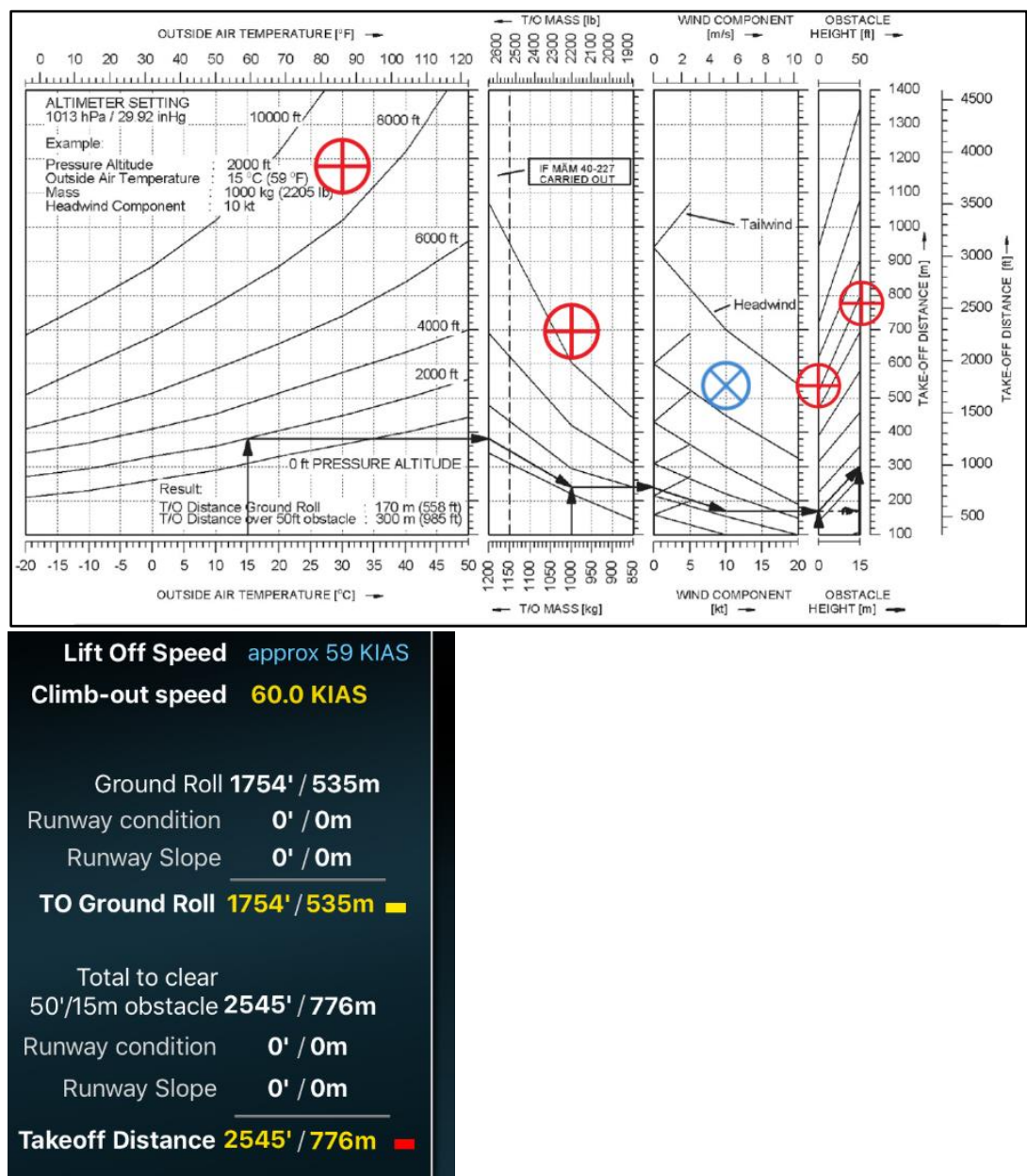

Figure 14. Gyronimo Hot and High Takeoff Determination

Takeoff Comparison 9: ISA at MSL with No Wind 


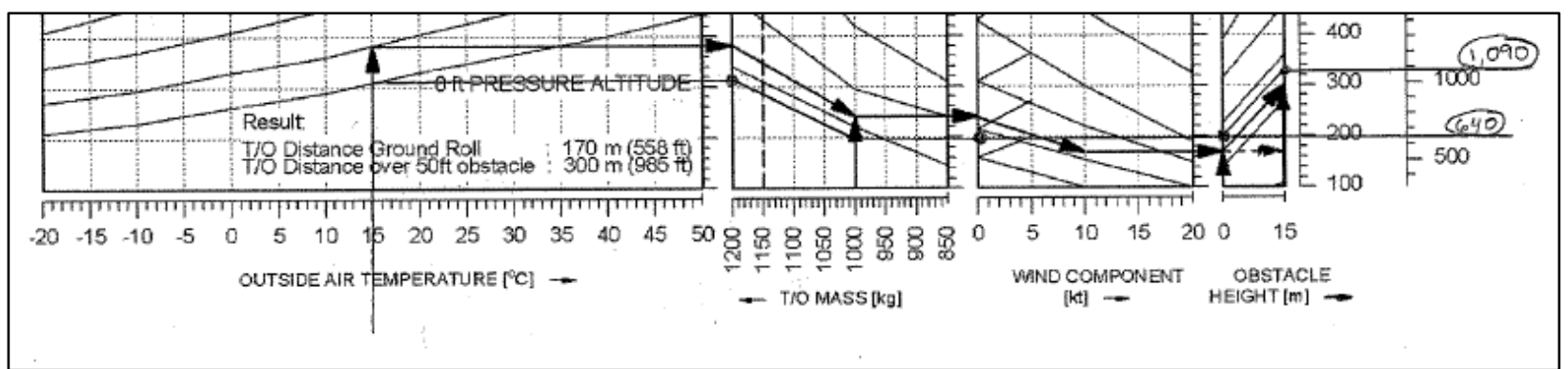

Figure 15. AFM ISA at MSL with No Wind Takeoff Determination

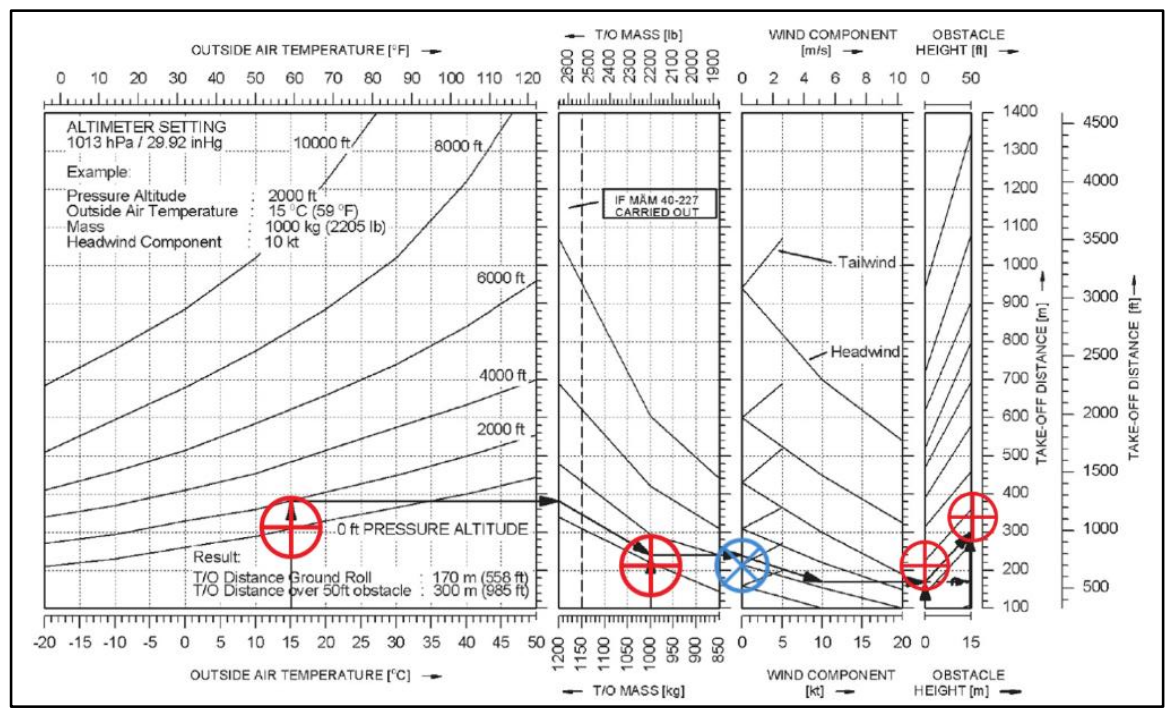

Lift Off Speed approx 59 KIAS Climb-out speed $60.0 \mathrm{KIAS}$

Ground Roll 688'/210m

Runway condition $\quad \mathbf{O}^{\prime} / \mathbf{O m}$

Runway Slope $\quad \mathbf{0}^{\prime} / \mathbf{O m}$

TO Ground Roll $\overline{688^{\prime} / 210 m}$ -

Total to clear

$50^{\prime} / 15 \mathrm{~m}$ obstacle $1106^{\prime} / \mathbf{3 3 7 m}$

Runway condition $\quad \mathbf{0}^{\prime} / \mathbf{O m}$

Runway Slope $\quad \mathbf{0}^{\prime} / 0 \mathrm{~m}$

Takeoff Distance $1106^{\prime} / 337 m$

Figure 16. Gyronimo ISA at MSL with No Wind Takeoff Determination 


\section{Takeoff Comparison 10: ISA at MSL with 20 Knot Headwind}

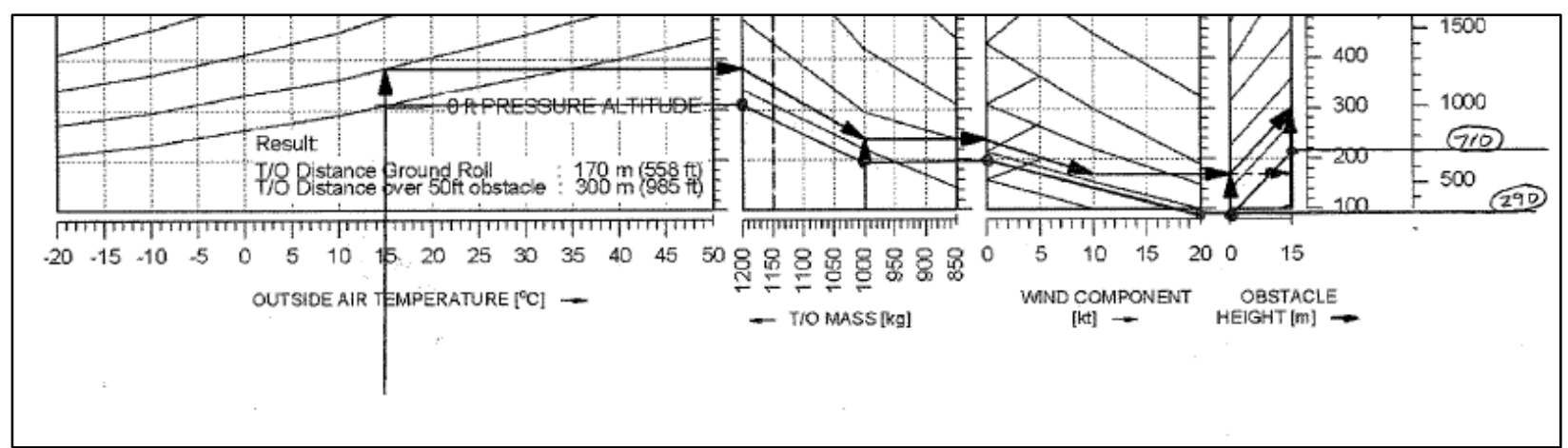

Figure 17. AFM ISA at MSL with 20 Knot Headwind Takeoff Determination 
International Journal of Aviation, Aeronautics, and Aerospace, Vol. 5 [2018], Iss. 4, Art. 1
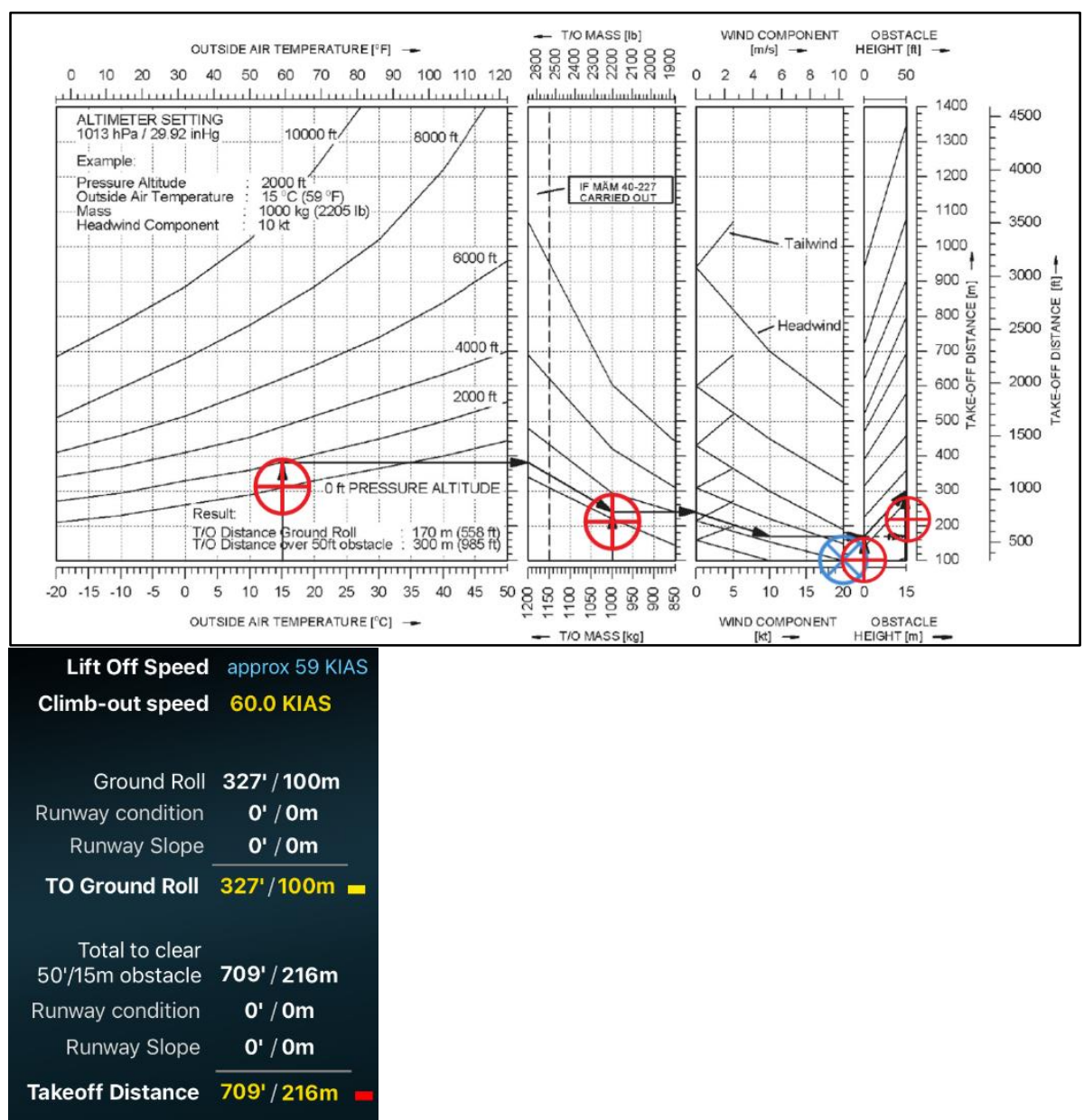

Figure 18. Gyronimo ISA at MSL with 20 Knot Headwind Takeoff Determination 


\section{Takeoff Comparison 11: ISA at 5,000 Feet with No Wind}

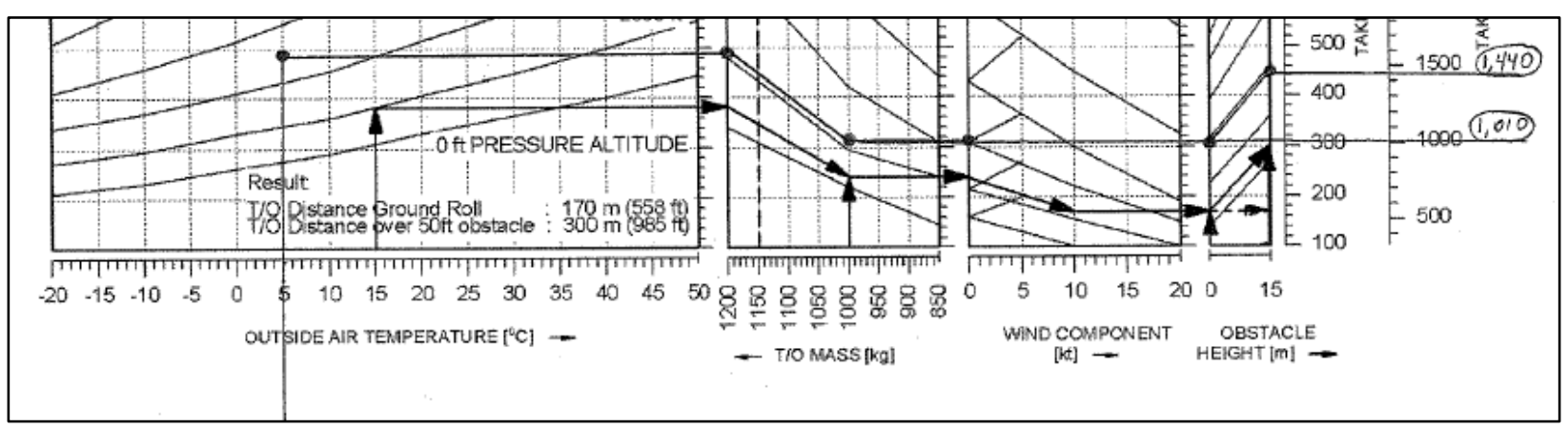

Figure 19. AFM ISA at 5,000 Feet with No Wind Takeoff Determination

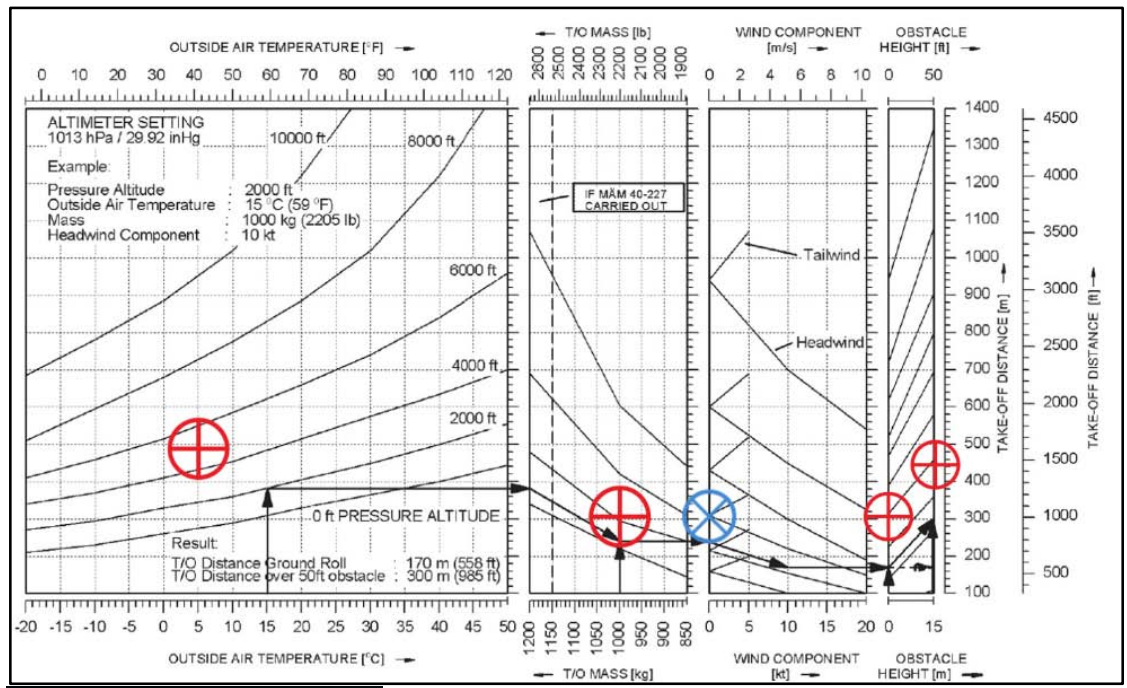

Lift Off Speed approx 59 KIAS

Climb-out speed $60.0 \mathrm{KIAS}$

Ground Roll 997' / 304m

Runway condition $\quad \mathbf{0}^{\prime} / \mathrm{Om}$

Runway Slope $\quad 0^{\prime} / 0 \mathrm{~m}$

TO Ground Roll $997^{\prime} / 304 \mathrm{~m}$ =

Total to clear

$50^{\prime} / 15 \mathrm{~m}$ obstacle $1454^{\prime} / 443 \mathrm{~m}$

Runway condition $\quad 0^{\prime} / 0 \mathrm{~m}$

Runway Slope $\quad 0^{\prime} / 0 \mathrm{~m}$

Takeoff Distance $1454^{\prime} / 443 m$ 
International Journal of Aviation, Aeronautics, and Aerospace, Vol. 5 [2018], Iss. 4, Art. 1

Figure 20. Gyronimo ISA at MSL with No Wind Takeoff Determination

\section{Takeoff Comparison 12: ISA at 5,000 Feet with 20 Knot Headwind}

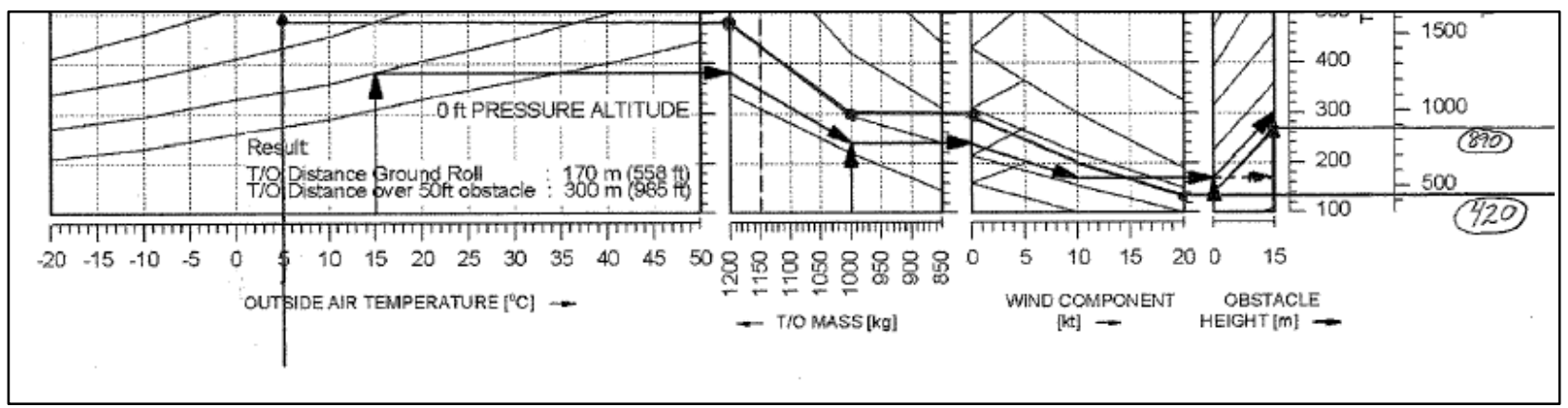

Figure 21. AFM ISA at 5,000 Feet with 20 Knot Headwind Takeoff Determination 


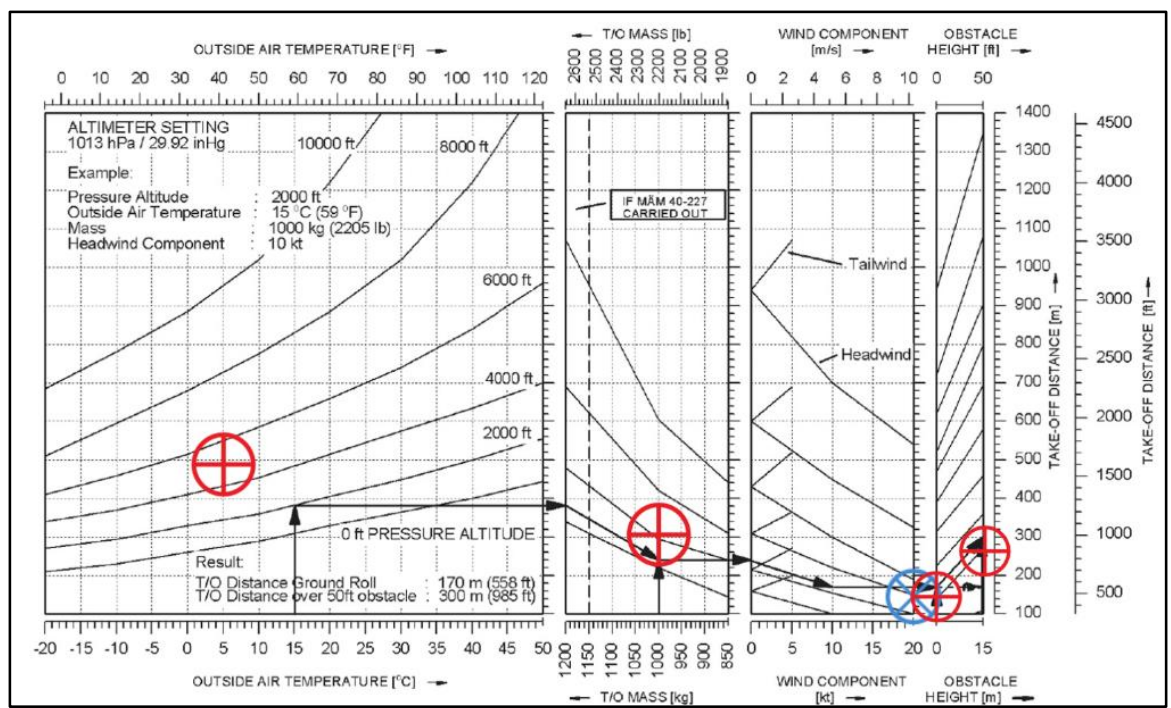

Lift Off Speed approx 59 KIAS

Climb-out speed $60.0 \mathrm{KIAS}$

Ground Roll $467^{\prime} / 142 m$

Runway condition $\quad \mathbf{0}^{\prime} / \mathrm{Om}$

Runway Slope $\quad \mathbf{O}^{\prime} / \mathbf{O m}$

TO Ground Roll $\overline{467^{\prime} / 142 \mathrm{~m}}$

Total to clear

$50^{\prime} / 15 \mathrm{~m}$ obstacle $\mathbf{8 5 6} / \mathbf{2 6 1 \mathrm { m }}$

Runway condition $\quad 0^{\prime} / 0 \mathrm{~m}$

Runway Slope $\quad \mathbf{0}^{\prime} / \mathbf{O m}$

Takeoff Distance $\overline{856^{\prime} / 261 \mathrm{~m}}$

Figure 22. Gyronimo ISA at 5,000 Feet with 20 Knot Headwind Takeoff Determination 


\section{Takeoff Comparison 13: AFM Extreme Low Temperature (Pressure Altitude} 1,000 feet)

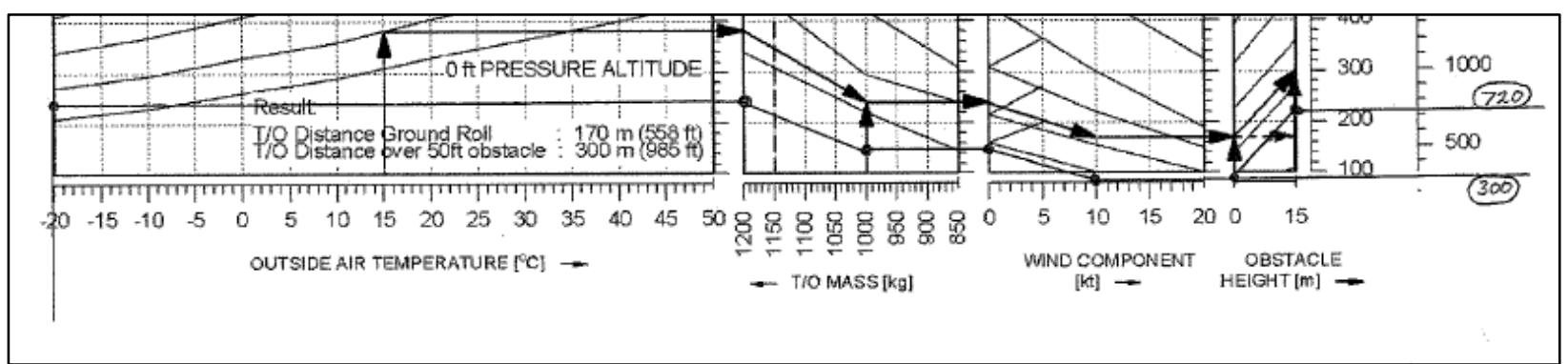

Figure 23. AFM Extreme Low Temperature (Pressure Altitude 1,000 feet) Takeoff Determination 


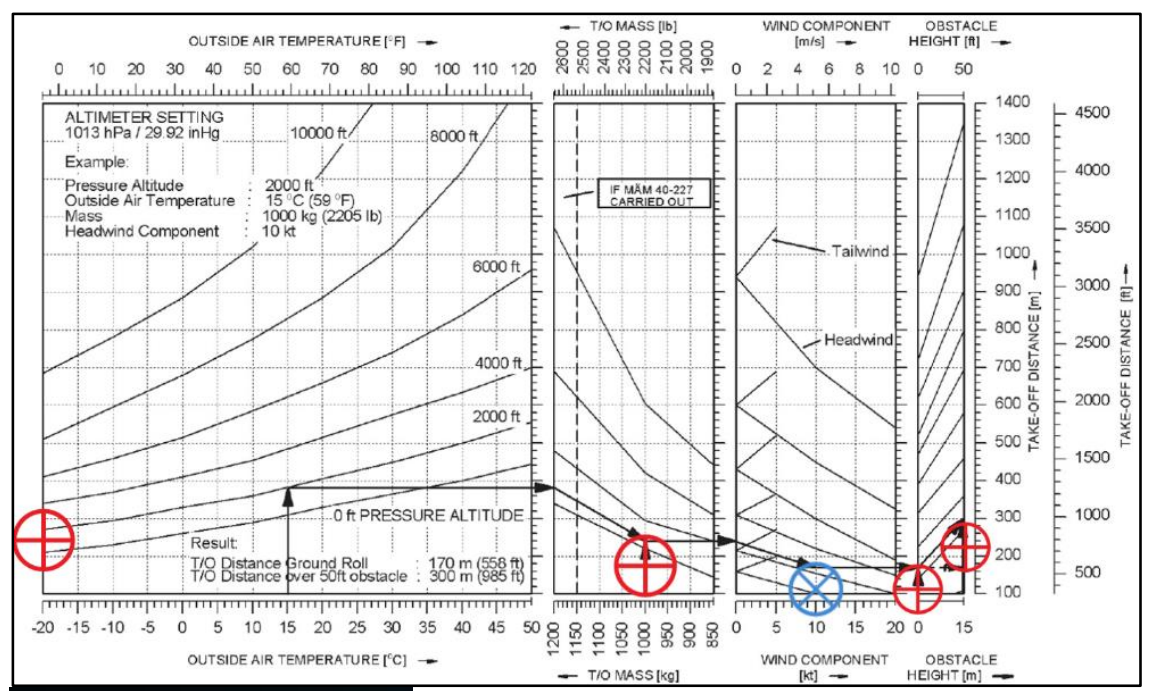

\section{Lift Off Speed approx 59 KIAS}

Climb-out speed $60.0 \mathrm{KIAS}$

Ground Roll 359' / 109m

Runway condition $\quad \mathbf{O}^{\prime} / \mathbf{O m}$

Runway Slope $\quad 0^{\prime} / 0 \mathrm{~m}$

TO Ground Roll $\overline{359^{\prime} / 109 m}$.

Total to clear

$50^{\prime} / 15 \mathrm{~m}$ obstacle $726^{\prime} / 221 \mathrm{~m}$

Runway condition $\quad \mathbf{0}^{\prime} / 0 \mathrm{~m}$

Runway Slope $\quad \mathbf{0}^{\prime} / \mathbf{O m}$

Takeoff Distance $\overline{726^{\prime} / 221 \mathrm{~m}}$

Figure 24. Gyronimo Extreme Low Temperature (Pressure Altitude 1,000 feet) Takeoff Determination 


\section{Takeoff Comparison 14: Temperature -5 C and Default Conditions}

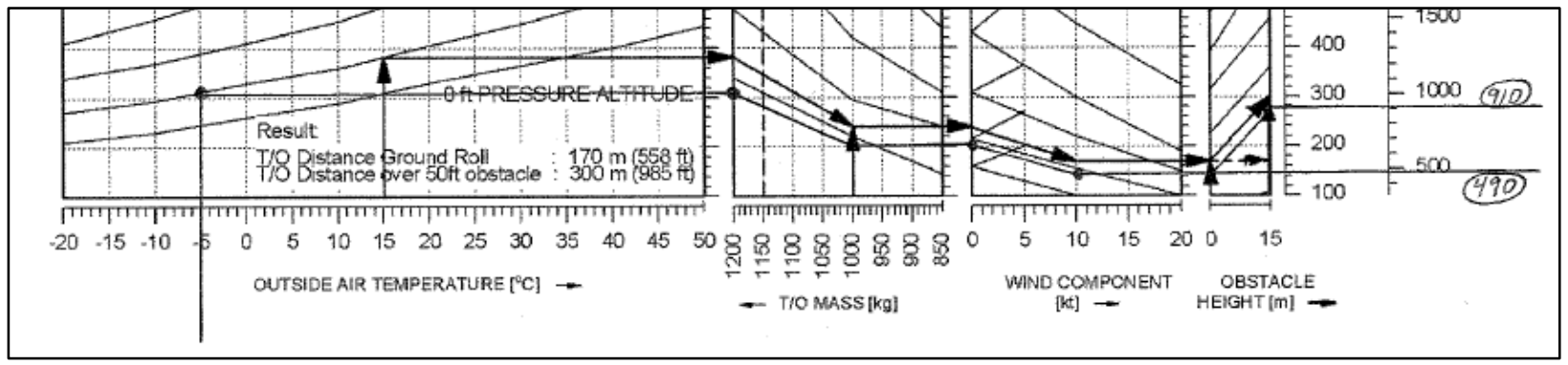

Figure 25. AFM Temperature - 5 Degrees C Takeoff Determination

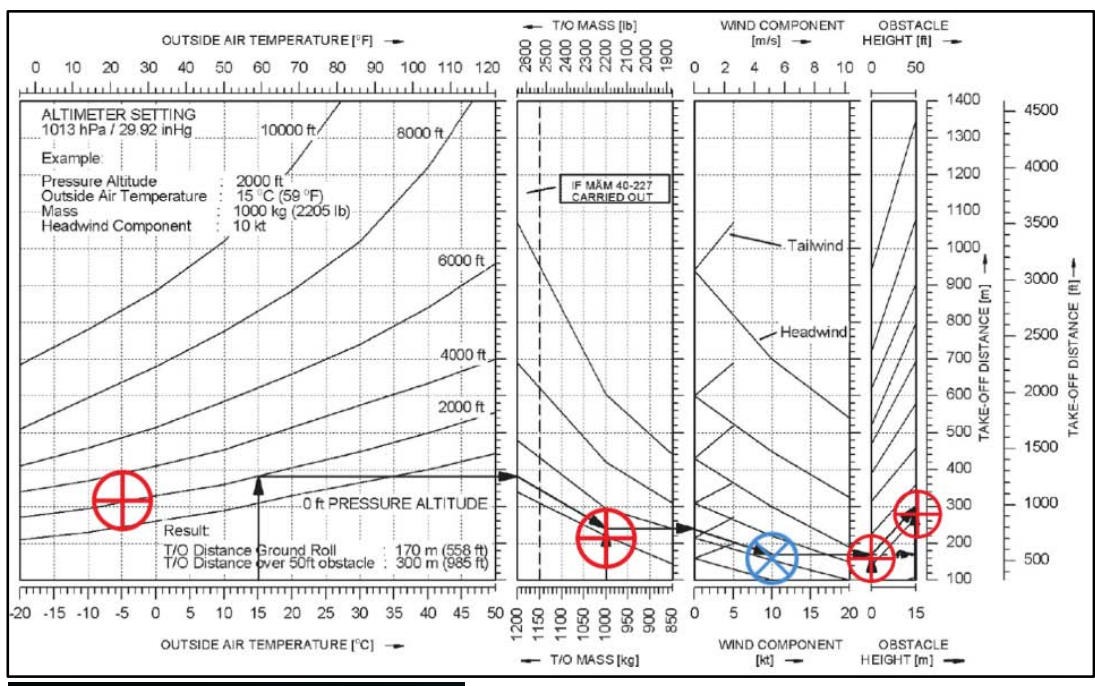

Lift Off Speed approx 59 KIAS

Climb-out speed $60.0 \mathrm{KIAS}$

Ground Roll 512' / $156 \mathrm{~m}$

Runway condition $\quad \mathbf{0}^{\prime} / \mathrm{Om}$

Runway Slope $\quad \mathbf{0}^{\prime} / \mathrm{Om}$

TO Ground Roll $\overline{512^{\prime} / 156 m}$.

Total to clear

$50^{\prime} / 15 \mathrm{~m}$ obstacle $908^{\prime} / \mathbf{2 7 7 m}$

Runway condition $\quad \mathbf{0}^{\prime} / \mathbf{O m}$

Runway Slope $\quad \mathbf{0}^{\prime} / \mathbf{O m}$

Takeoff Distance $\overline{908^{\prime} / 277 m}$ 
Figure 26. Gyronimo - 5 Degrees C Takeoff Determination

\section{Takeoff Comparison 15: Temperature 15 Degrees C and Default Conditions}

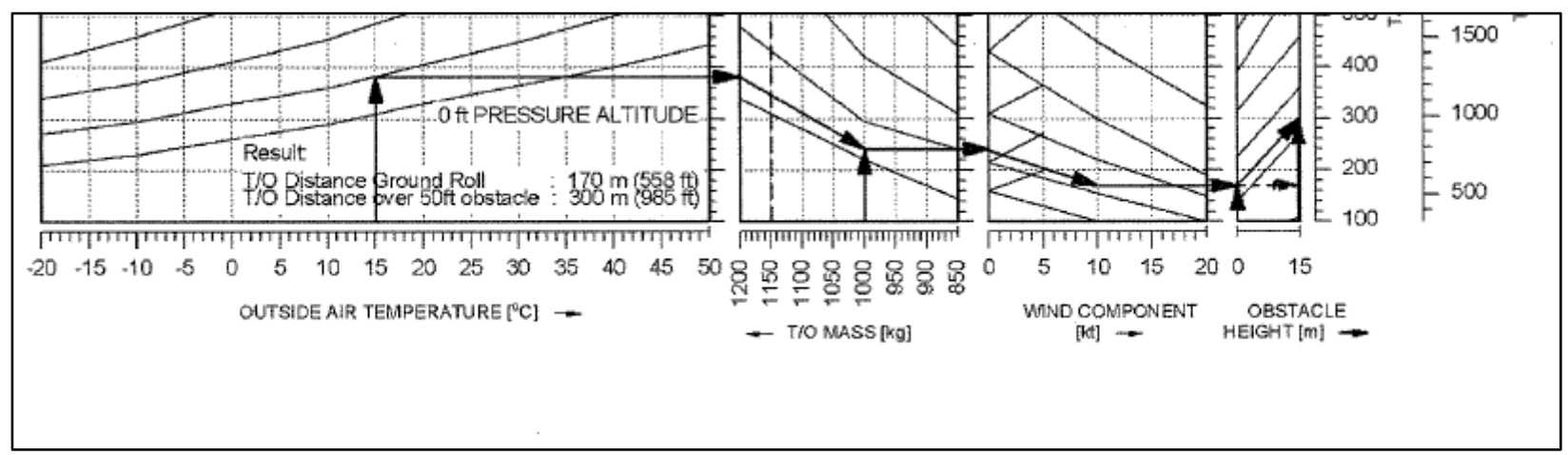

Figure 27. AFM Temperature 15 Degrees C Takeoff Determination 
International Journal of Aviation, Aeronautics, and Aerospace, Vol. 5 [2018], Iss. 4, Art. 1

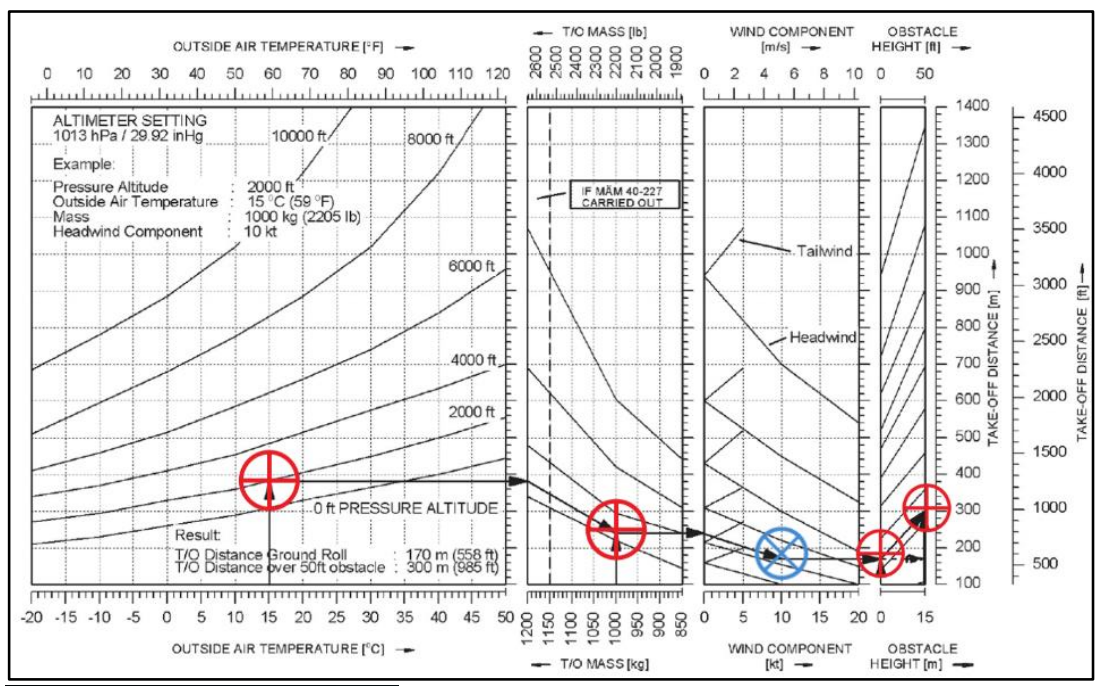

Lift Off Speed approx 59 KIA

Climb-out speed $60.0 \mathrm{KIAS}$

Ground Roll 598'/182m

Runway condition $\quad \mathbf{0}^{\prime} / \mathrm{Om}$

Runway Slope $\quad \mathbf{0}^{\prime} / \mathbf{O m}$

TO Ground Roll $\overline{598^{1} / 182 m}$ -

Total to clear

$50^{\prime} / 15 \mathrm{~m}$ obstacle $1005^{\prime} / 306 \mathrm{~m}$

Runway condition $\quad \mathbf{0}^{\prime} / \mathbf{O m}$

Runway Slope $\quad \mathbf{0}^{\prime} / \mathrm{Om}$

Takeoff Distance $1005^{\prime} / 306 \mathrm{~m}$

Figure 28. Gyronimo Temperature 15 Degrees C Takeoff Determination 


\section{Takeoff Comparison 16: Temperature 30 Degrees $C$ and Default Conditions}

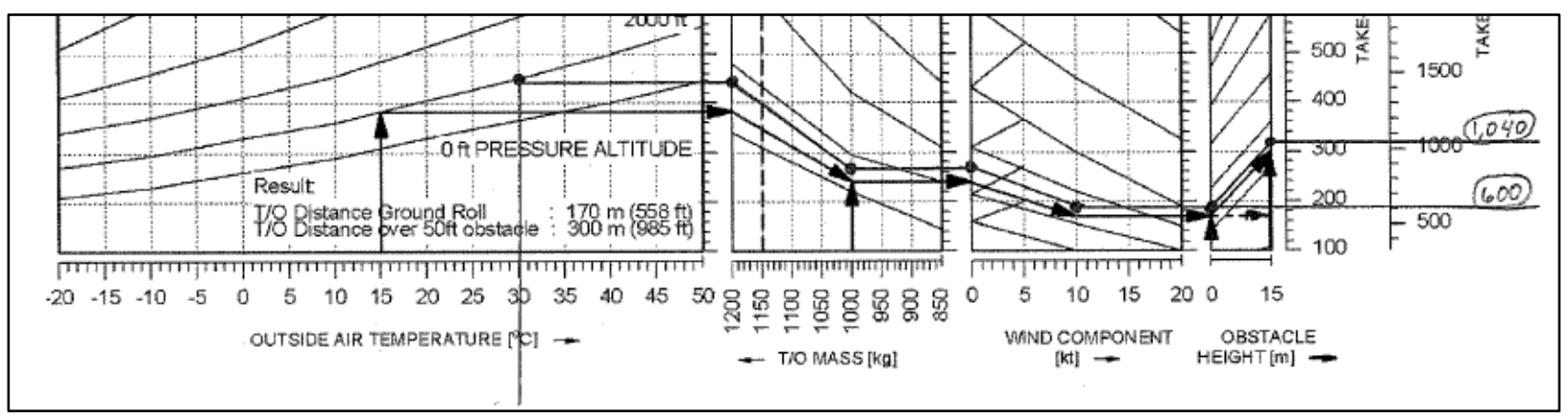

Figure 29. AFM Temperature 30 Degrees C Takeoff Determination

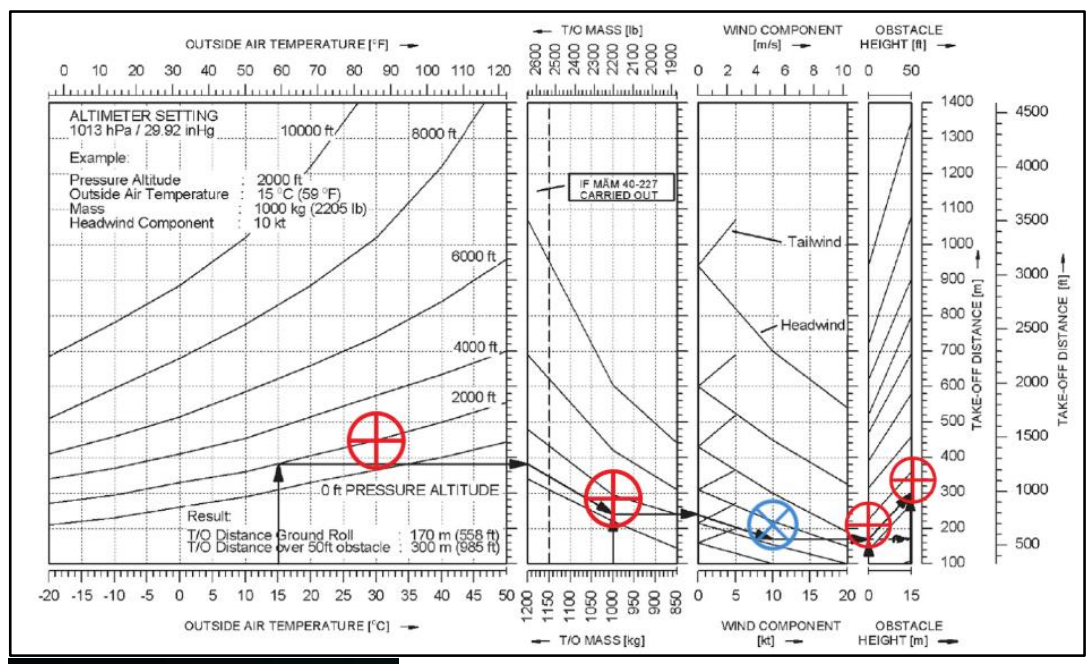

\footnotetext{
Lift Off Speed approx 59 KIAS

Climb-out speed $60.0 \mathrm{KIAS}$

Ground Roll $679^{\prime} / 207 m$

Runway condition $\quad 0^{\prime} / 0 \mathrm{~m}$

Runway Slope $\quad 0^{\prime} / 0 \mathrm{~m}$

TO Ground Roll $679^{\prime} / 207 \mathrm{~m}$ -

Total to clear

$50^{\prime} / 15 \mathrm{~m}$ obstacle $1096^{\prime} / 334 \mathrm{~m}$

Runway condition $\quad \mathbf{O}^{\prime} / \mathrm{Om}$

Runway Slope $\quad 0^{\prime} / 0 \mathrm{~m}$

Takeoff Distance $1096^{\prime} / 334 \mathrm{~m}$
} 
International Journal of Aviation, Aeronautics, and Aerospace, Vol. 5 [2018], Iss. 4, Art. 1

Figure 30. Gyronimo Temperature 30 Degrees C Takeoff Determination

Takeoff Comparison 17: Pressure Altitude 1,000 Feet Takeoff Comparison

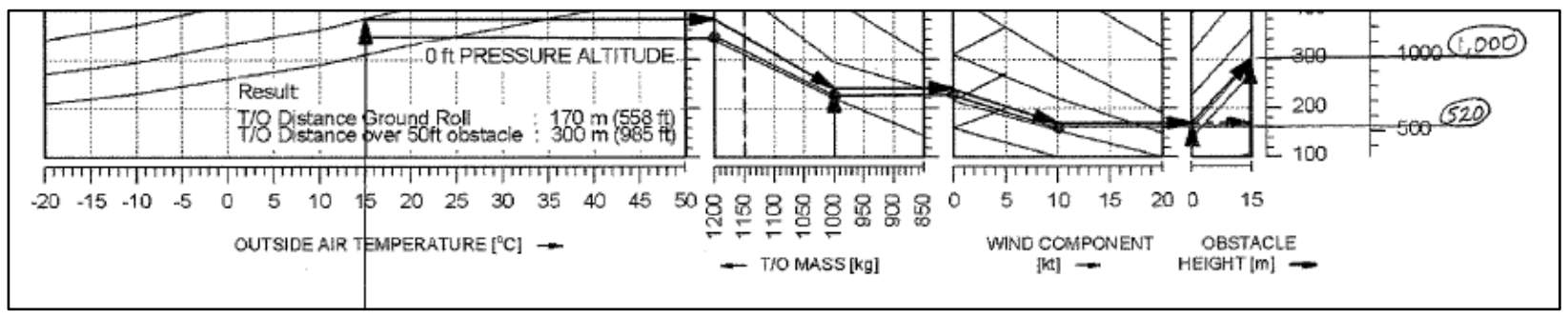

Figure 31. AFM Pressure Altitude 1,000 Feet Takeoff Determination 


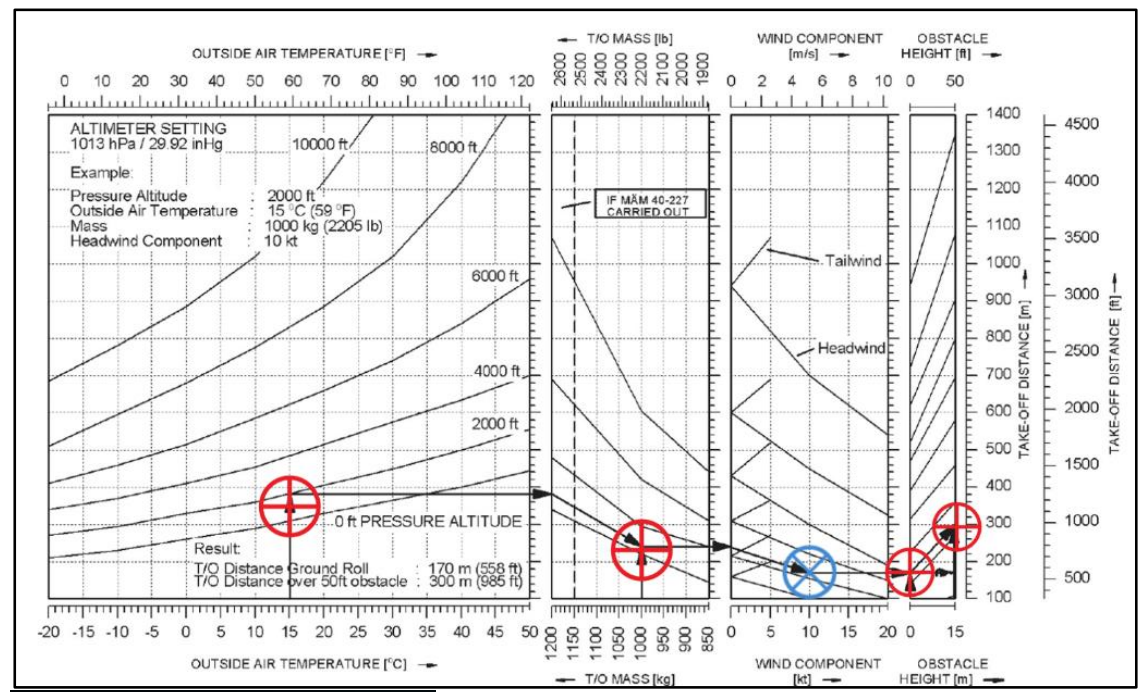

Lift Off Speed approx 59 KIAS

Climb-out speed $60.0 \mathrm{KIAS}$

Ground Roll 553'/169m

Runway condition $\quad \mathbf{0}^{\prime} / \mathbf{O m}$

Runway Slope $\quad \mathbf{0}^{\prime} / \mathbf{O m}$

TO Ground Roll $\overline{553^{1} / 169 m}$

Total to clear

$50^{\prime} / 15 \mathrm{~m}$ obstacle $954^{\prime} / 291 \mathrm{~m}$

Runway condition $\quad \mathbf{O}^{\prime} / 0 \mathrm{~m}$

Runway Slope $\quad \mathbf{0}^{\prime} / 0 \mathrm{~m}$

Takeoff Distance $954^{\prime} / 291 \mathrm{~m}$

Figure 32. Gyronimo Pressure Altitude 1,000 Feet Takeoff Determination 


\section{Takeoff Comparison 18: Pressure Altitude 4,000 Feet Takeoff Comparison}

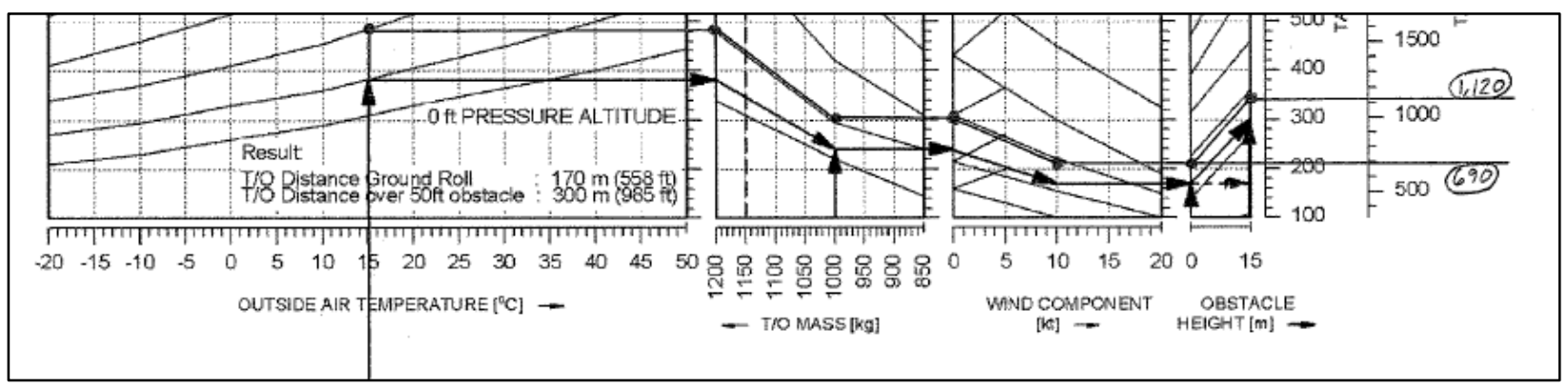

Figure 33. AFM Pressure Altitude 4,000 Feet Takeoff Determination

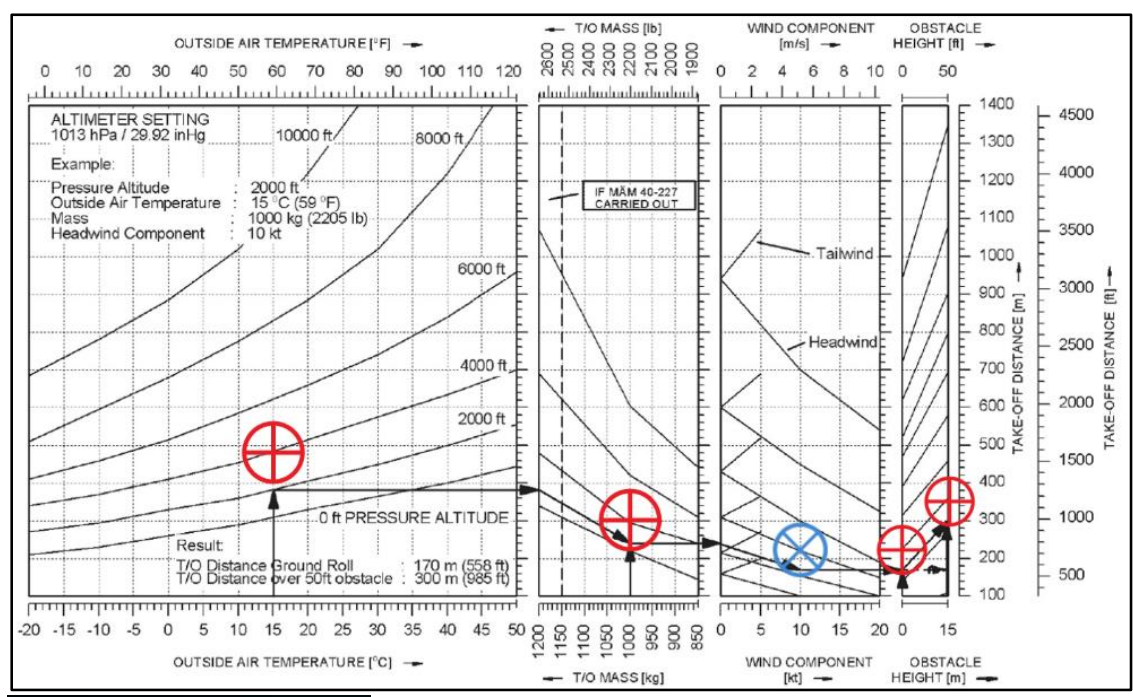

Lift Off Speed approx 59 KIAS

Climb-out speed 60.0 KIAS

Ground Roll $722^{\prime} / 220 m$

Runway condition $\quad \mathbf{0}^{\prime} / \mathrm{Om}$

Runway Slope $\quad 0^{\prime} / 0 \mathrm{~m}$

TO Ground Roll $\overline{722^{\prime} / 220 \mathrm{~m}}$ -

Total to clear

$50^{\prime} / 15 \mathrm{~m}$ obstacle $1144^{\prime} / 349 \mathrm{~m}$

Runway condition $\quad 0^{\prime} / 0 m$

Runway Slope $\quad \mathbf{0}^{\prime} / 0 \mathrm{~m}$

Takeoff Distance $\overline{1144^{\prime} / 349 m}$ 
Figure 34. Gyronimo Pressure Altitude 4,000 Feet Takeoff Determination

\section{Takeoff Comparison 19: Pressure Altitude 8,000 Feet Takeoff Comparison}

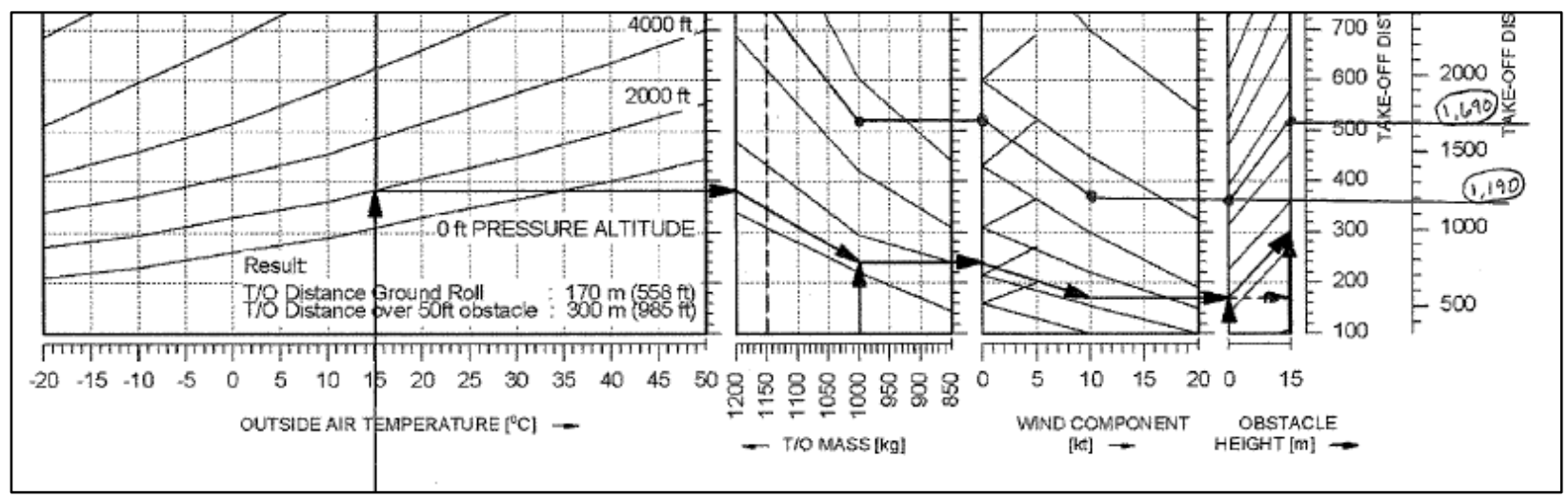

Figure 35. AFM Pressure Altitude 8,000 Feet Takeoff Determination 
International Journal of Aviation, Aeronautics, and Aerospace, Vol. 5 [2018], Iss. 4, Art. 1

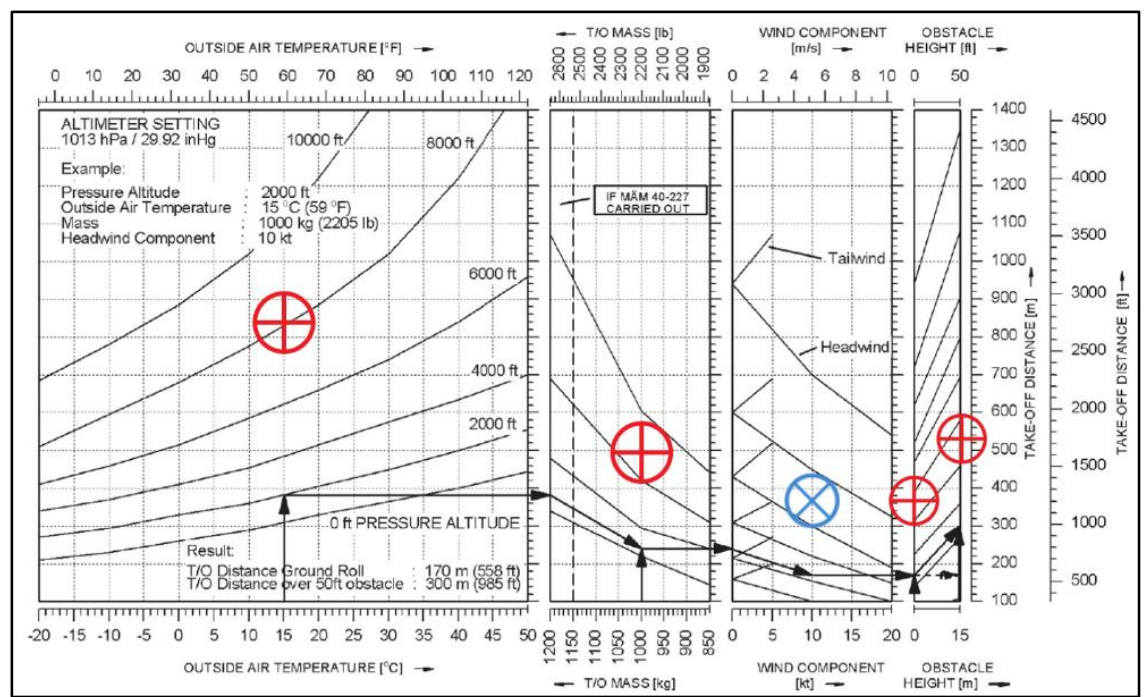

Lift Off Speed approx 59 KIAS

Climb-out speed 60.0 KIAS

Ground Roll 1196' / 365m

Runway condition $\quad 0^{\prime} / 0 \mathrm{~m}$

Runway Slope $\quad 0^{\prime} / \mathrm{Om}$

To Ground Roll $\overline{11966^{\prime} / 365 \mathrm{~m}}$

Total to clear

$50^{\prime} / 15 \mathrm{~m}$ obstacle $1735^{\prime} / 529 \mathrm{~m}$

Runway condition $\quad 0^{\prime} / 0 \mathrm{~m}$

Runway Slope $\mathbf{0}^{\prime} / \mathrm{Om}$

Takeoff Distance $1735^{\prime} / 529 \mathrm{~m}$

Figure 36. Gyronimo Pressure Altitude 8,000 Feet Takeoff Determination

\section{Takeoff Comparison 20: Weight 2,000 Pounds Takeoff Comparison}




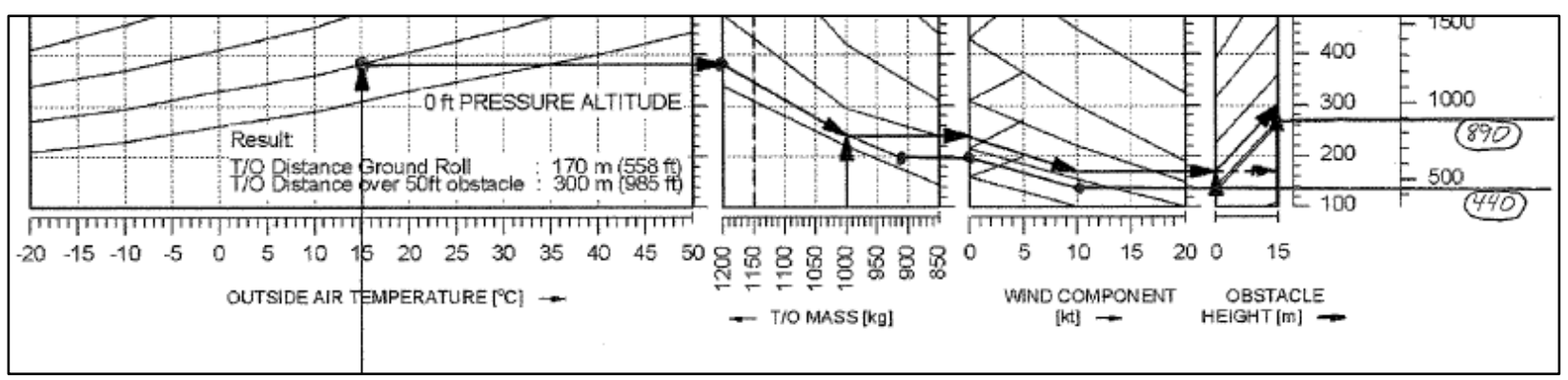

Figure 37. AFM Weight 2,000 Pounds Takeoff Determination
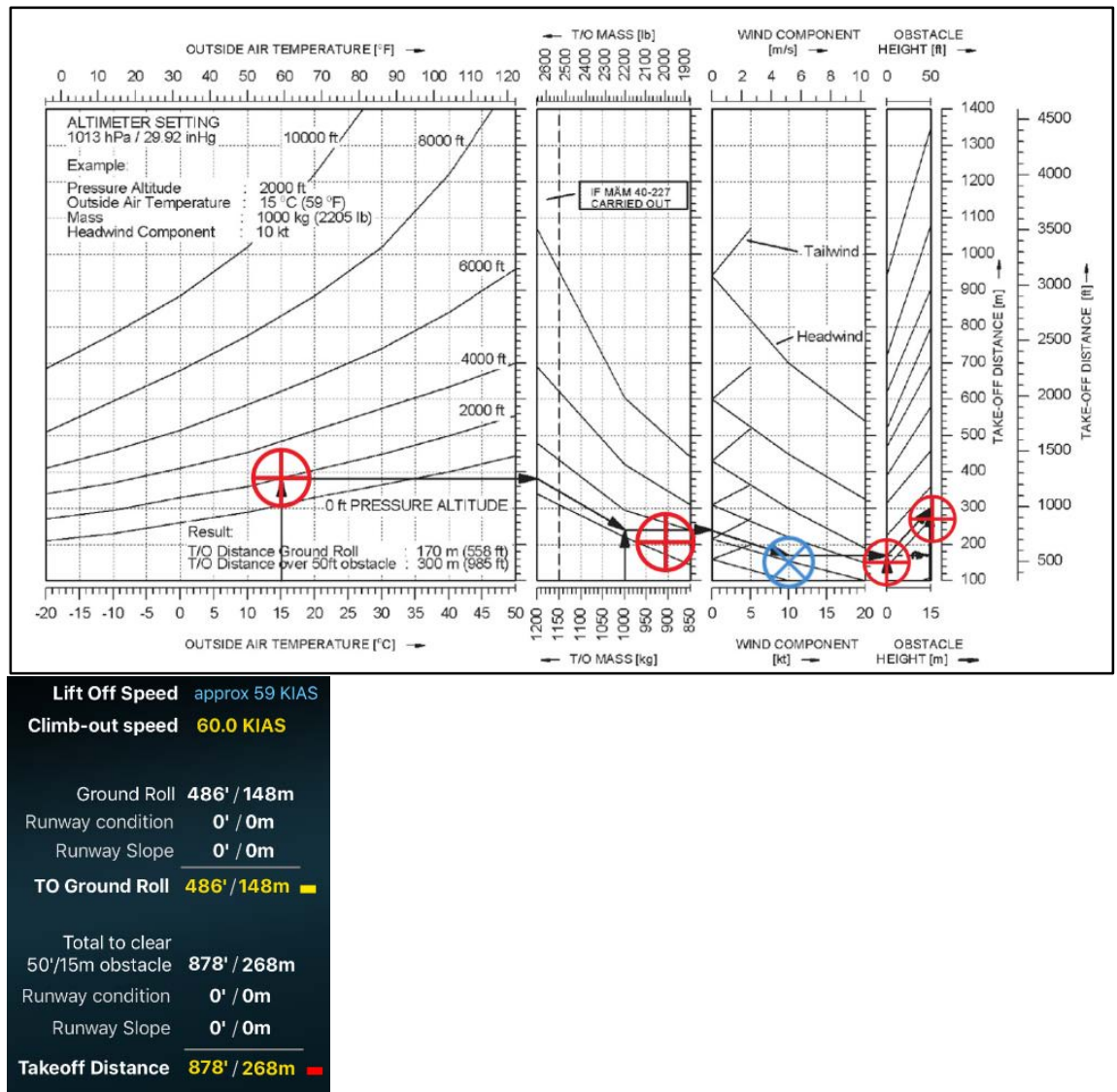

Figure 38. Gyronimo Weight 2,000 Pounds Takeoff Determination 
International Journal of Aviation, Aeronautics, and Aerospace, Vol. 5 [2018], Iss. 4, Art. 1

Takeoff Comparison 21: Weight 2,400 Pounds Takeoff Comparison

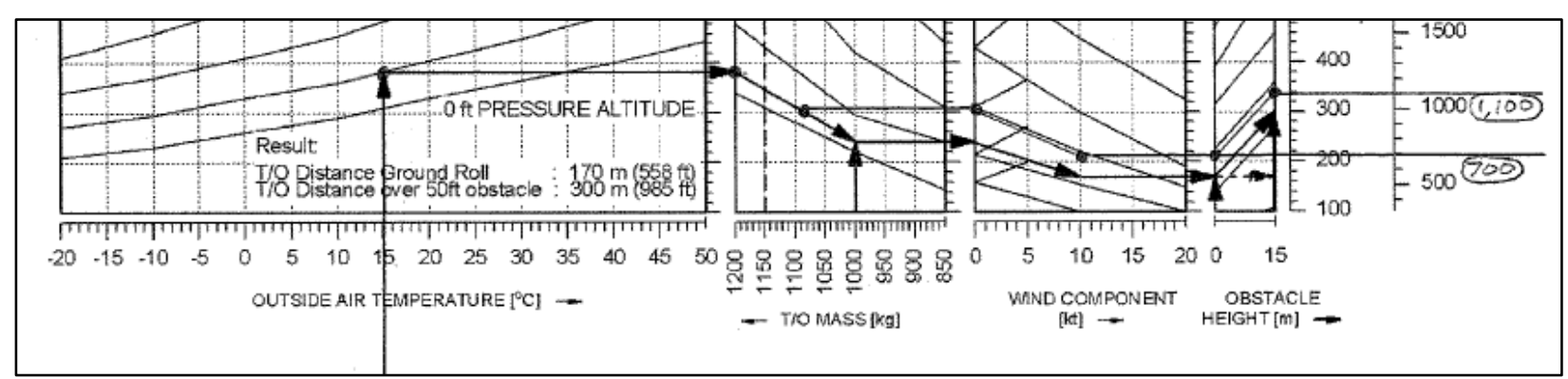

Figure 39. AFM Weight 2,400 Pounds Takeoff Determination 


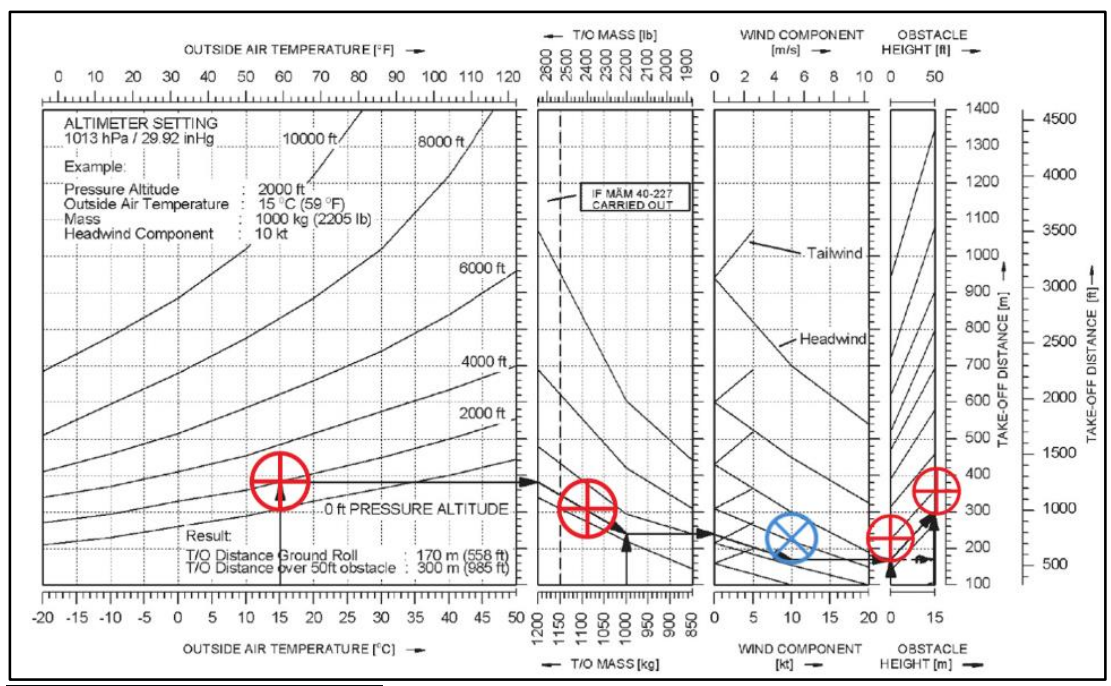

\begin{tabular}{cc} 
Lift Off Speed & approx $59 \mathrm{KIAS}$ \\
Climb-out speed & $63.5 \mathrm{KIAS}$ \\
Ground Roll & $739^{\prime} / 225 \mathrm{~m}$ \\
Runway condition & $0^{\prime} / 0 \mathrm{~m}$ \\
Runway Slope & $0^{\prime} / 0 \mathrm{~m}$ \\
\cline { 2 - 2 } TO Ground Roll & $739^{\prime} / 225 \mathrm{~m}=$ \\
Total to clear & \\
$50^{\prime} / 15 \mathrm{~m}$ obstacle & $1164^{\prime} / 355 \mathrm{~m}$ \\
Runway condition & $0^{\prime} / 0 \mathrm{~m}$ \\
Runway Slope & $0^{\prime} / 0 \mathrm{~m}$ \\
\cline { 2 - 2 } Takeoff Distance & $1164^{\prime} / 355 \mathrm{~m}$
\end{tabular}

Figure 40. Gyronimo Weight 2,400 Pounds Takeoff Determination 


\section{Takeoff Comparison 22: Weight 2,600 Pounds Takeoff Comparison}

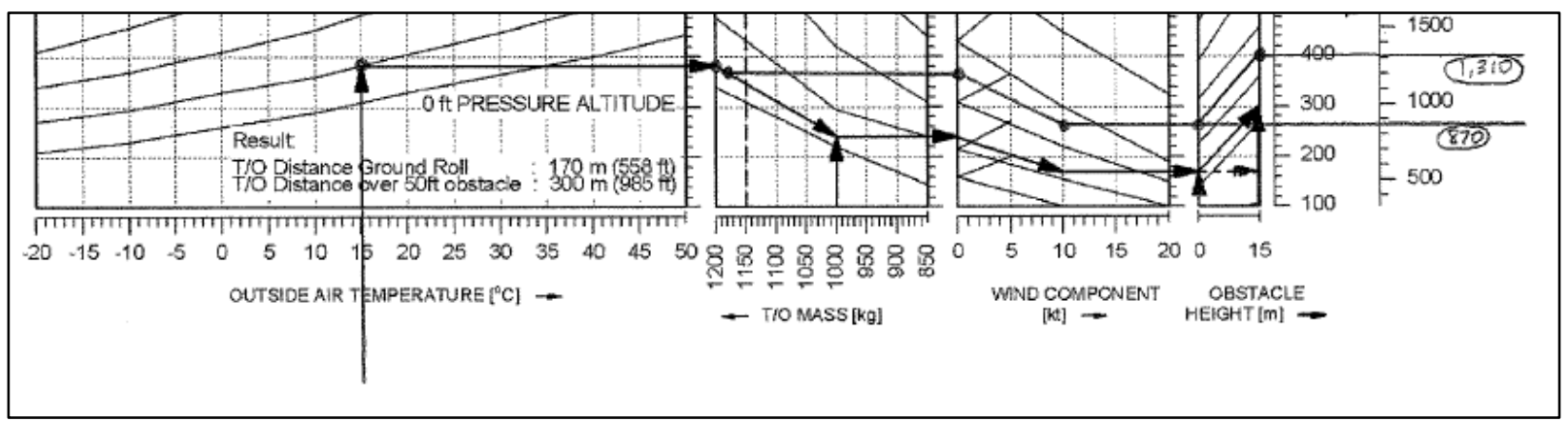

Figure 41. AFM Weight 2,600 Pounds Takeoff Determination 


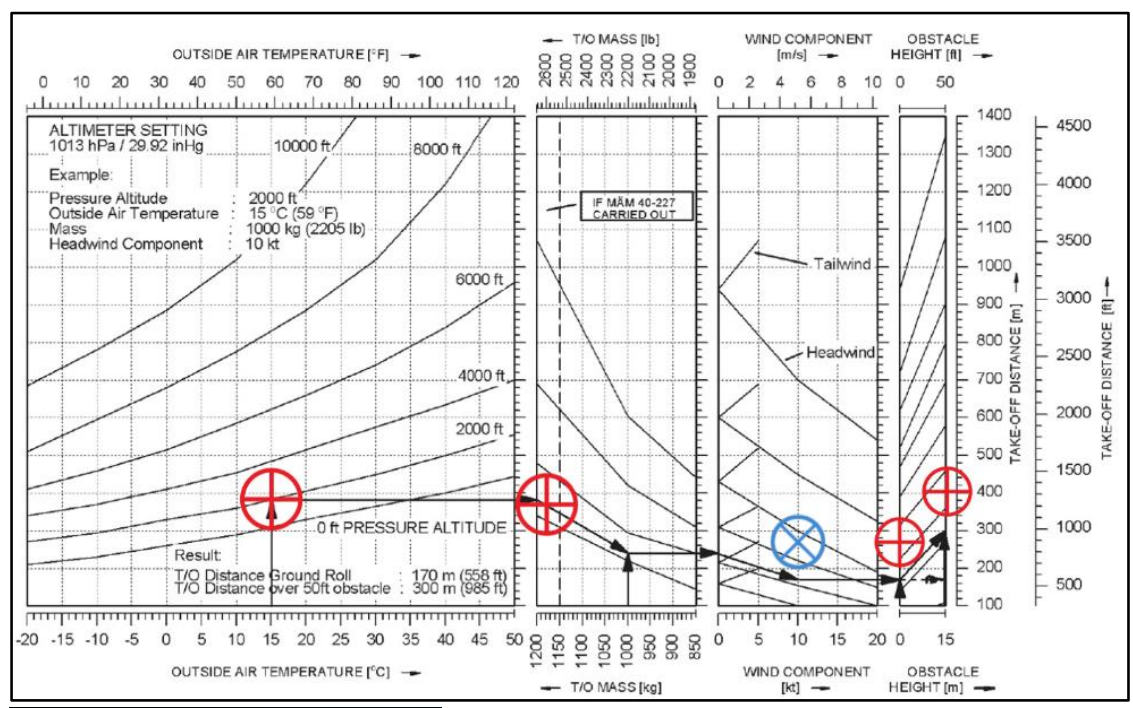

Lift Off Speed approx 59 KIAS

Climb-out speed $66.6 \mathrm{KIAS}$

Ground Roll $877^{\prime} / 267 m$

Runway condition $\quad \mathbf{O}^{\prime} / \mathbf{O m}$

Runway Slope $\quad \mathbf{0}^{\prime} / \mathbf{O m}$

TO Ground Roll $\overline{877^{\prime} / 267 m}$

Total to clear

$50^{\prime} / 15 \mathrm{~m}$ obstacle $1318^{\prime} / 402 \mathrm{~m}$

Runway condition $\quad \mathbf{O}^{\prime} / \mathbf{O m}$

Runway Slope $\quad \mathbf{0}^{\prime} / 0 \mathrm{~m}$

Takeoff Distance $1318^{\prime} / 402 m$

Figure 42. Gyronimo Weight 2,600 Pounds Takeoff Determination 


\section{Takeoff Comparison 23: 7 Knot Headwind Takeoff Comparison}

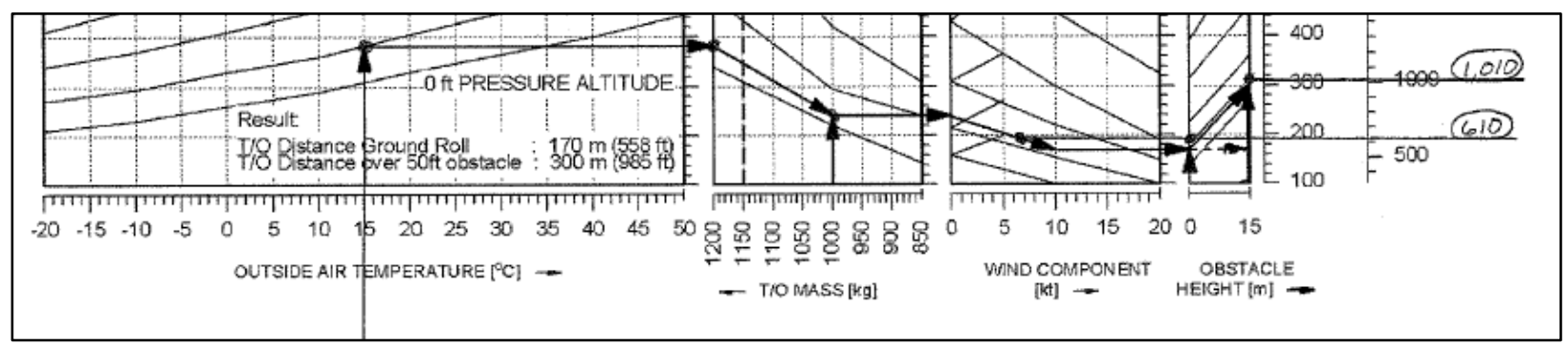

Figure 43. AFM 7 Knot Headwind Takeoff Determination 


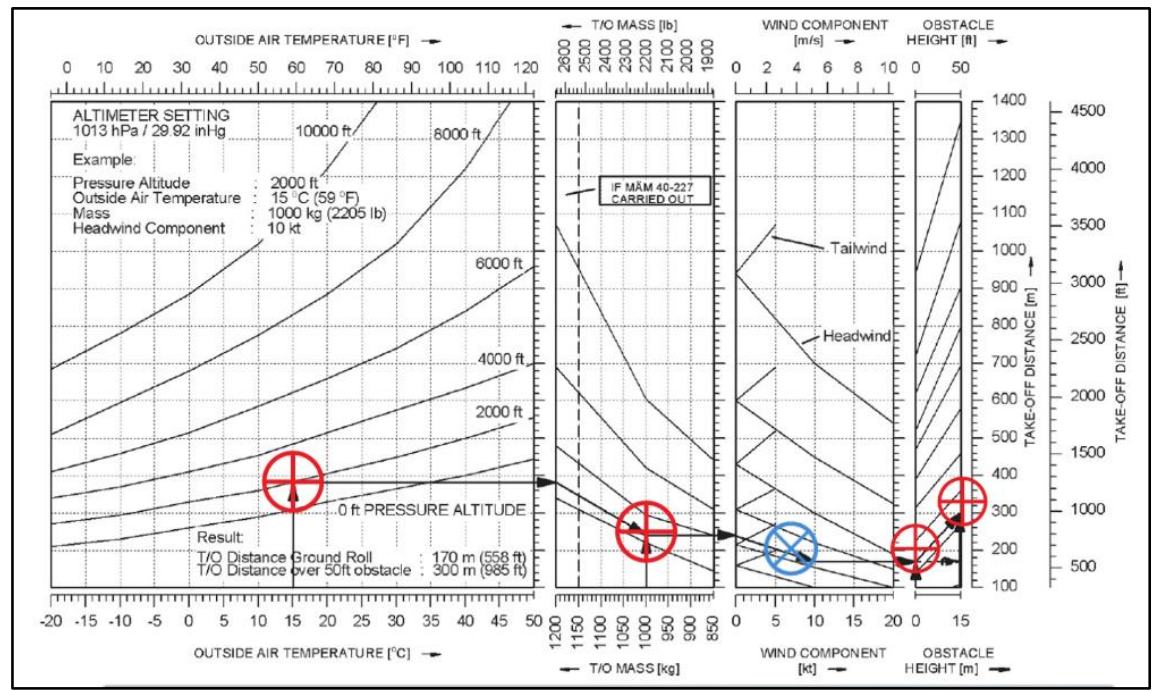

Lift Off Speed approx 59 KIAS

Climb-out speed $60.0 \mathrm{KIAS}$

Ground Roll 662' / 202m

Runway condition $\quad \mathbf{O}^{\prime} / \mathrm{Om}$

Runway Slope $\quad \mathbf{O}^{\prime} / \mathrm{Om}$

TO Ground Roll $\overline{662^{\prime} / 202 m}$

Total to clear

$50^{\prime} / 15 \mathrm{~m}$ obstacle $1077^{\prime} / \mathbf{3 2 8 m}$

Runway condition $\quad \mathbf{O}^{\prime} / \mathbf{O m}$

Runway Slope $\quad \mathbf{O}^{\prime} / \mathbf{O m}$

Takeoff Distance $1077^{\prime} / 328 \mathrm{~m}$

Figure 44. Gyronimo 7 Knot Headwind Takeoff Determination 


\section{Takeoff Comparison 24: 14 Knot Headwind Takeoff Comparison}

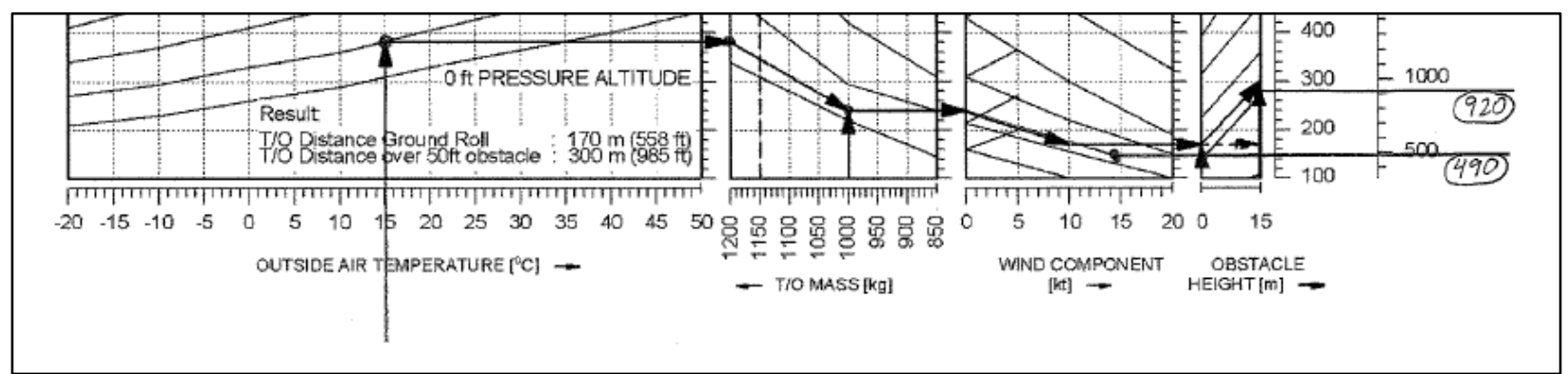

Figure 45. AFM 14 Knot Headwind Takeoff Determination 

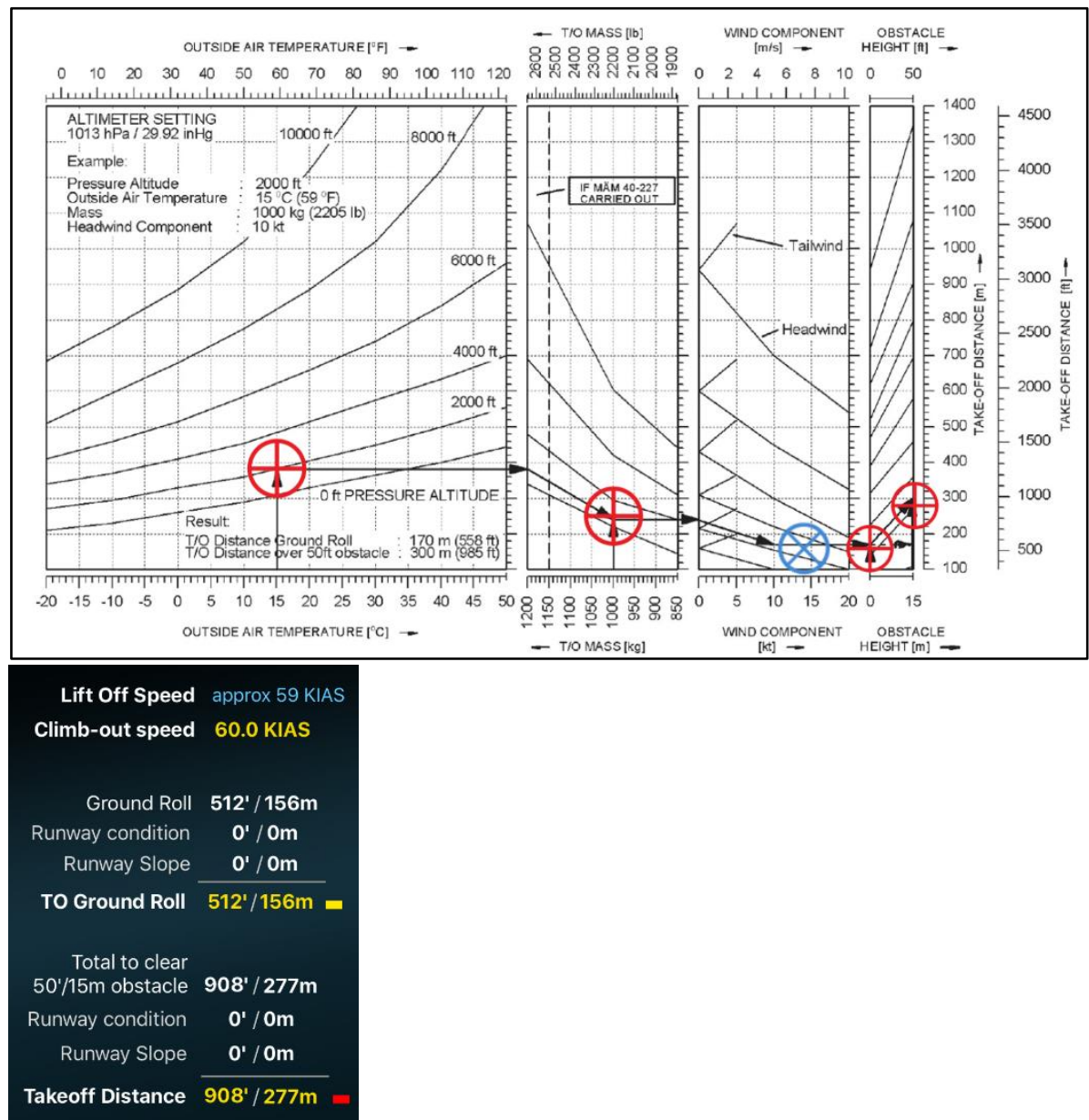

Figure 46. Gyronimo 14 Knot Headwind Takeoff Determination 


\section{Takeoff Comparison 25: 20Knot Headwind Takeoff Comparison}

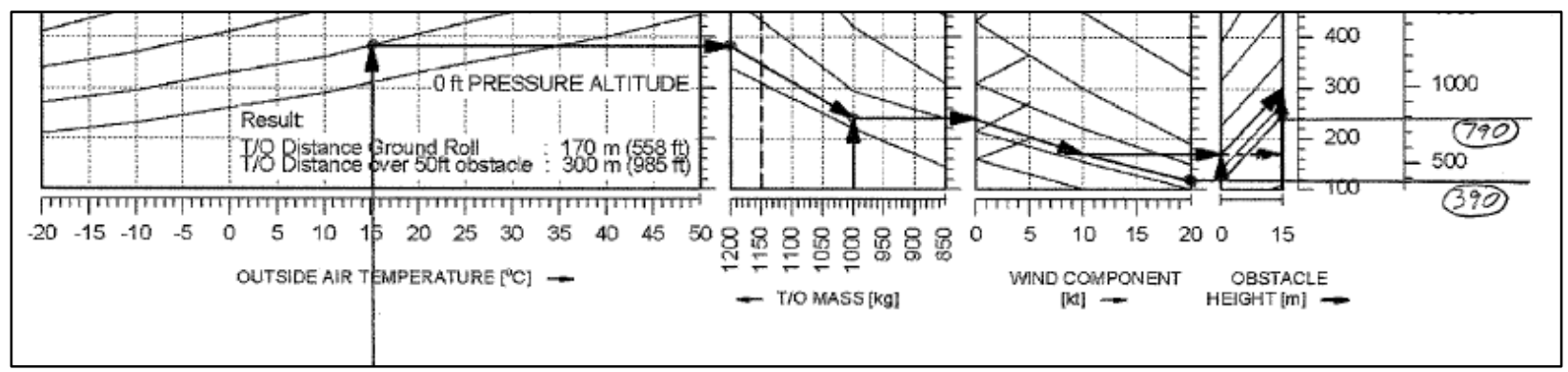

Figure 47. AFM 20 Knot Headwind Takeoff Determination

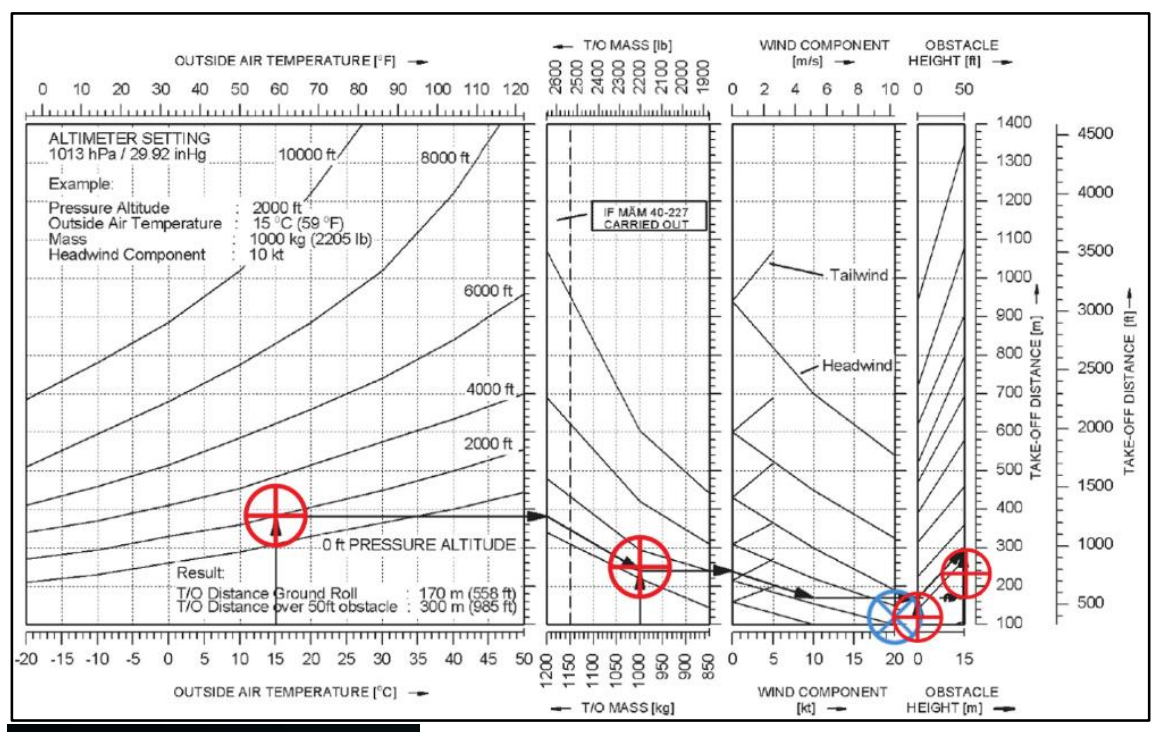

\footnotetext{
Lift Off Speed approx 59 KIAS

Climb-out speed $60.0 \mathrm{KIAS}$

Ground Roll 384'/117m

Runway condition $\quad \mathbf{O}^{\prime} / \mathrm{Om}$

Runway Slope $\quad 0^{\prime} / 0 \mathrm{~m}$

TO Ground Roll $\overline{384^{\prime} / 117 m}$.

Total to clear

$50^{\prime} / 15 \mathrm{~m}$ obstacle $756^{\prime} / 230 \mathrm{~m}$

Runway condition $\quad \mathbf{0}^{\prime} / \mathrm{Om}$

Runway Slope $\quad \mathbf{0}^{\prime} / \mathbf{O m}$

Takeoff Distance $756^{\prime} / 230 m$
} 
Babb and Hiers: Determination of TOLD Data Using an iPad Application

Figure 48. Gyronimo 20 Knot Headwind Takeoff Determination 
International Journal of Aviation, Aeronautics, and Aerospace, Vol. 5 [2018], Iss. 4, Art. 1

\section{Appendix B: Landing Performance Chart Comparisons}

\section{Landing Comparison 1: AFM Default Information}

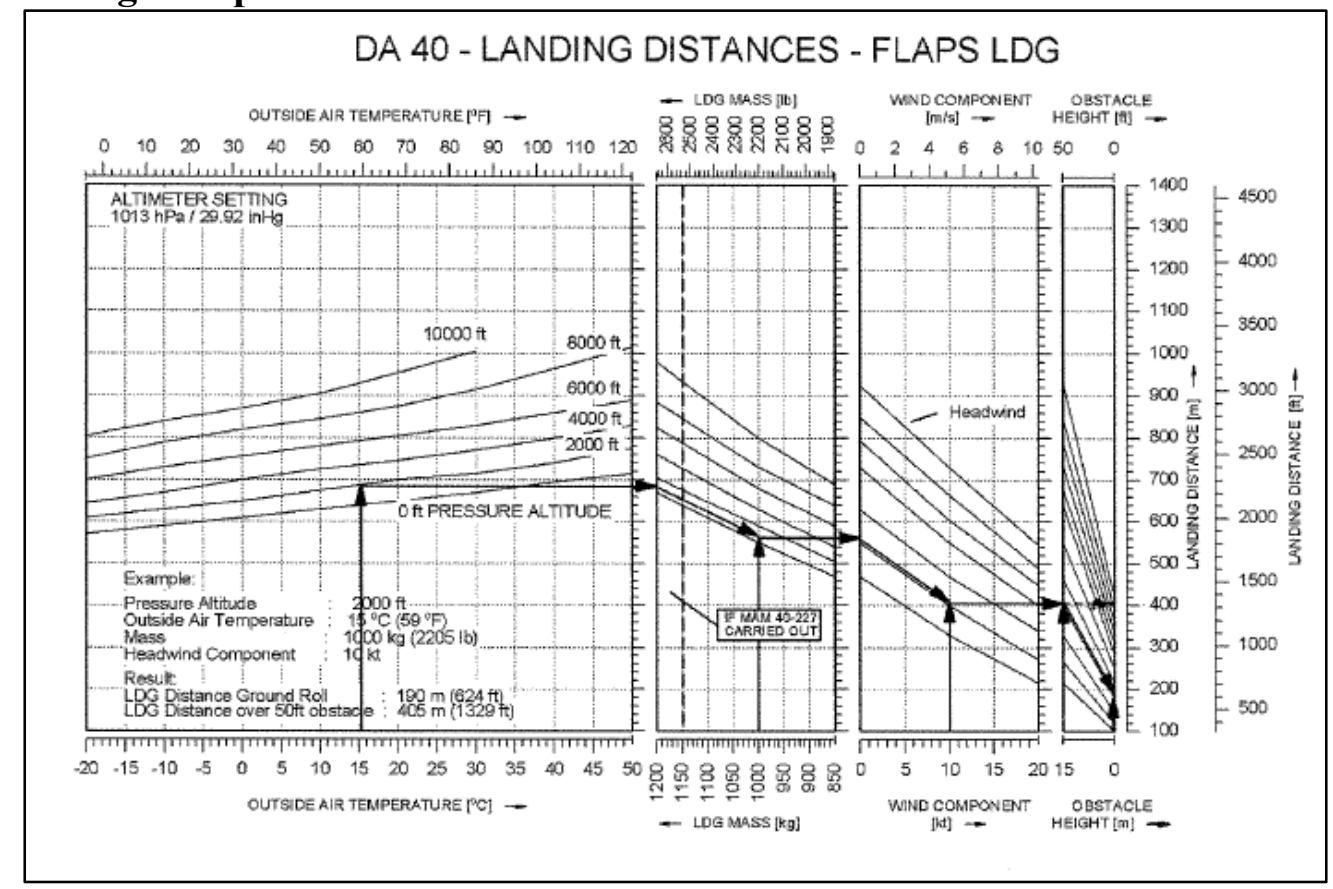

Figure 1. AFM Default Variables Landing Determination 


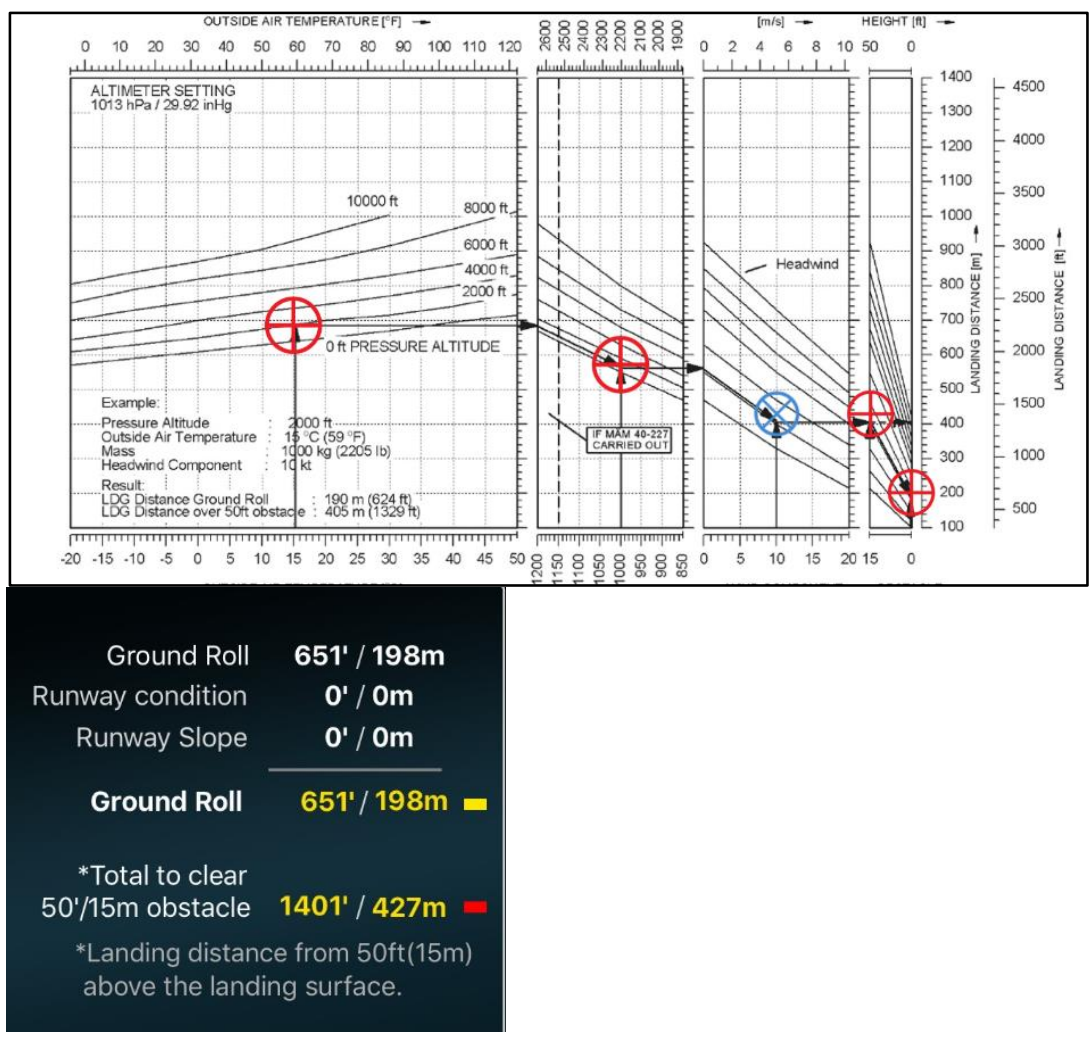

Figure 2. Gyronimo Default Variables Landing Determination

\section{Landing Comparison 2: Maximum Gross Weight}




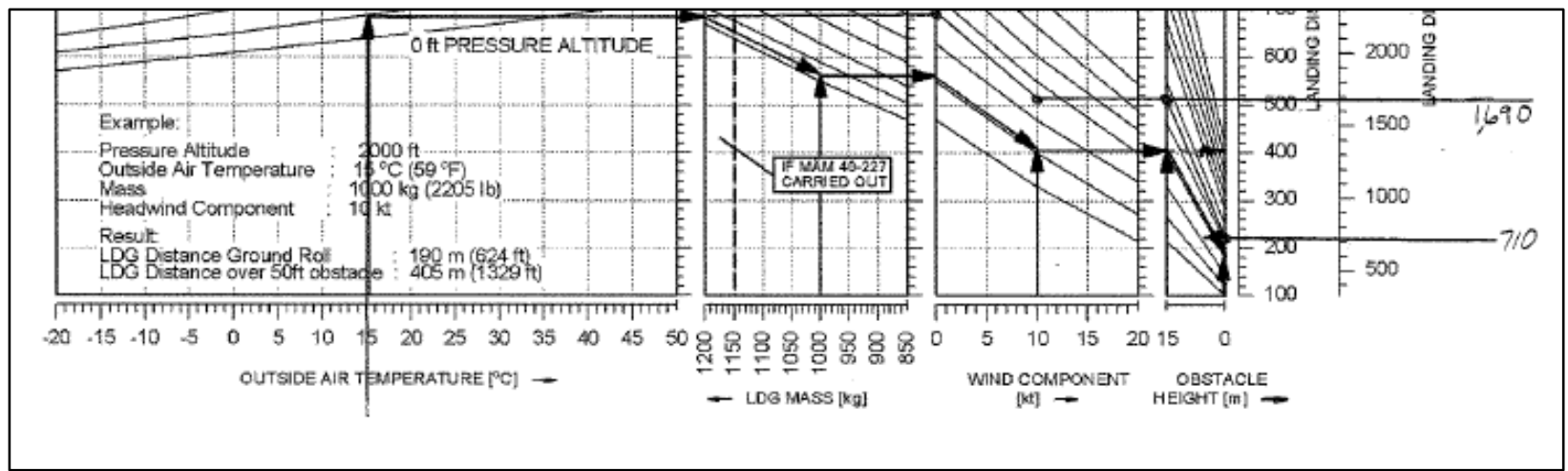

Figure 3. AFM Maximum Gross Weight Landing Determination
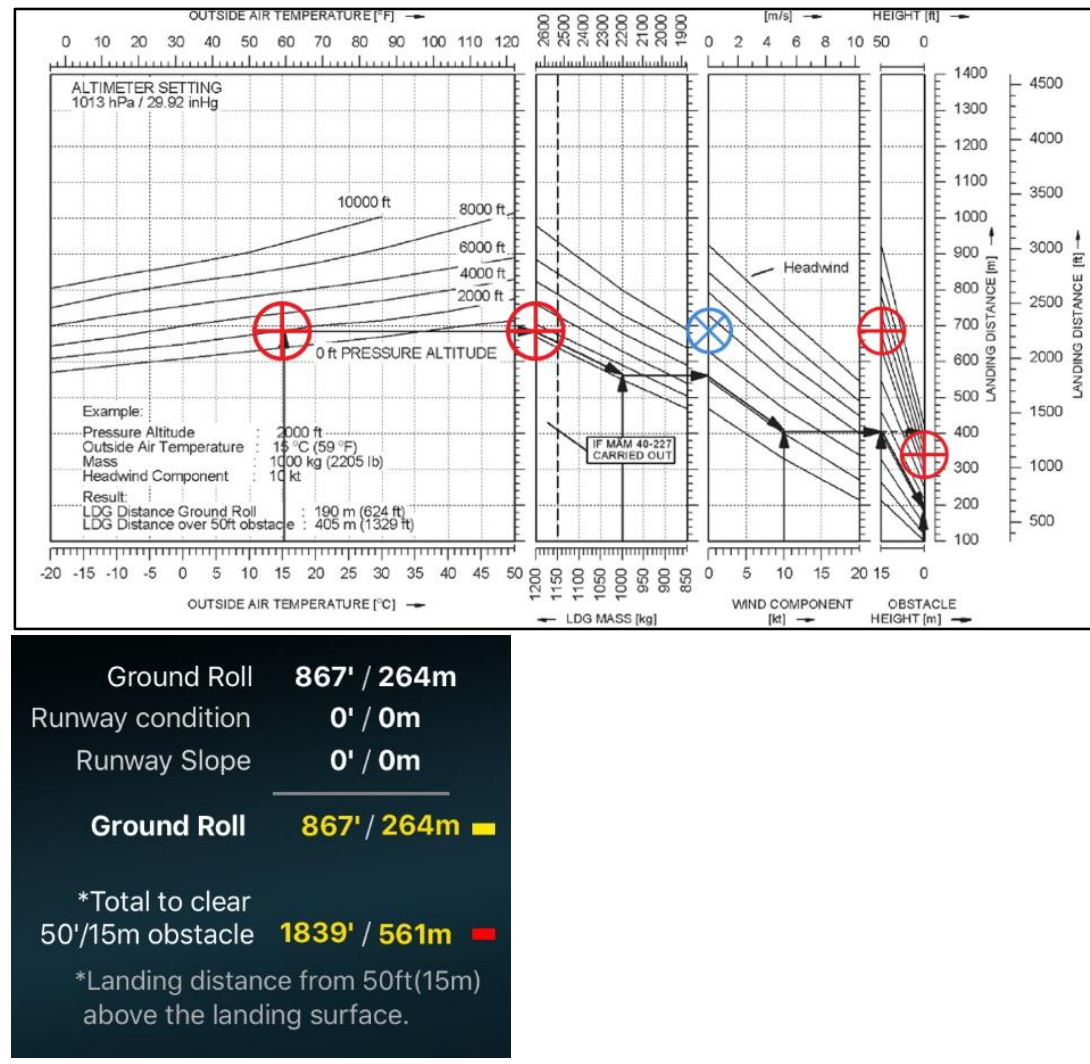

Figure 4. Gyronimo Maximum Gross Weight Landing Determination 


\section{Landing Comparison 3: Maximum Pressure Altitude (10,000 feet)}

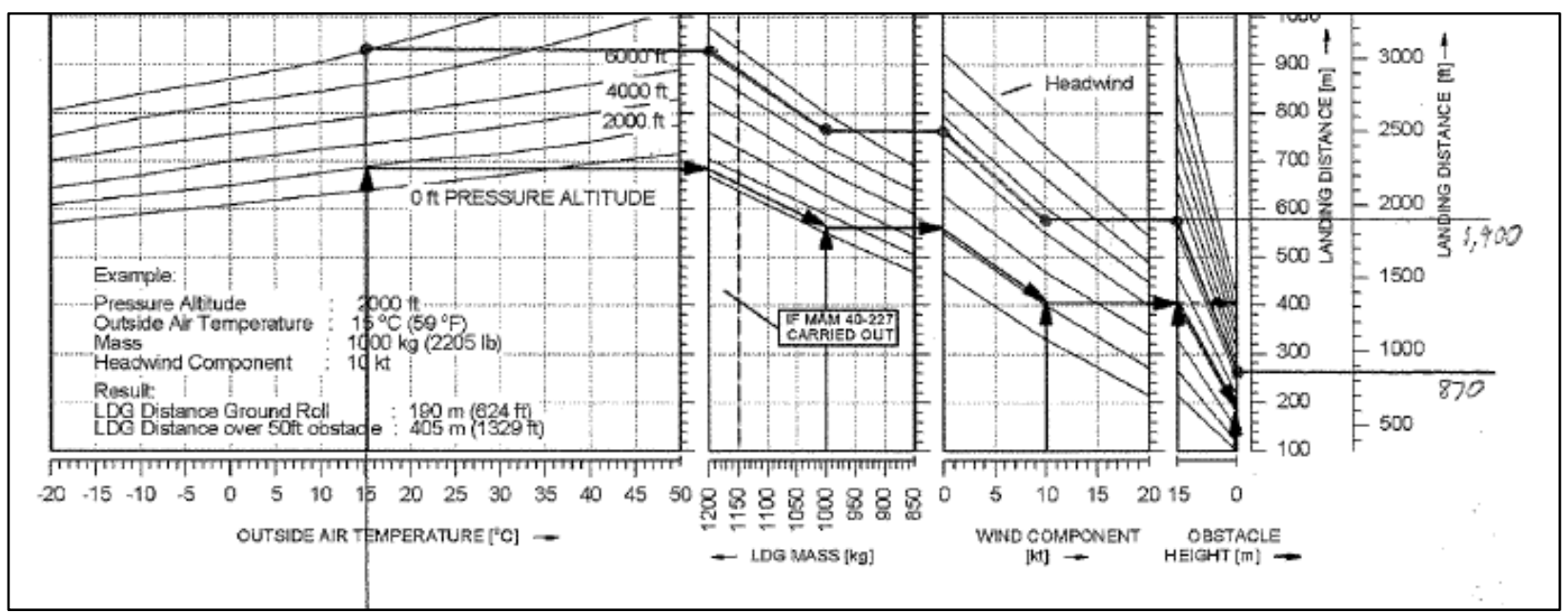

Figure 5. AFM Maximum Pressure Altitude Landing Determination 
International Journal of Aviation, Aeronautics, and Aerospace, Vol. 5 [2018], Iss. 4, Art. 1

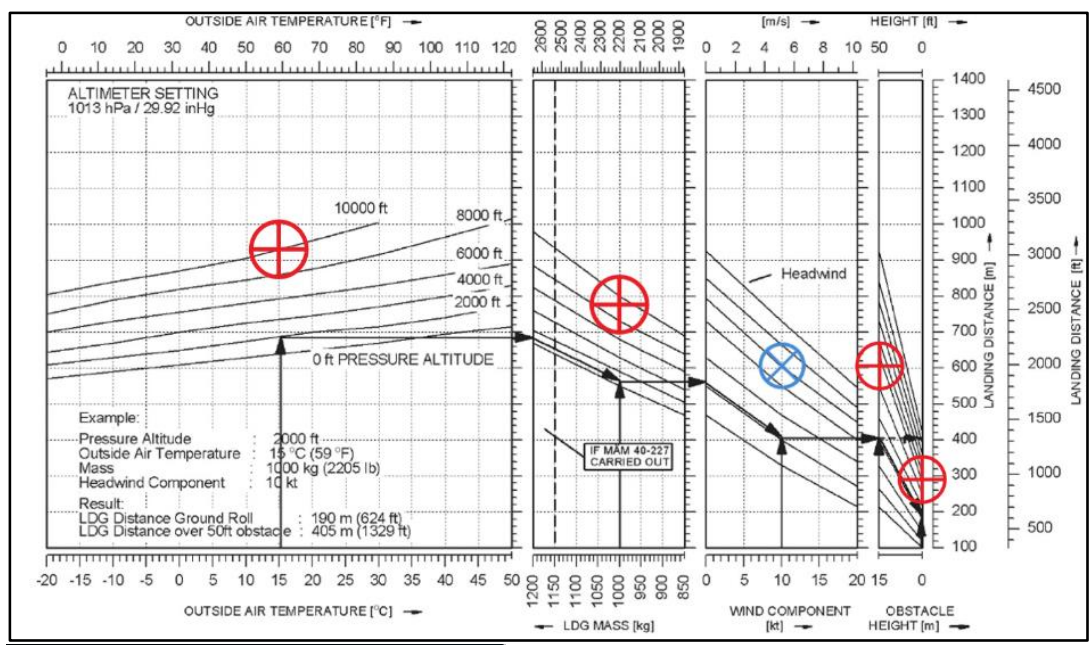

\begin{tabular}{rc}
\hline Ground Roll & $\begin{array}{c}943^{\prime} / 287 m \\
\mathbf{O}^{\prime} / 0 \mathrm{~m}\end{array}$ \\
$\begin{array}{r}\text { Runway condition } \\
\text { Runway Slope }\end{array}$ & $\mathbf{O}^{\prime} / \mathbf{O m}$ \\
\cline { 2 - 2 } Ground Roll & $943^{\prime} / 287 \mathrm{~m}$ \\
*Total to clear & \\
$50^{\prime} / 15 \mathrm{~m}$ obstacle & $1984^{\prime} / 605 \mathrm{~m}$ \\
*Landing distance from $50 \mathrm{ft}(15 \mathrm{~m})$ \\
above the landing surface.
\end{tabular}

Figure 6. Gyronimo Maximum Pressure Altitude Landing Determination

\section{Landing Comparison 4: Maximum OAT (50 degrees C)}




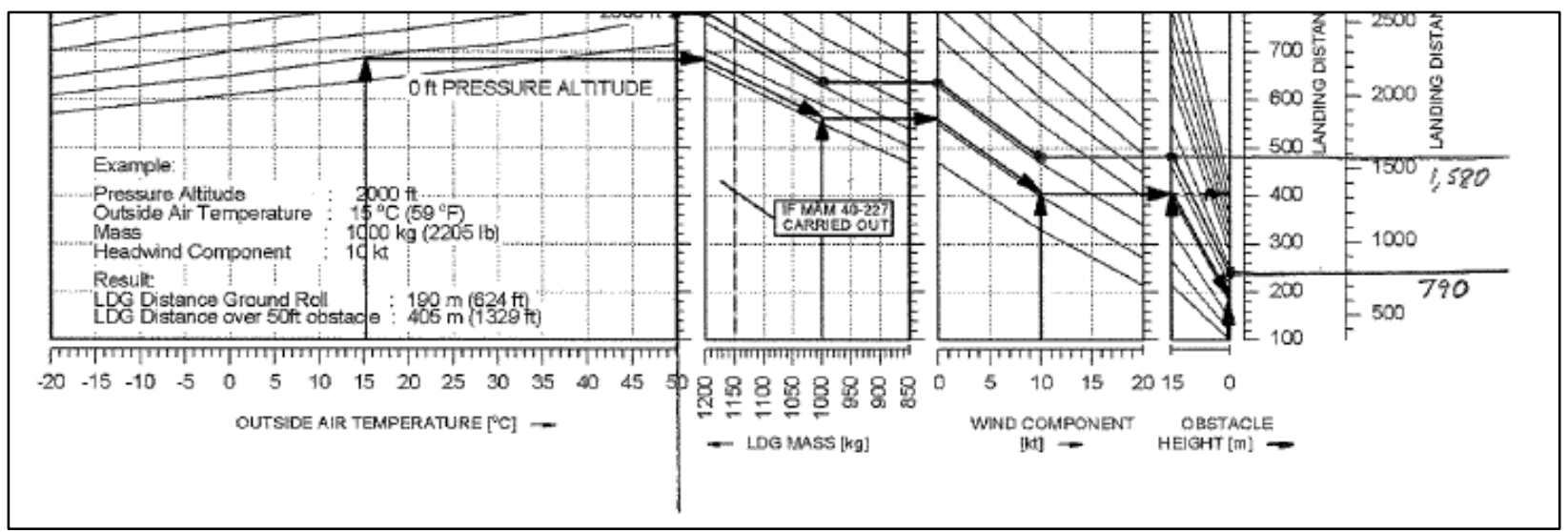

Figure 7. AFM Maximum OAT Landing Determination

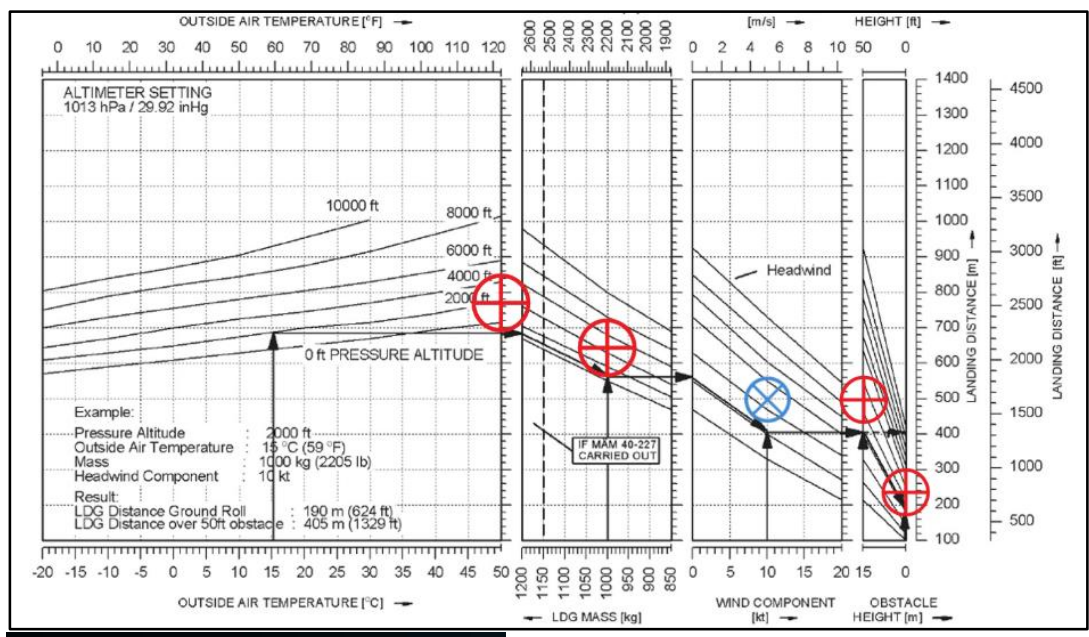

\begin{tabular}{|c|c|}
\hline Ground Roll & $763^{\prime} / 233 m$ \\
\hline Runway condition & $0^{\prime} / 0 \mathrm{~m}$ \\
\hline Runway Slope & $\mathrm{O}^{\prime} / \mathrm{Om}$ \\
\hline Ground Roll & $763^{\prime} / 233 m=$ \\
\hline $\begin{array}{l}{ }^{*} \text { Total to clear } \\
50^{\prime} / 15 \mathrm{~m}\end{array}$ & $1624^{\prime} / 495 m$ \\
\hline $\begin{array}{l}\text { *Landing distan } \\
\text { above the lanc }\end{array}$ & $\begin{array}{l}\text { ing surface. } \\
\text { ing }(15 \mathrm{~m}) \\
\end{array}$ \\
\hline
\end{tabular}

Figure 8. Gyronimo Maximum OAT Landing Determination 
International Journal of Aviation, Aeronautics, and Aerospace, Vol. 5 [2018], Iss. 4, Art. 1

\section{Landing Comparison 5: Hot and High Landing Determination (EASA)}

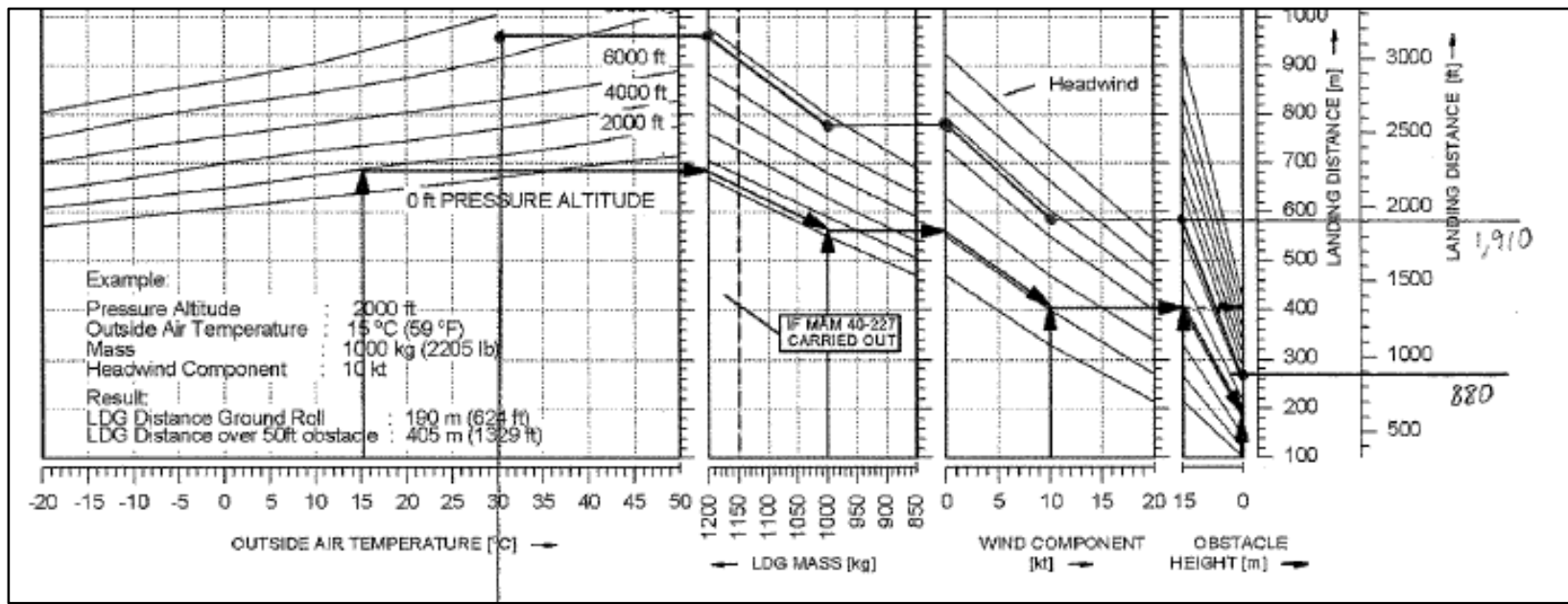

Figure 9. AFM Hot and High Landing Determination 


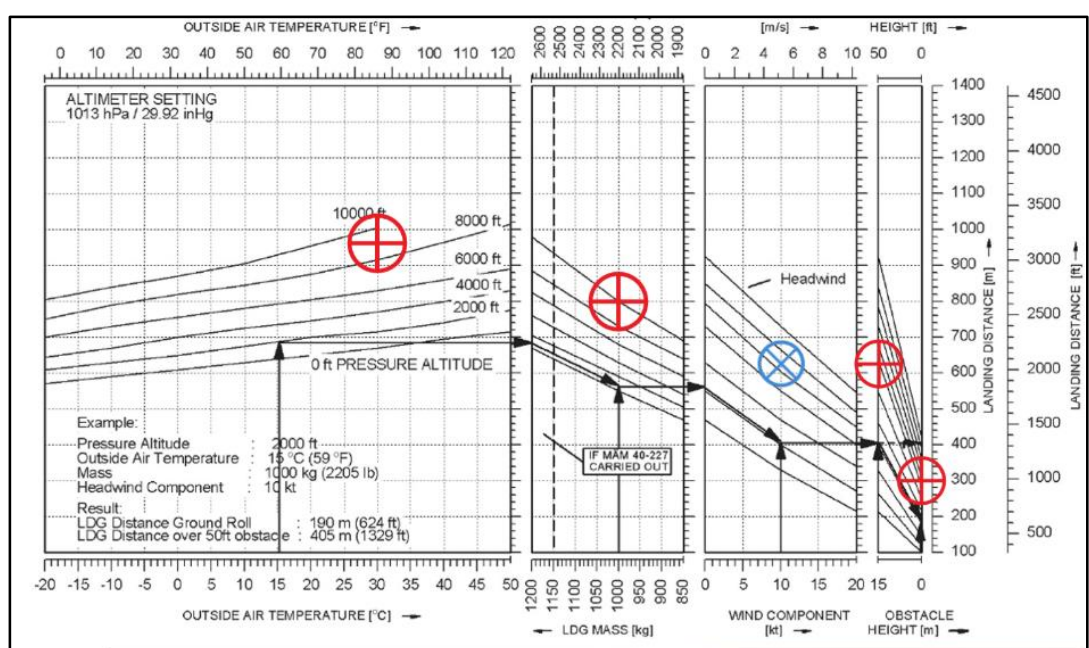

\begin{tabular}{rc}
\hline Ground Roll & $975^{\prime} / 297 m$ \\
Runway condition & $0^{\prime} / 0 \mathrm{~m}$ \\
Runway Slope & $0^{\prime} / 0 \mathrm{~m}$ \\
\cline { 2 - 2 } Ground Roll & $975^{\prime} / 297 \mathrm{~m}$ \\
& \\
*Total to clear & \\
$50^{\prime} / 15 \mathrm{~m}$ obstacle & $2048^{\prime} / 624 \mathrm{~m}$ \\
*Landing distance from $50 \mathrm{ft}(15 \mathrm{~m})$ \\
above the landing surface.
\end{tabular}

Figure 10. Gyronimo Hot and High Landing Determination

\section{Landing Comparison 6: ISA Condition (MSL) with No Wind}




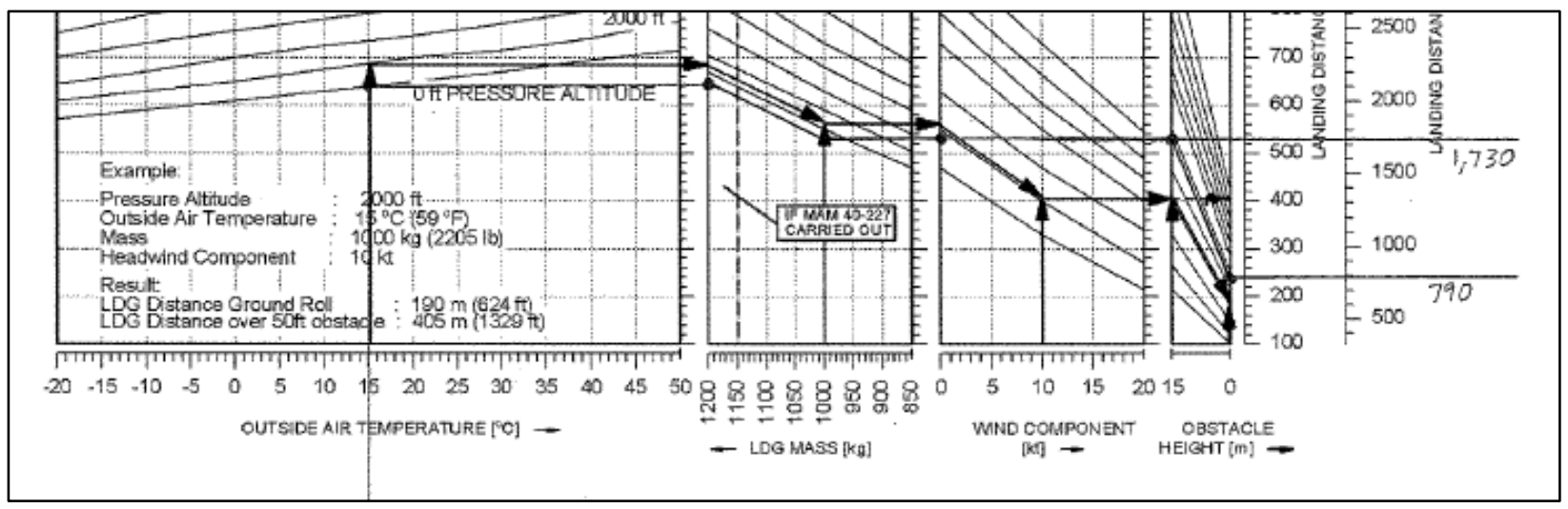

Figure 11. AFM Landing Determination at ISA with No Wind
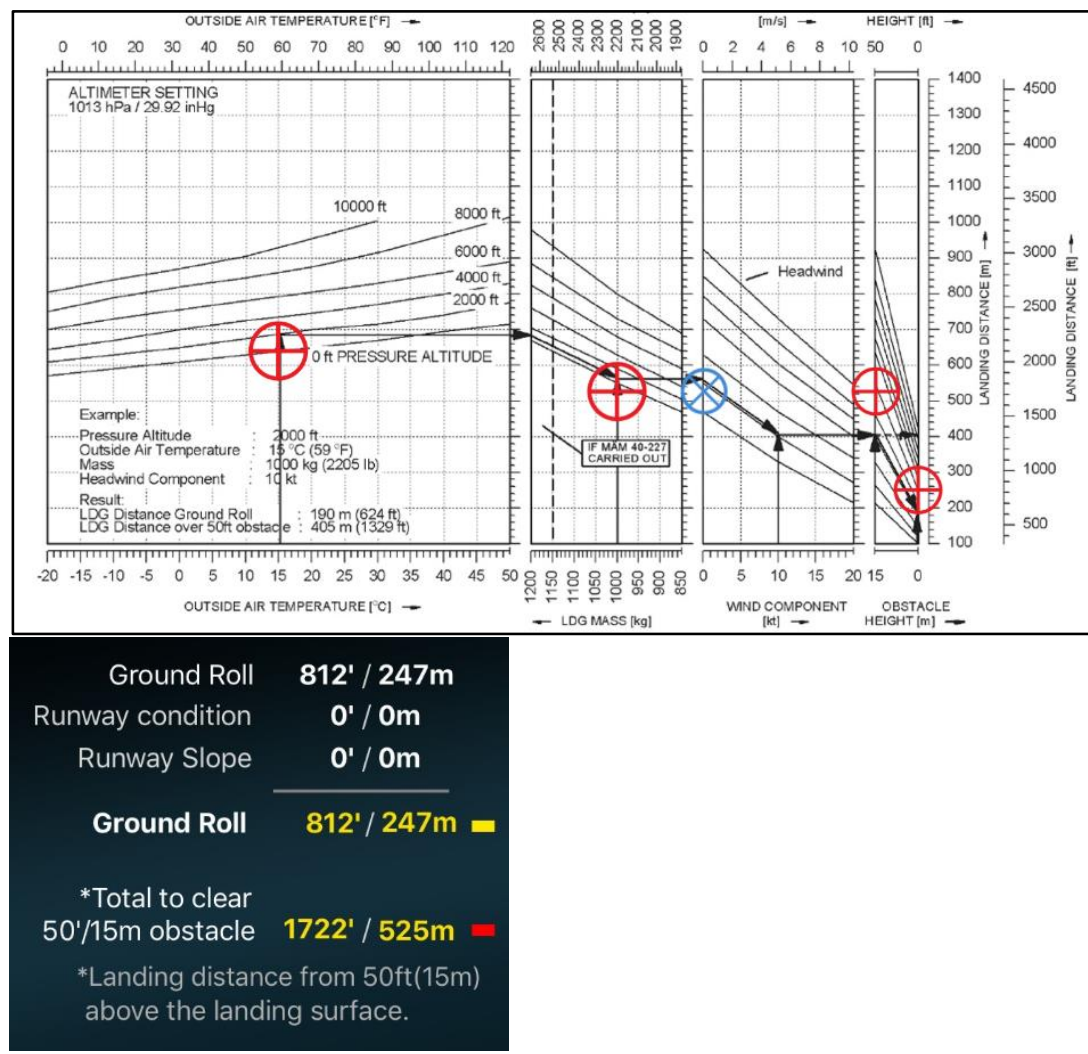

Figure 21. Gyronimo Landing Determination at ISA with No Wind 


\section{Landing Comparison 7: ISA Condition (MSL) with 20 Knot Headwind}

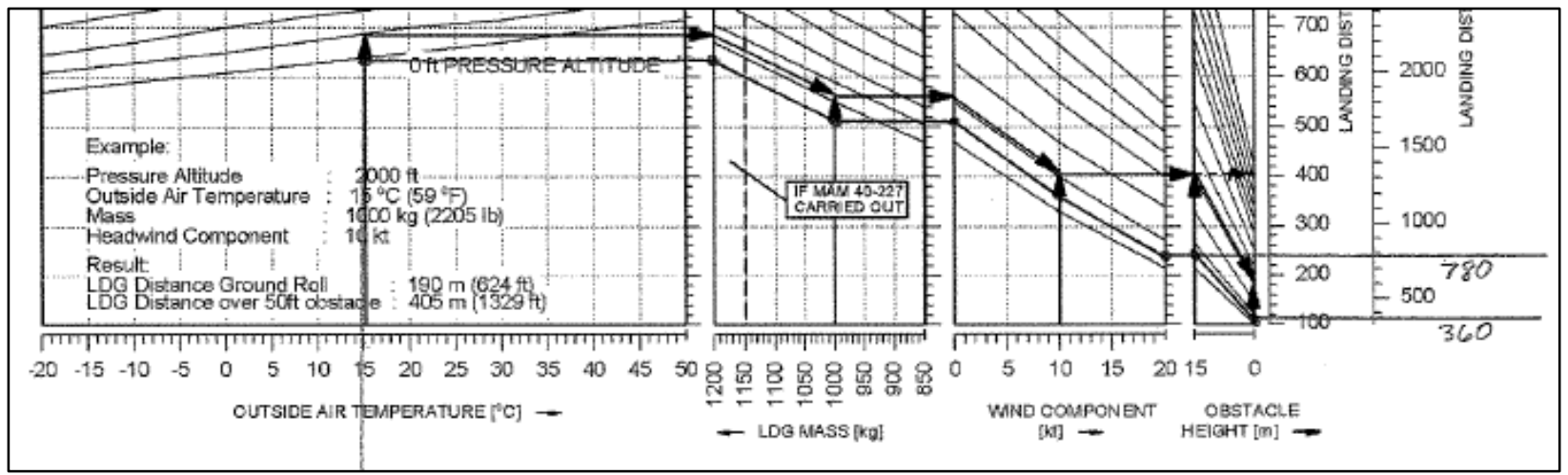

Figure 13. Gyronimo Default Landing at ISA with 20 Knot Headwind 
International Journal of Aviation, Aeronautics, and Aerospace, Vol. 5 [2018], Iss. 4, Art. 1

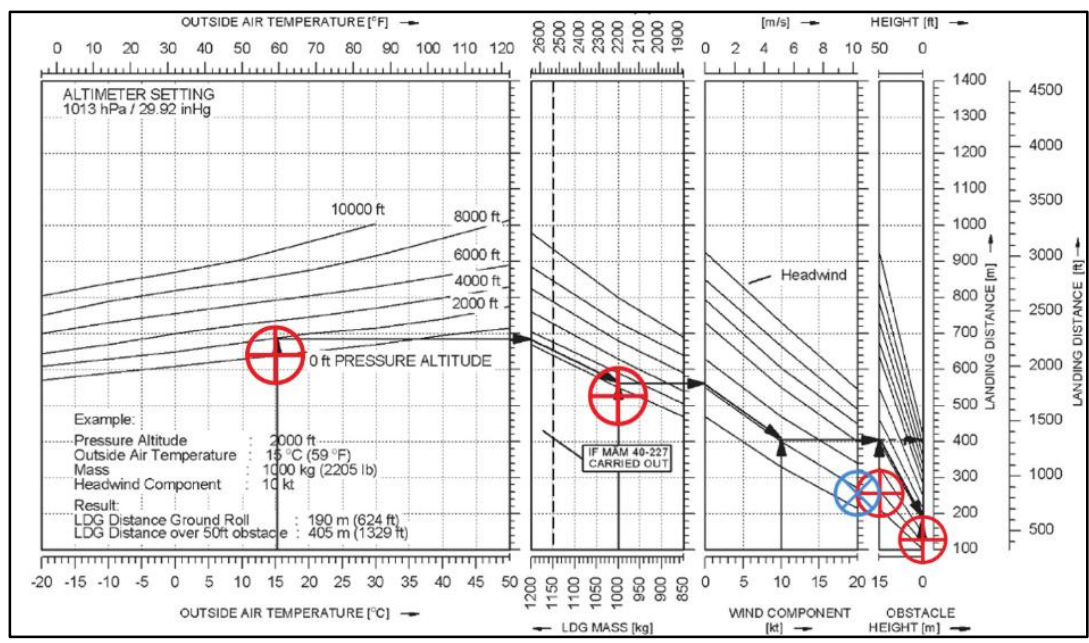

\begin{tabular}{|c|c|}
\hline Ground Roll & $408^{\prime} / 124 m$ \\
\hline Runway condition & $\mathrm{O}^{\prime} / \mathrm{Om}$ \\
\hline Runway Slope & $0^{\prime} / 0 \mathrm{~m}$ \\
\hline Ground Roll & $408^{\prime} / 124 m=$ \\
\hline $\begin{array}{l}{ }^{*} \text { Total to clear } \\
50^{\prime} / 15 \mathrm{~m}\end{array}$ & $830^{\prime} / 253 \mathrm{~m}$ \\
\hline $\begin{array}{l}\text { *Landing distan } \\
\text { above the land }\end{array}$ & $\begin{array}{l}\text { from } 50 f t(15 m) \\
\text { surface. }\end{array}$ \\
\hline
\end{tabular}

Figure 14. Gyronimo Default Landing at ISA with 20 Knot Headwind

\section{Landing Comparison 8: ISA Condition (5,000 feet) with No Wind}




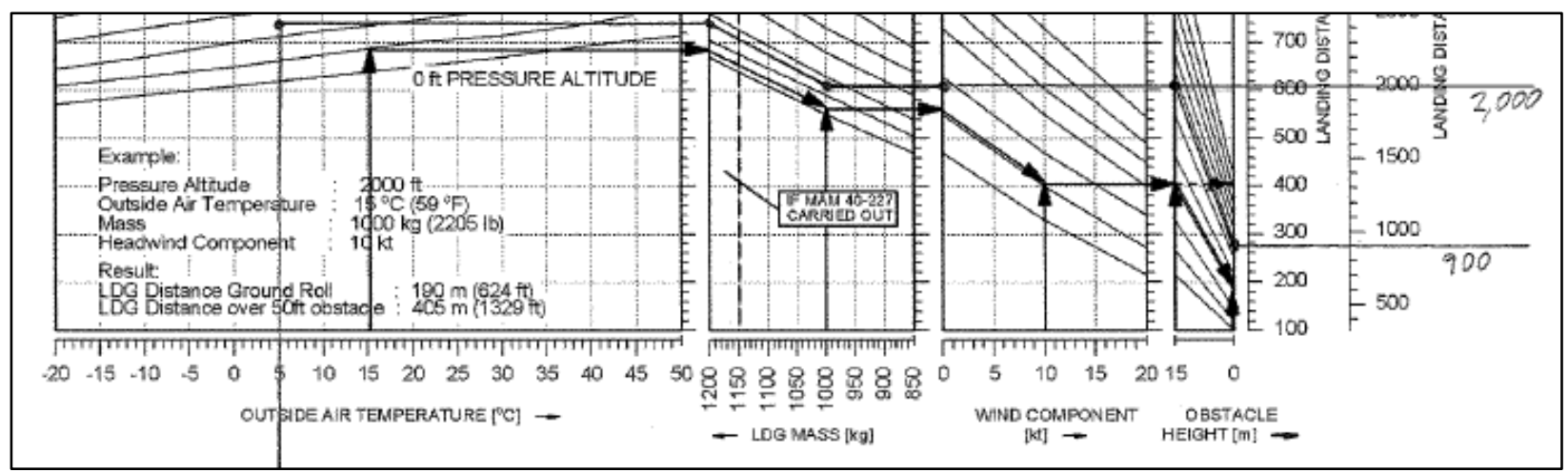

Figure 14. AFM Hot at ISA Condition (5,000 feet) with No Wind
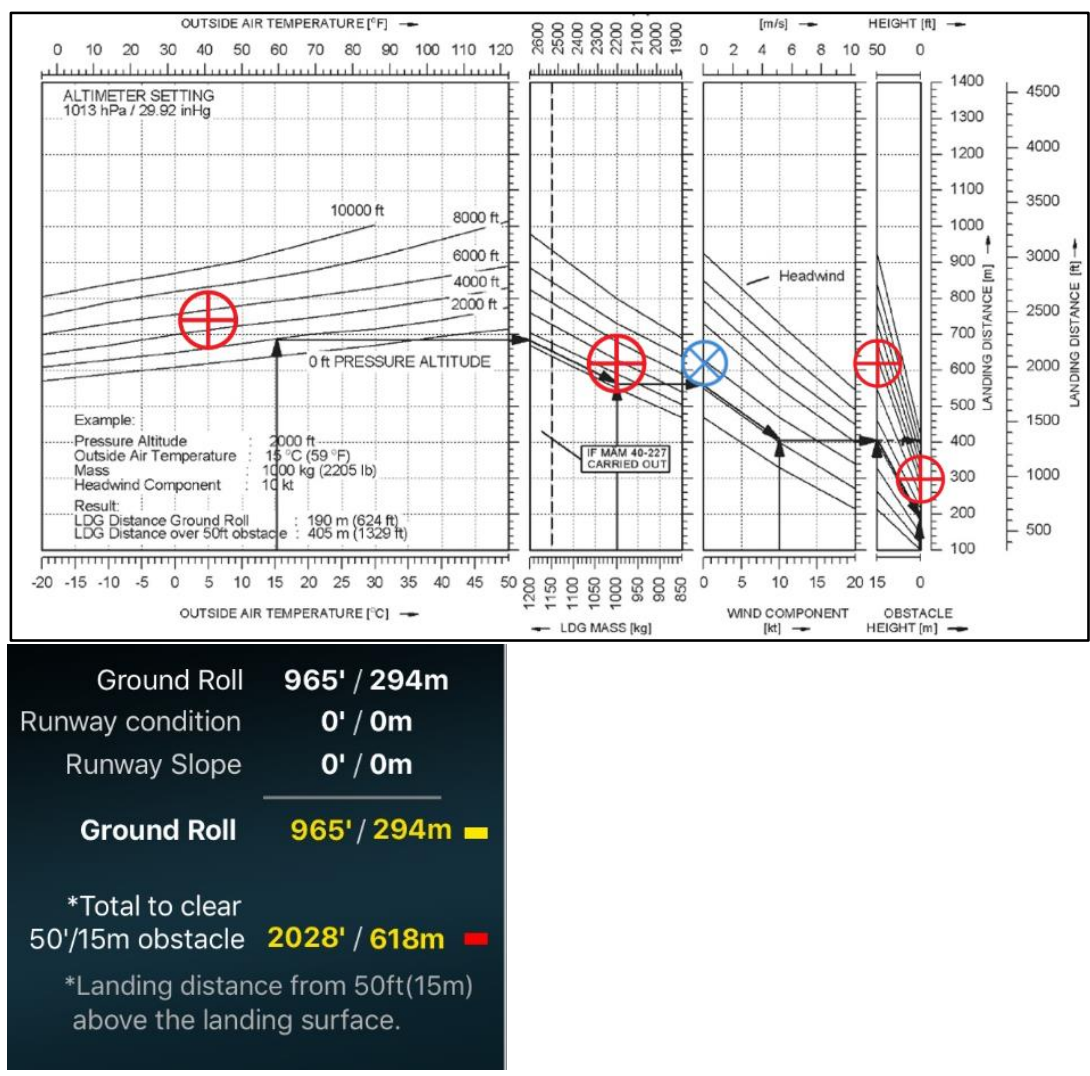

Figure 15. Gyronimo Hot ISA Condition (5,000 feet) with No Wind 


\section{Landing Comparison 9: ISA Condition (5,000 feet) with 20 Knot Headwind}

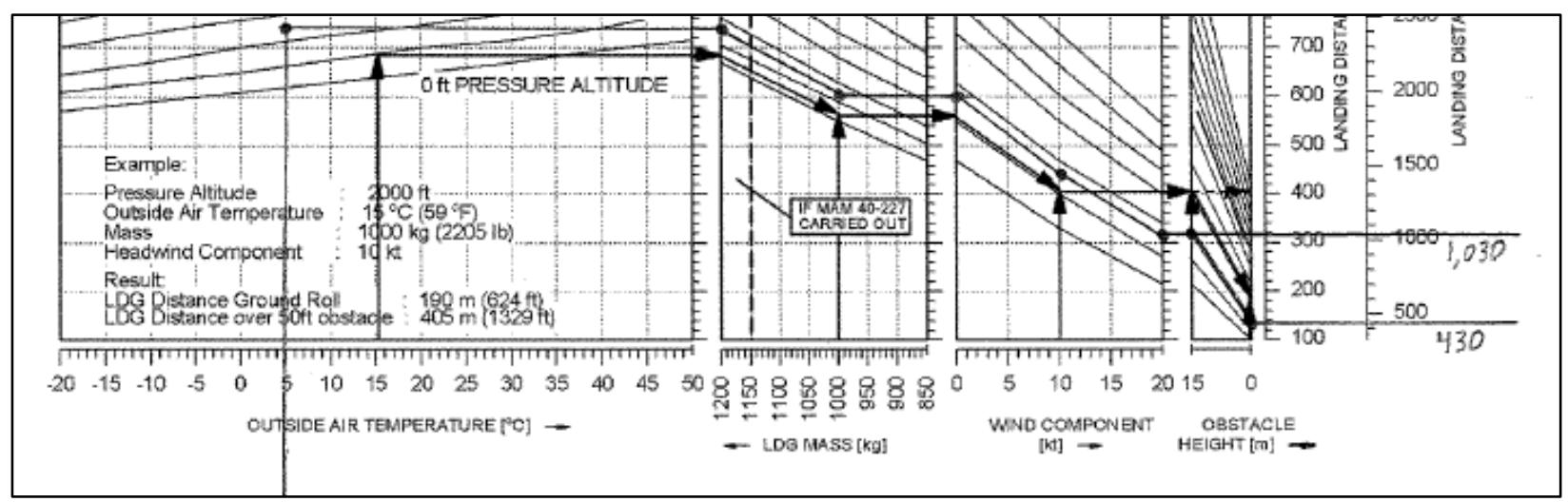

Figure 16. AFM ISA at 5,000 feet with 20 Knot Headwind Landing Determination 

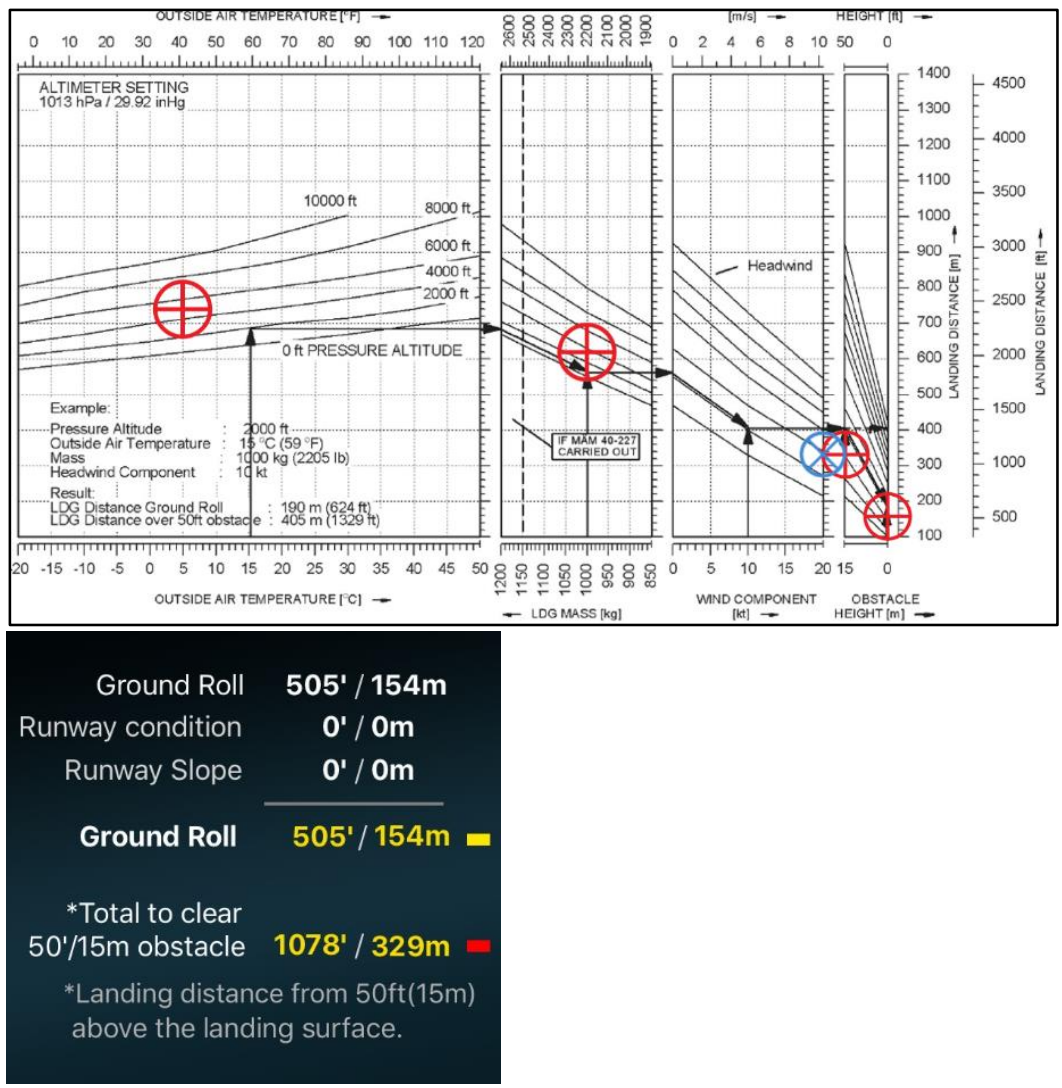

Figure 17. Gyronimo ISA at MSL with 20 Knot Headwind Landing Determination 


\section{Landing Comparison 10: Extreme Low Temperature}

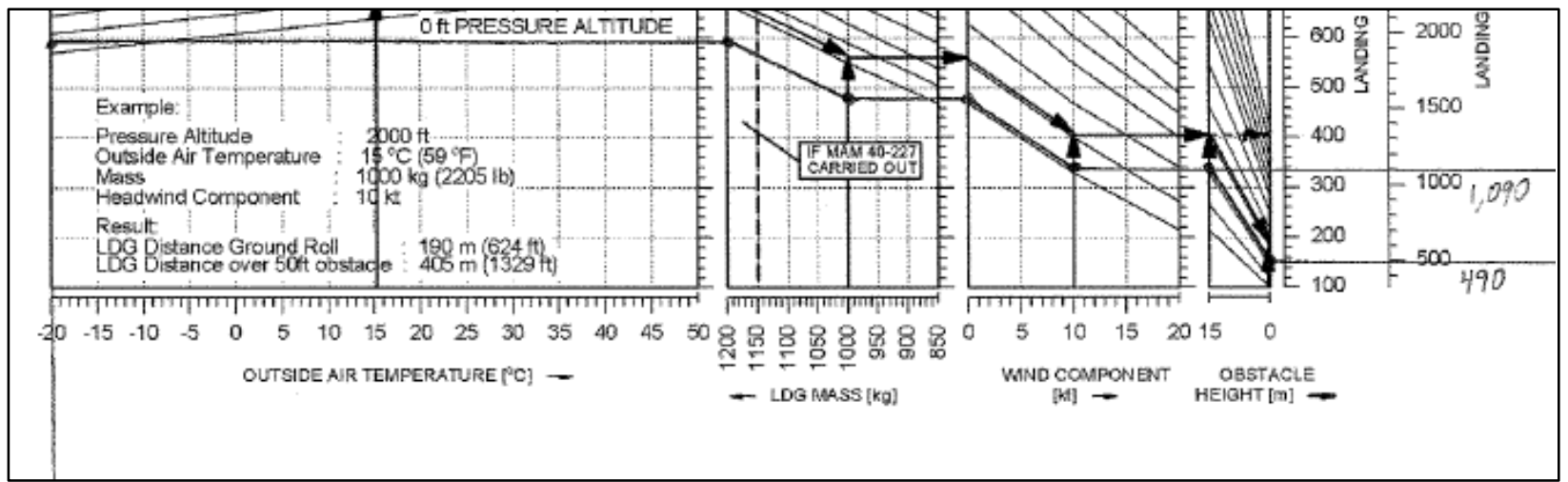

Figure 18. AFM Extreme Low Temperature Landing Determination

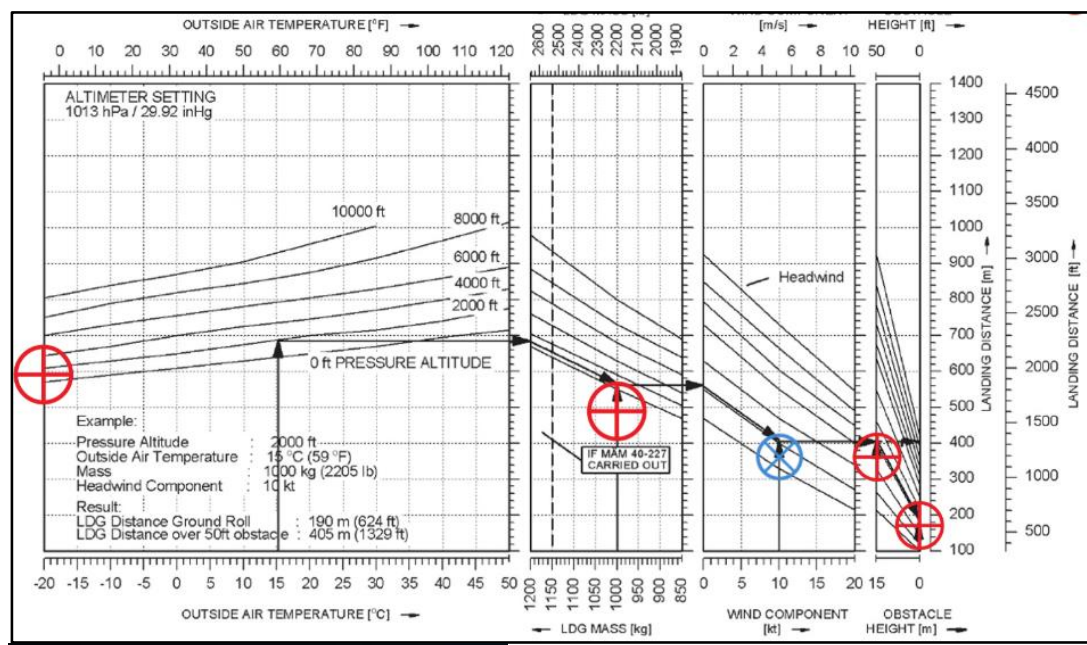

Ground Roll $549^{\prime} / 167 m$

Runway condition $\quad 0^{\prime} / 0 \mathrm{~m}$

Runway Slope $\quad \mathbf{0}^{\prime} / \mathbf{O m}$

Ground Roll $549^{\prime} / 167 m$

*Total to clear

$50^{\prime} / 15 \mathrm{~m}$ obstacle $1178^{\prime} / 359 \mathrm{~m}$

*Landing distance from $50 \mathrm{ft}(15 \mathrm{~m})$

above the landing surface.

Figure 19. Gyronimo Extreme Low Temperature Landing Determination 


\section{Landing Comparison 11: Temperature - 5 C}

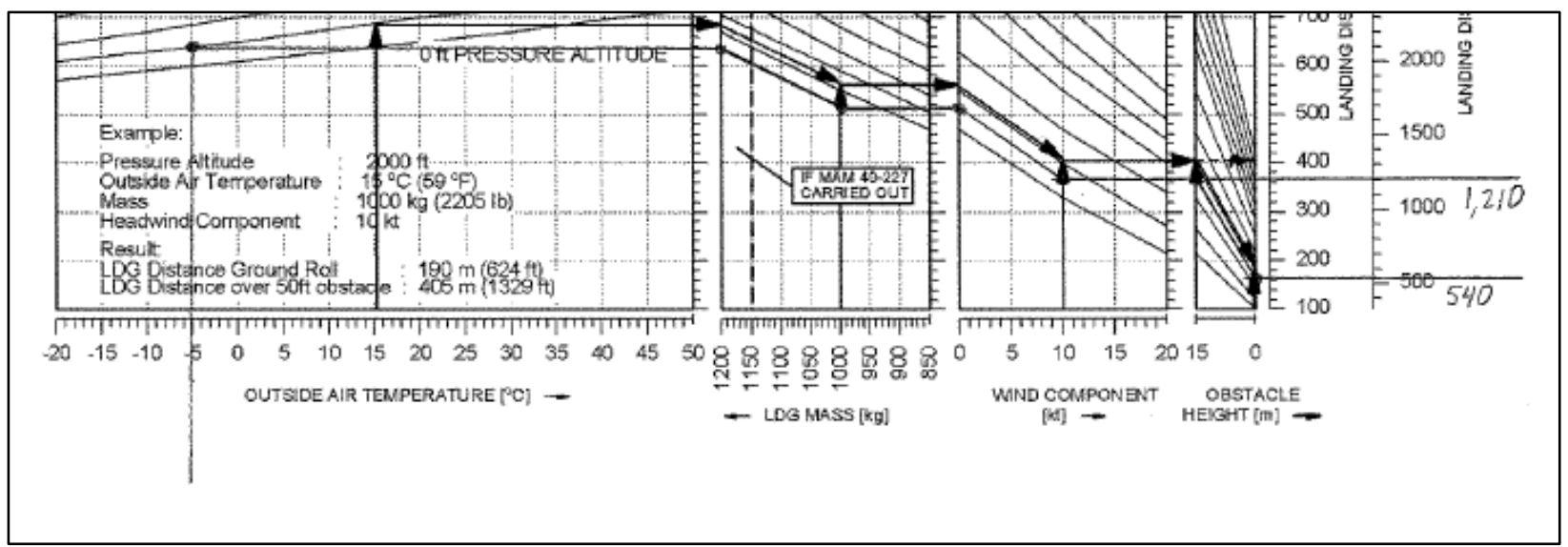

Figure 20. AFM Temperature - 5 C Landing Determination 


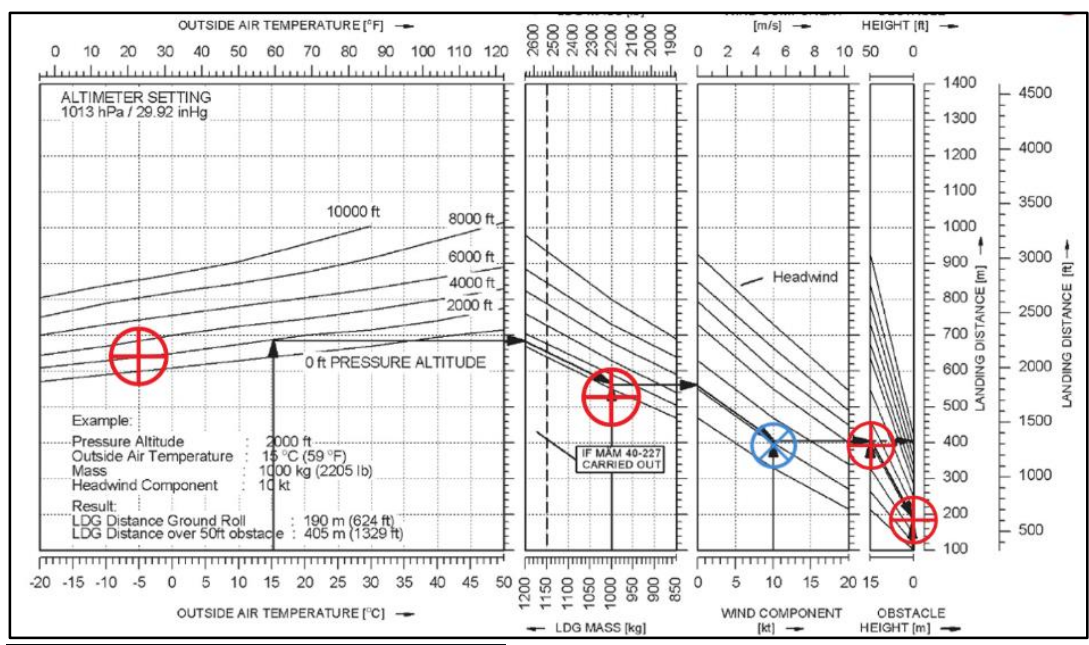

\begin{tabular}{|c|c|}
\hline Ground Roll & 594' / 181m \\
\hline Runway Slope & $0^{\prime} / 0 \mathrm{~m}$ \\
\hline Ground Roll & $594 ' / 181 \mathrm{~m}=$ \\
\hline *Total to clear & \\
\hline $50^{\prime} / 15 \mathrm{~m}$ obstacle & $1278^{\prime} / 390 m$ \\
\hline $\begin{array}{l}\text { *Landing distan } \\
\text { above the landi }\end{array}$ & $\begin{array}{l}\text { from } 50 \mathrm{ft}(15 \mathrm{~m}) \\
\text { g surface. }\end{array}$ \\
\hline
\end{tabular}

Figure 21. Gyronimo Temperature - 5 C Landing Determination

\section{Landing Comparison 12: Temperature $15 \mathrm{C}$}




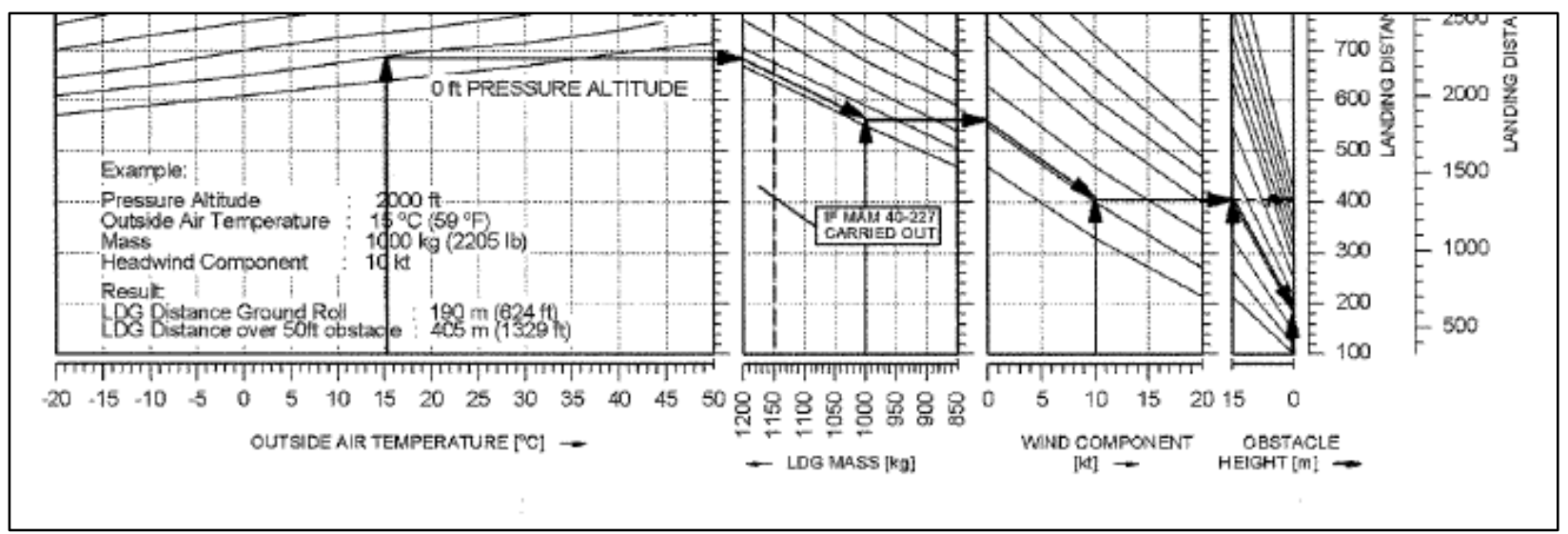

Figure 22. AFM 15 Degrees C Landing Determination.
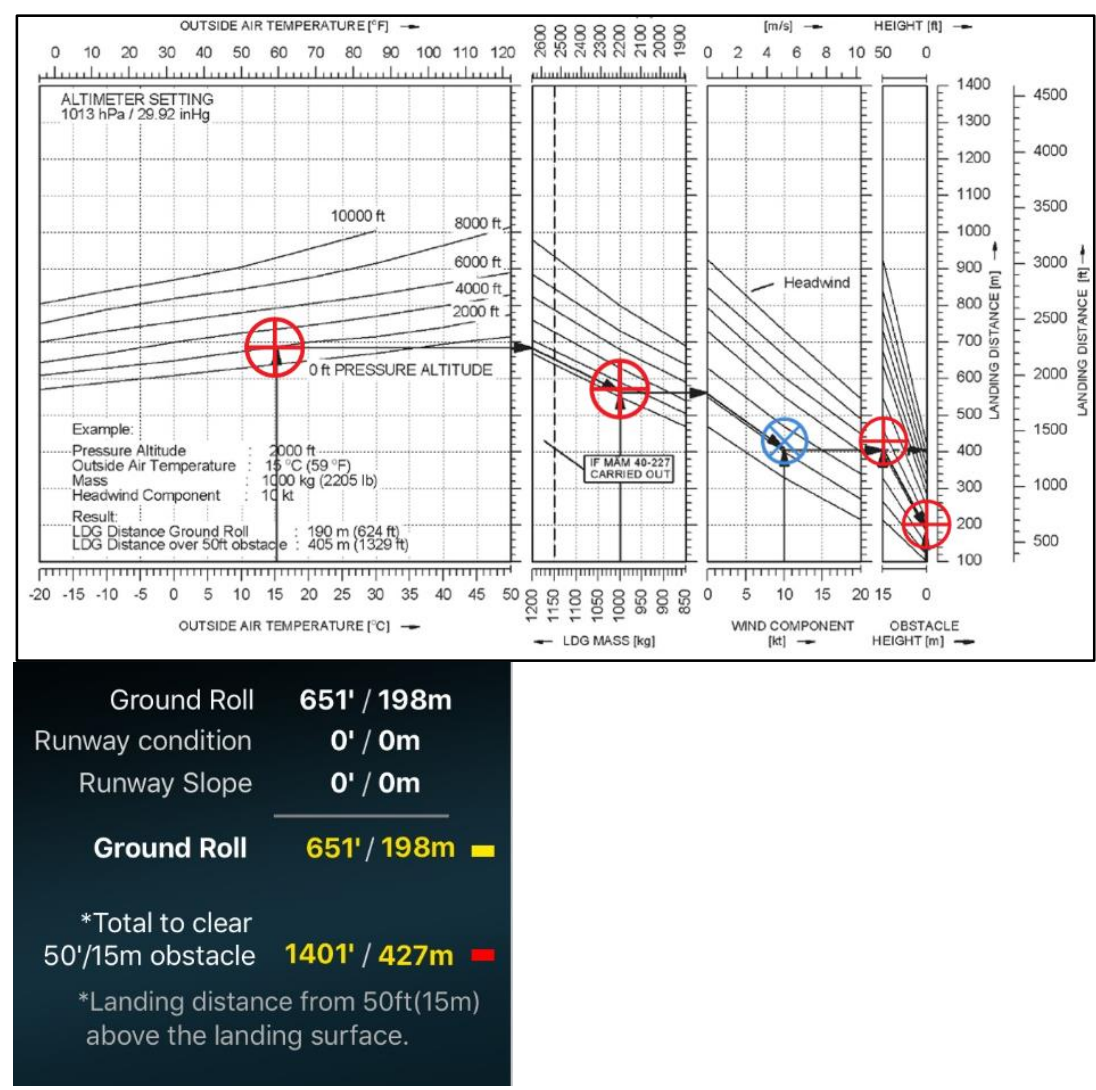

Figure 23. Gyronimo 15 Degrees C Landing Determination. 


\section{Landing Comparison 13: Temperature $30 \mathrm{C}$}

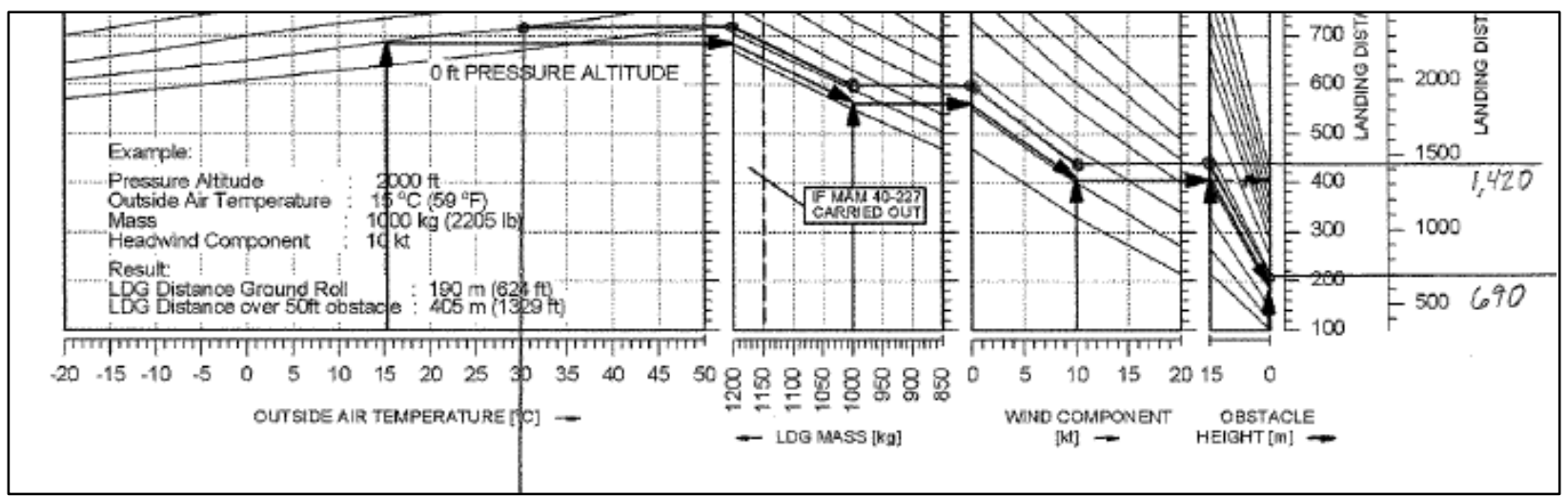

Figure 24. AFM Temperature 30 Degrees C Landing Determination 


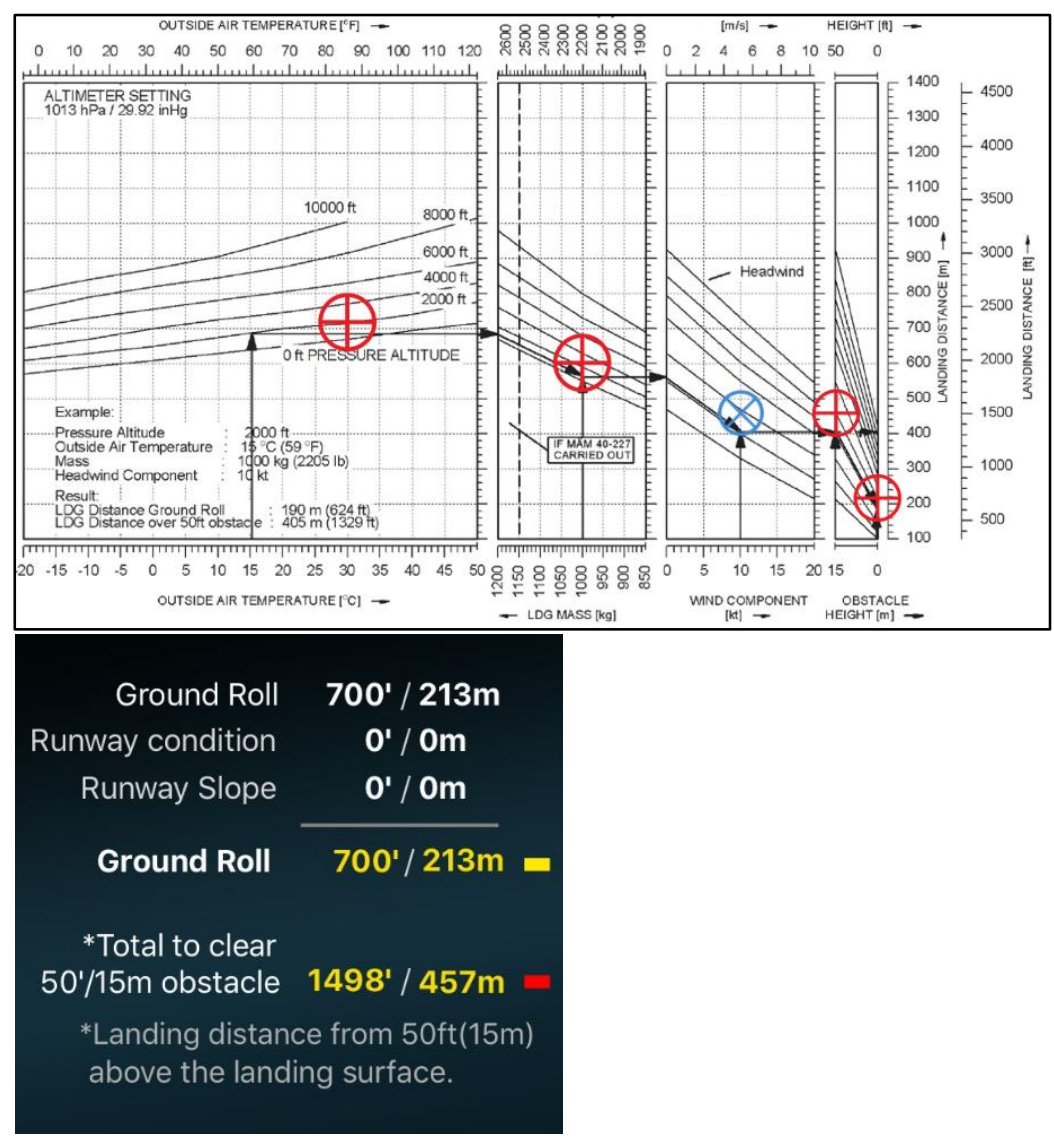

Figure 25. Gyronimo Temperature 30 Degrees C Landing Determination

Landing Comparison 14: Pressure Altitude 1,000 Feet 
International Journal of Aviation, Aeronautics, and Aerospace, Vol. 5 [2018], Iss. 4, Art. 1

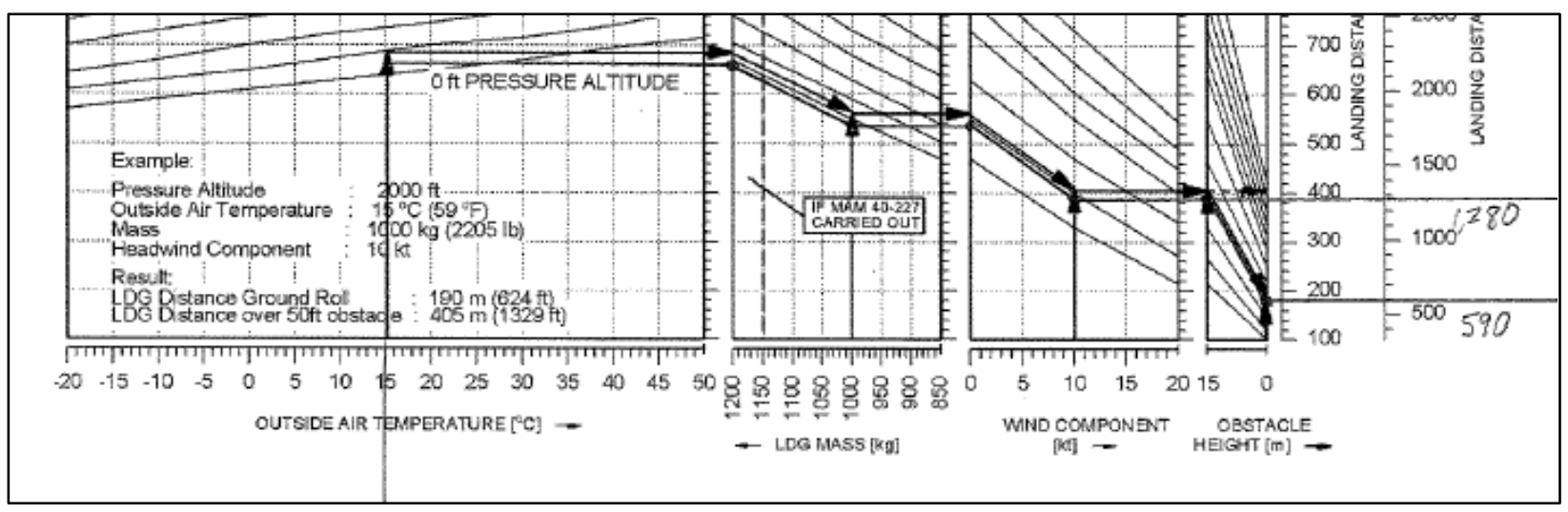

Figure 26. AFM Pressure Altitude 1,000 Feet Landing Determination
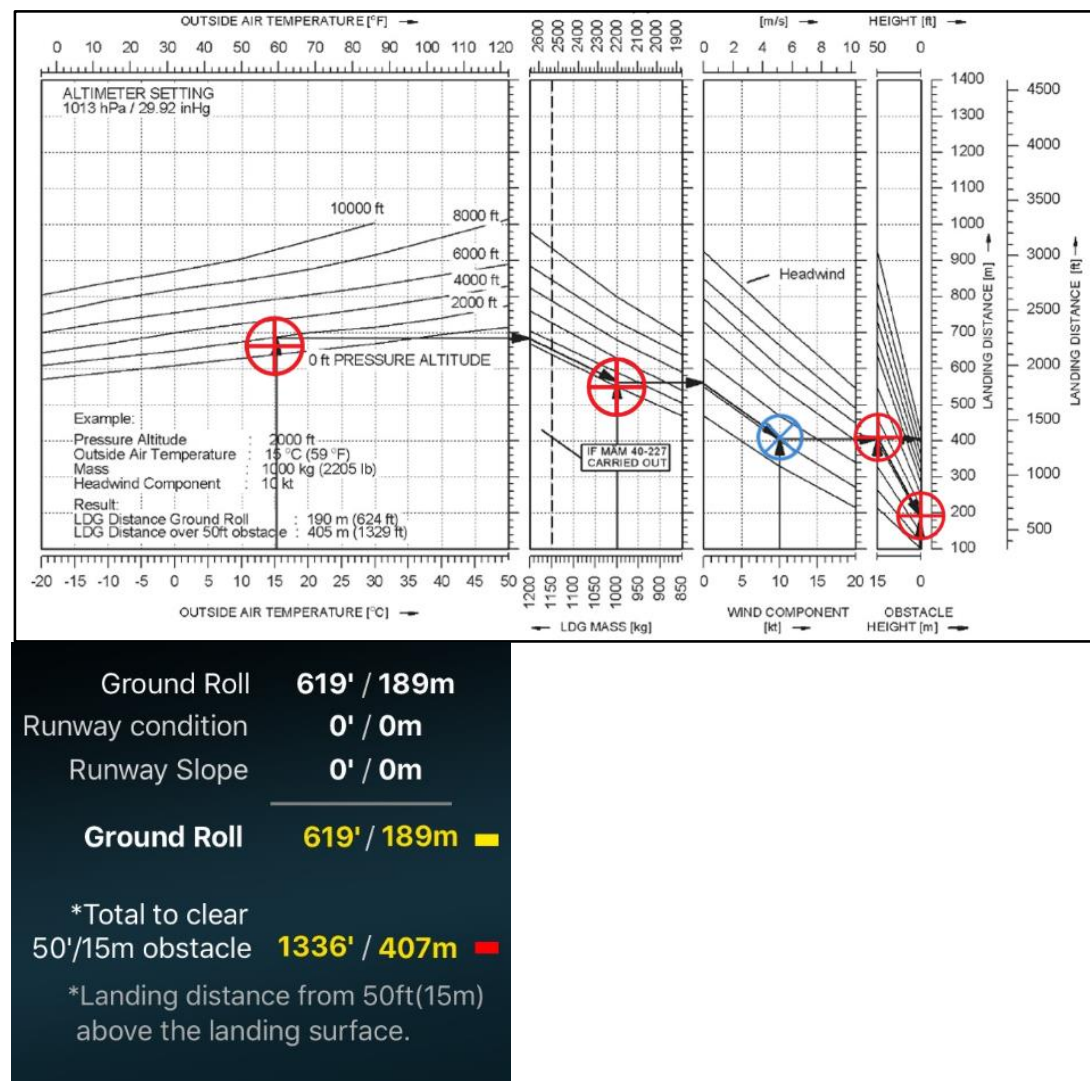

Figure 27. Gyronimo Pressure Altitude 1,000 Feet Landing Determination 


\section{Landing Comparison 15: Pressure Altitude 4,000 Feet}

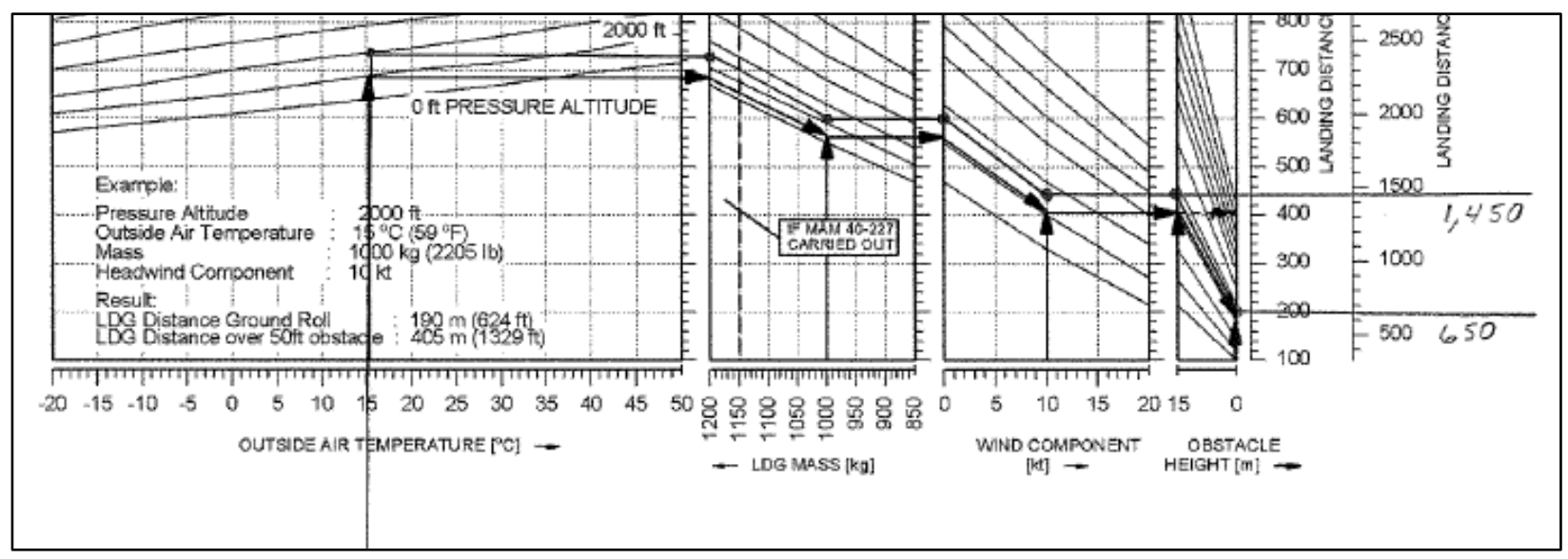

Figure 28. AFM Pressure Altitude 4,000 Feet Landing Determination 

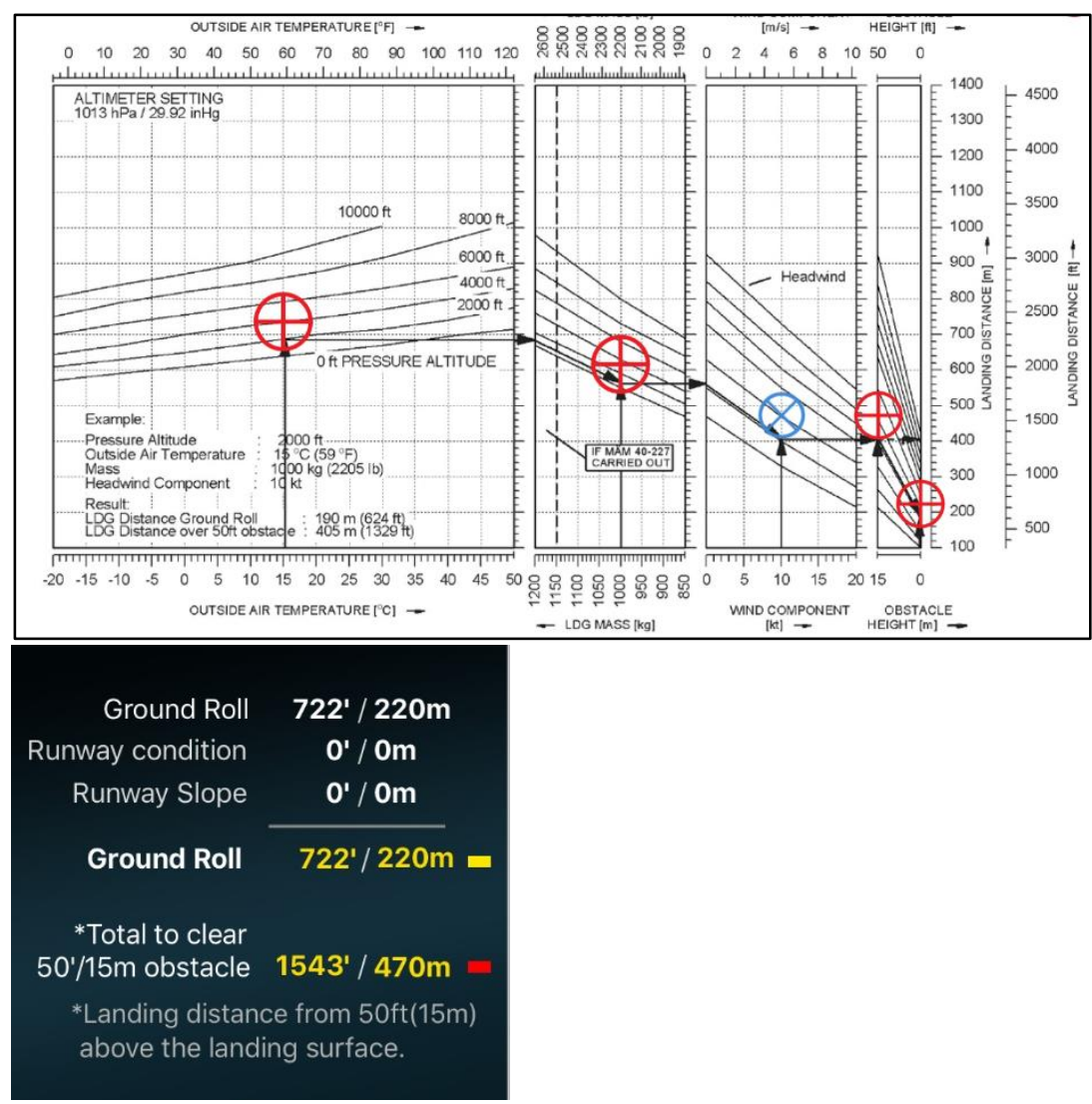

Figure 29. Gyronimo Pressure Altitude 4,000 Feet Landing Determination

\section{Landing Comparison 16: Pressure Altitude 8,000 Feet}




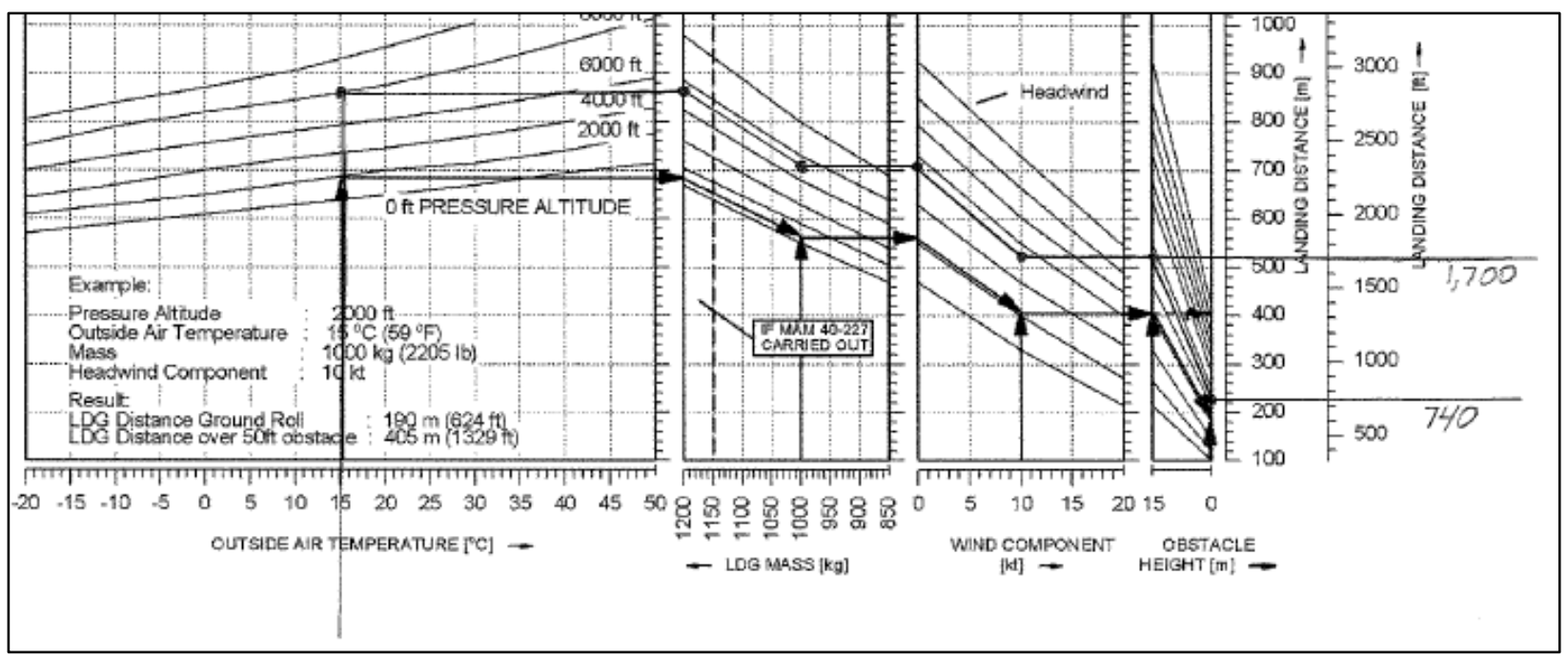

Figure 30. AFM Pressure Altitude 8,000 Feet Landing Determination

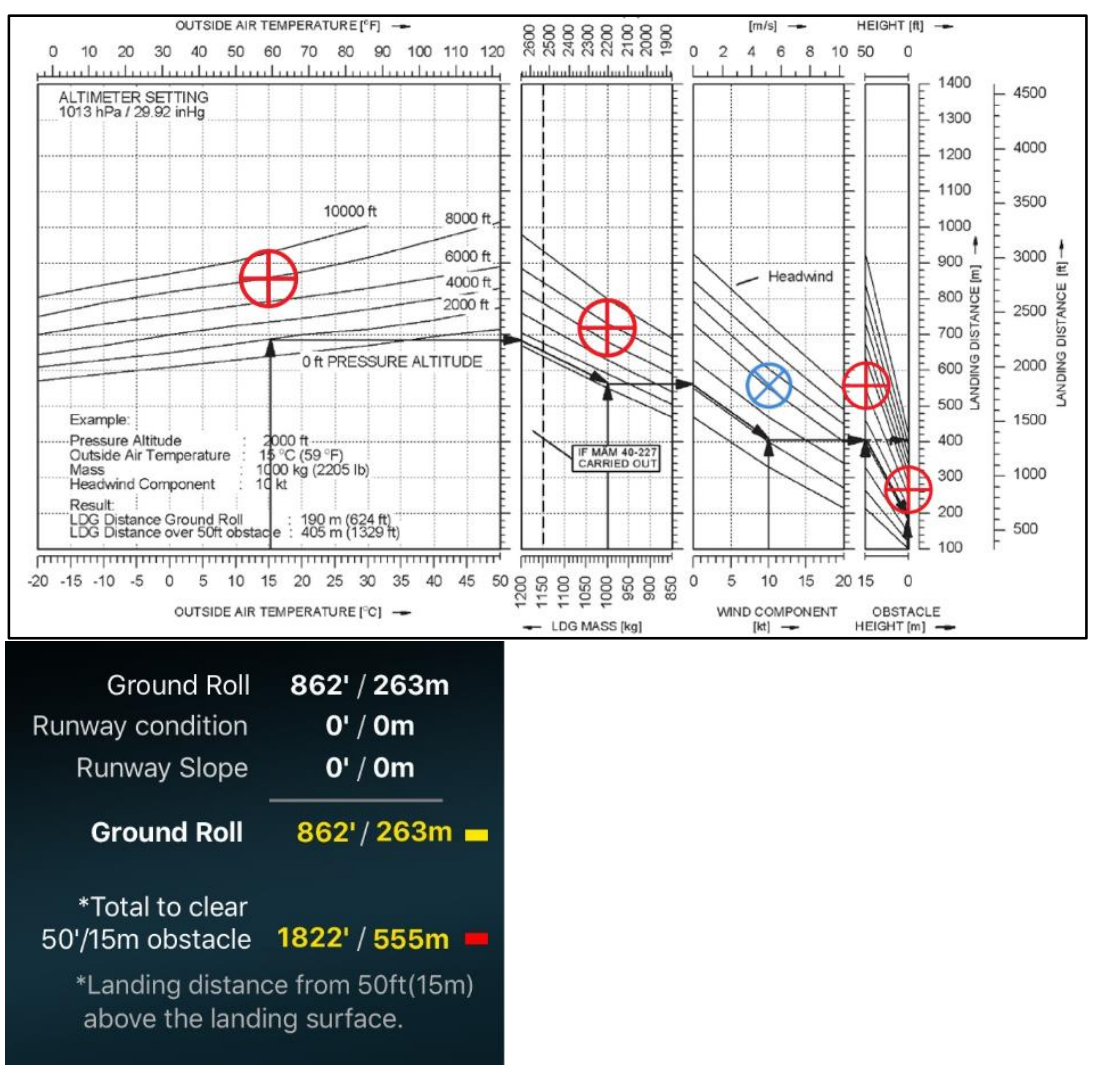

Figure 31. Gyronimo Pressure Altitude 8,000 Feet Landing Determination 
International Journal of Aviation, Aeronautics, and Aerospace, Vol. 5 [2018], Iss. 4, Art. 1

\section{Landing Comparison 17: Weight 2,000 Pounds}

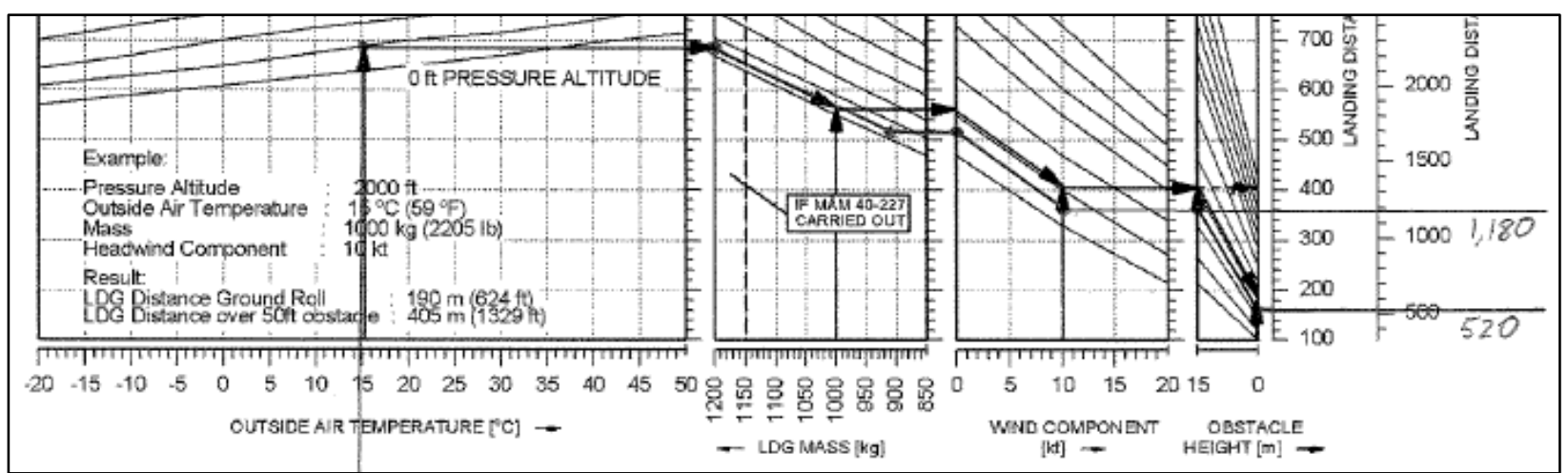

Figure 32. AFM Weight 2,000 Pounds Landing Determination 


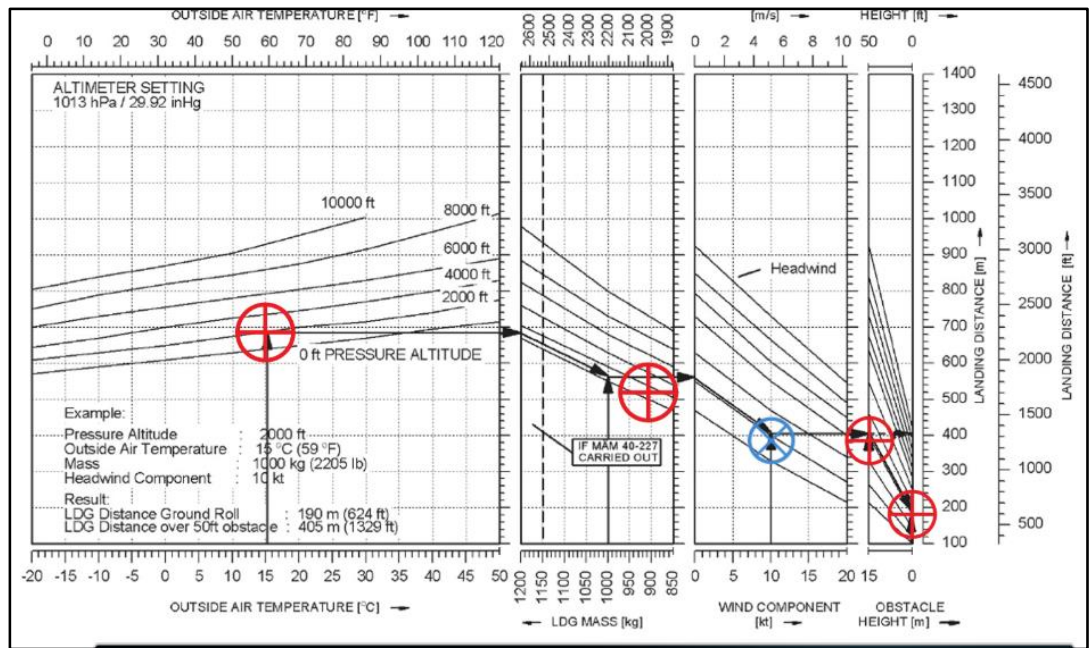

Ground Roll 584'/178m

Runway condition $\quad \mathbf{0}^{\prime} / \mathbf{O m}$

Runway Slope $\quad 0^{\prime} / 0 \mathrm{~m}$

Ground Roll $\quad 584^{\prime} / 178 m$

*Total to clear

$50^{\prime} / 15 \mathrm{~m}$ obstacle $1256^{\prime} / 383 \mathrm{~m}$

*Landing distance from $50 \mathrm{ft}(15 \mathrm{~m})$ above the landing surface.

Figure 33. Gyronimo Weight 2,000 Pounds Landing Determination

\section{Landing Comparison 18: Weight 2,400 Pounds}




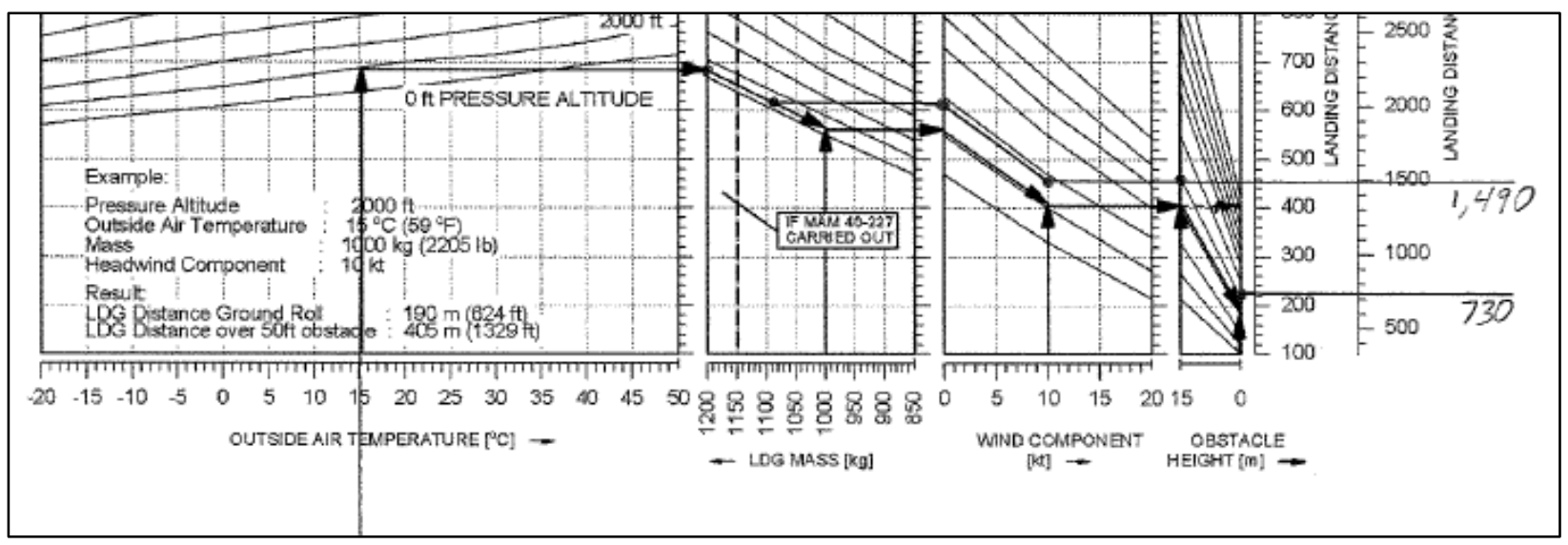

Figure 34. AFM Weight 2,400 Pounds Landing Determination
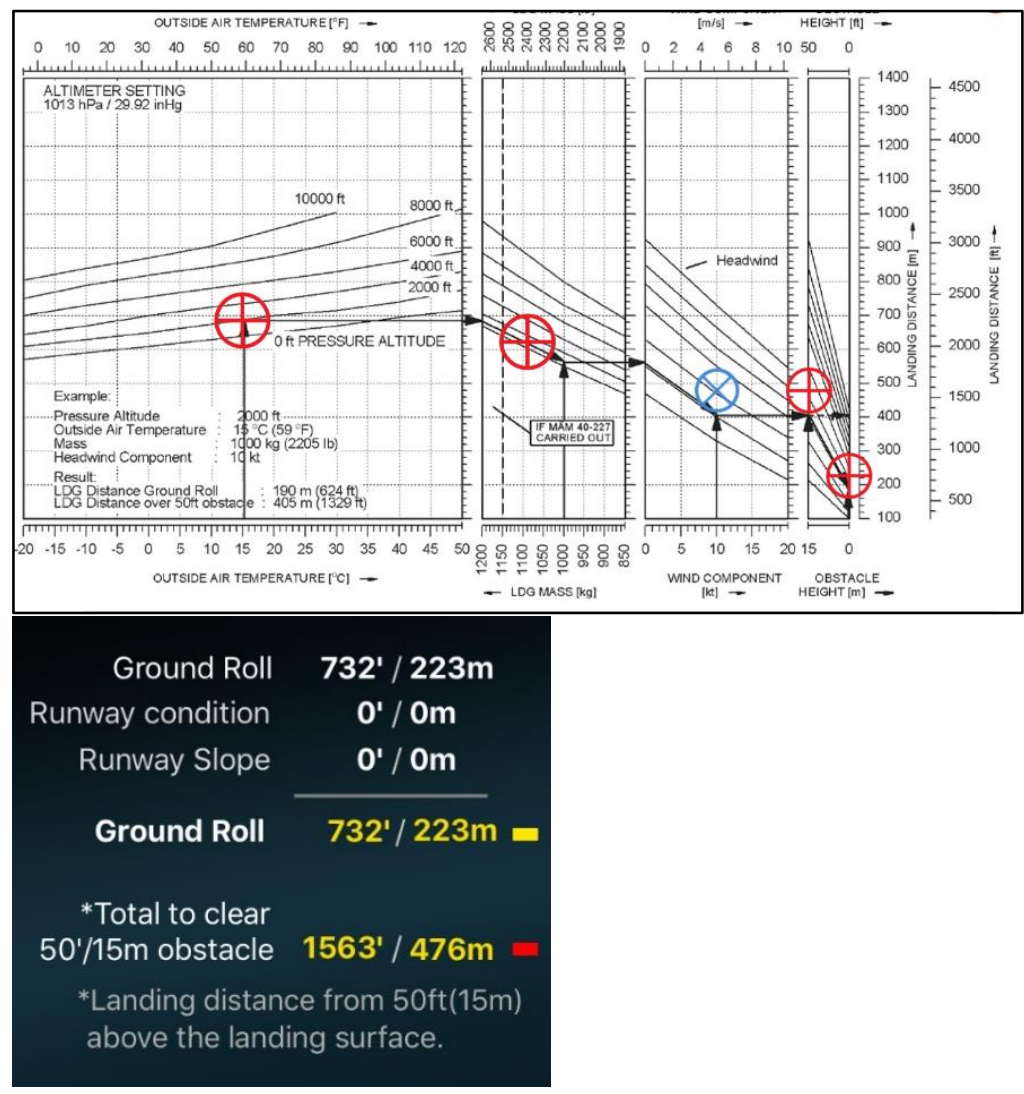

Figure 35. Gyronimo Weight 2,400 Pounds Landing Determination 


\section{Landing Comparison 19: Weight 2,600 Pounds}

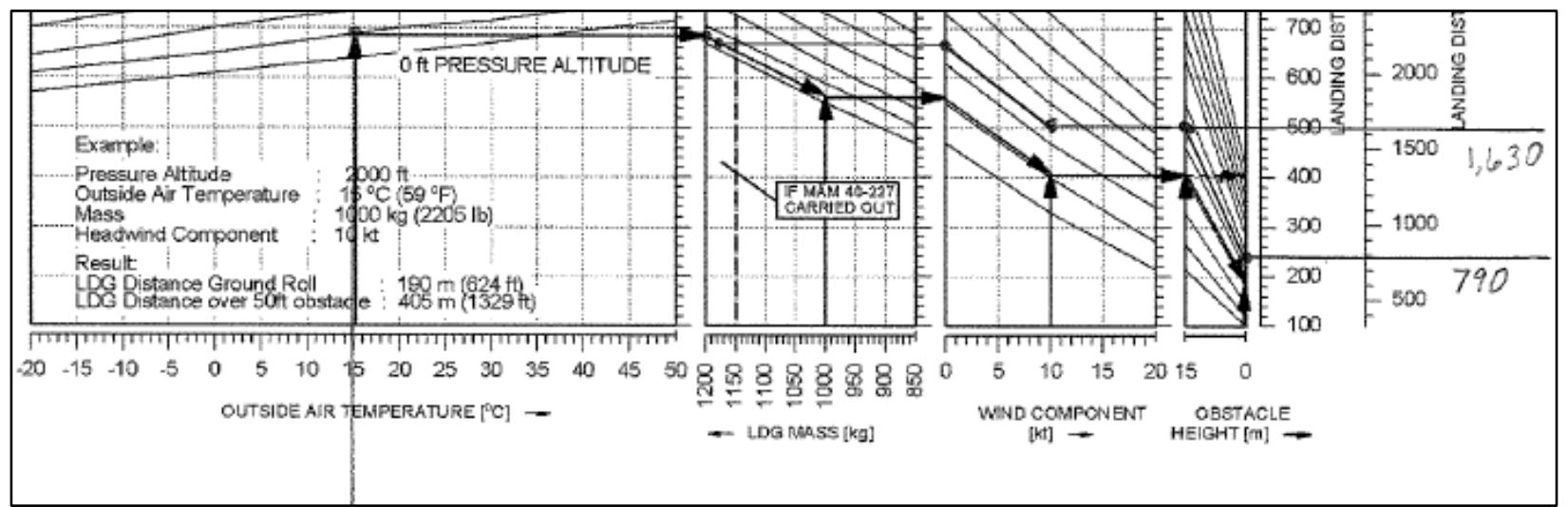

Figure 36. AFM Weight 2,600 Pounds Landing Determination 
International Journal of Aviation, Aeronautics, and Aerospace, Vol. 5 [2018], Iss. 4, Art. 1

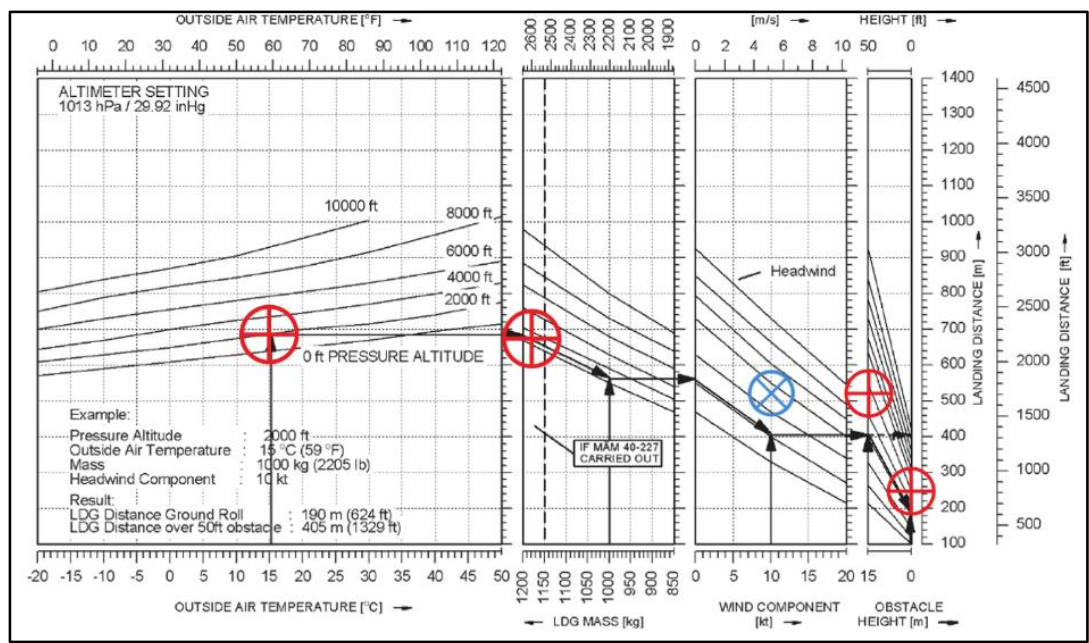

\begin{tabular}{|c|c|}
\hline Ground Roll & $851 '$ / 259m \\
\hline Runway condition & $0^{\prime} / 0 \mathrm{~m}$ \\
\hline Runway Slope & $0^{\prime} / 0 \mathrm{~m}$ \\
\hline Ground Roll & $851 ' / 259 m$ \\
\hline *Total to clear & \\
\hline $50^{\prime} / 15 \mathrm{~m}$ obstacle & $1806^{\prime} / 551 \mathrm{~m}$ \\
\hline $\begin{array}{l}\text { *Landing distan } \\
\text { above the landi }\end{array}$ & $\begin{array}{l}\text { e from } 50 \mathrm{ft}(15 \mathrm{~m}) \\
\text { ng surface. }\end{array}$ \\
\hline
\end{tabular}

Figure 37. Gyronimo Weight 2,600 Pounds Landing Determination

\section{Landing Comparison 20: 7 Knot Headwind}




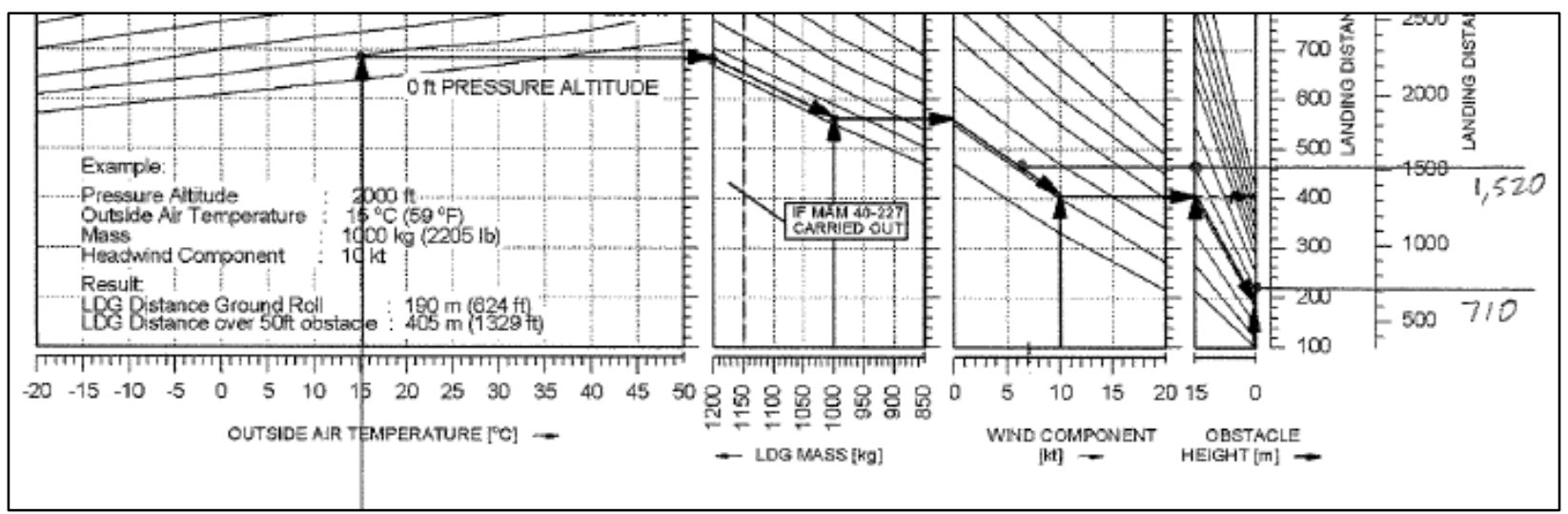

Figure 38. AFM 7 Knot Headwind Landing Determination
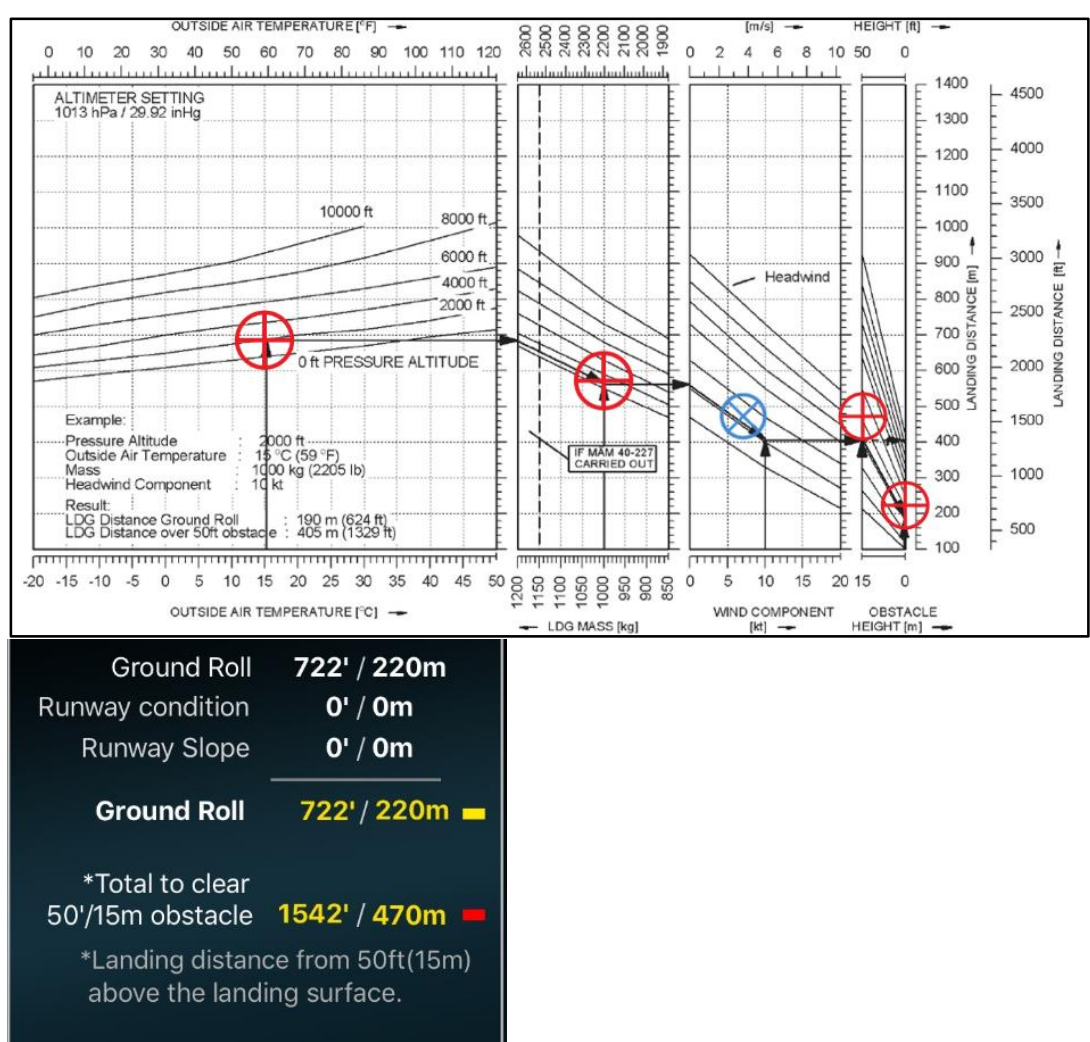

Figure 39. Gyronimo 7 Knot Headwind Landing Determination 


\section{Landing Comparison 21: 14 Knot Headwind}

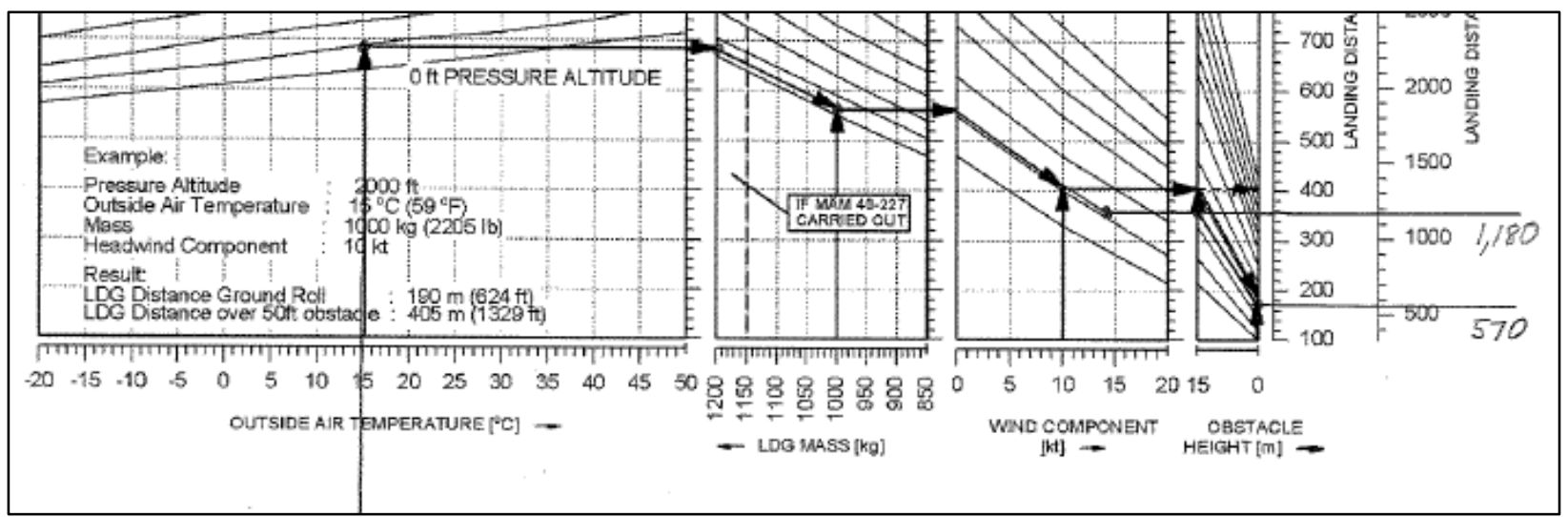

Figure 40. AFM 14 Knot Headwind Landing Determination 


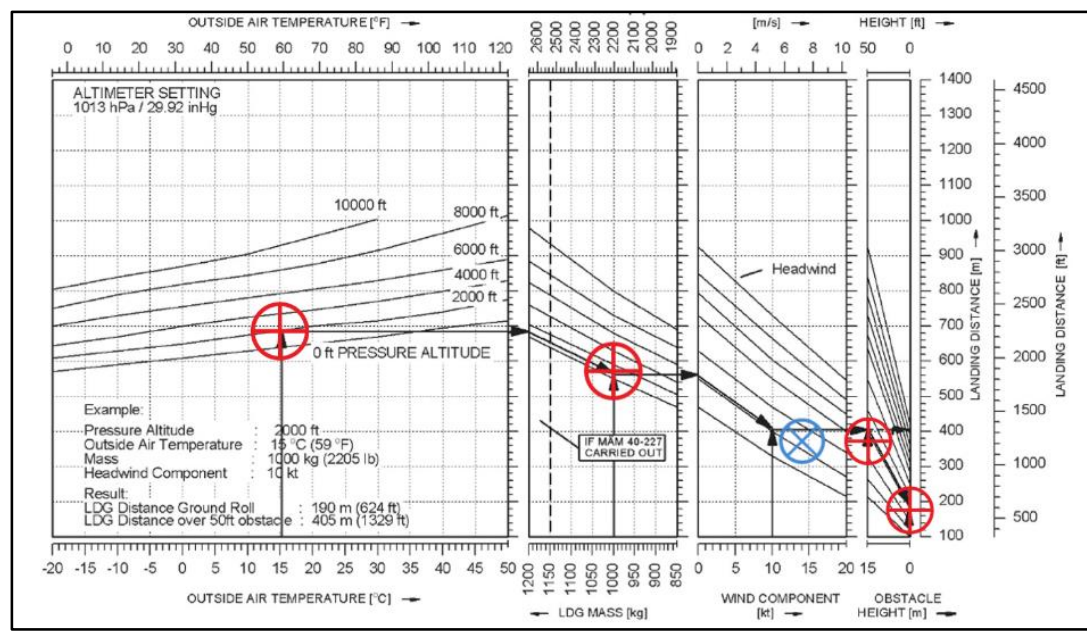

\begin{tabular}{rc} 
Ground Roll & $564^{\prime} / \mathbf{1 7 2 m}$ \\
Runway condition & $\mathbf{0}^{\prime} / \mathbf{O m}$ \\
Runway Slope & $\mathbf{0}^{\prime} / \mathbf{O m}$ \\
\cline { 2 - 2 } Ground Roll & $564^{\prime} / 172 \mathrm{~m}$ \\
& \\
*Total to clear & \\
$50^{\prime} / 15 \mathrm{~m}$ obstacle & $1212^{\prime} / 369 \mathrm{~m}$ \\
*Landing distance from $50 \mathrm{ft}(15 \mathrm{~m})$ \\
above the landing surface.
\end{tabular}

Figure 41. Gyronimo 14 Knot Headwind Landing Determination

\section{Landing Comparison 22: 20 Knot Headwind}




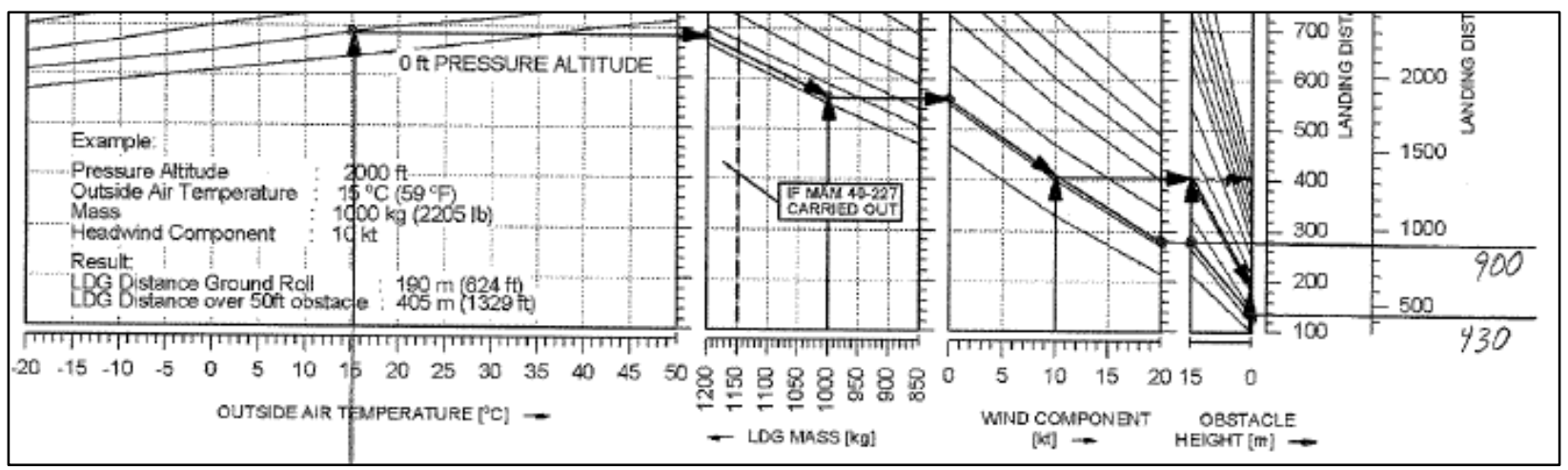

Figure 42. AFM 20 Knot Headwind Landing Determination

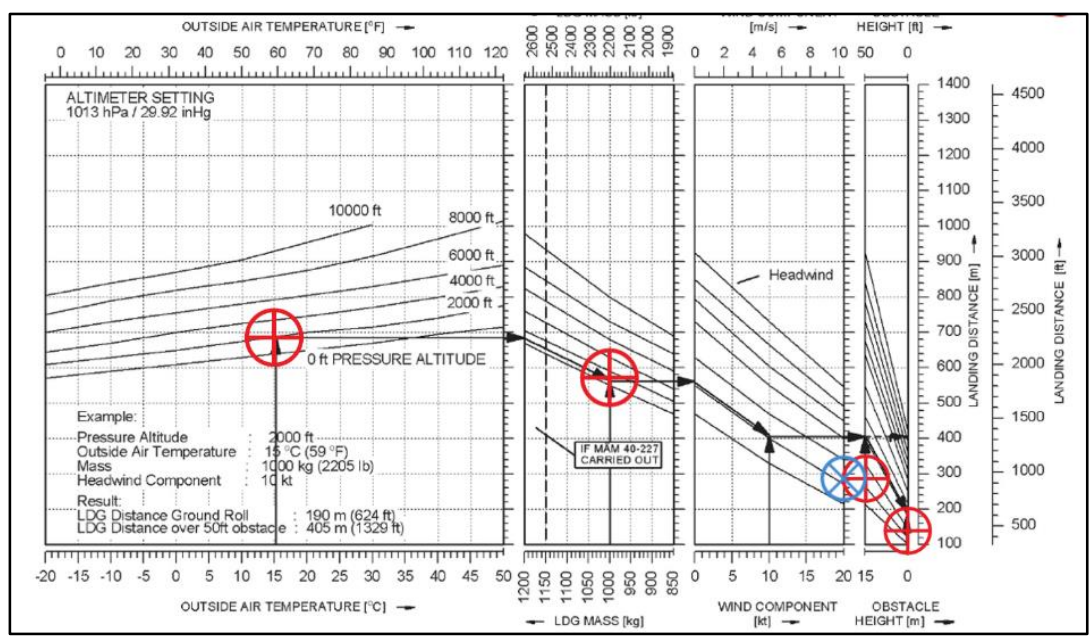

\begin{tabular}{|c|c|}
\hline Ground Roll & $444^{\prime} / 135 m$ \\
\hline Runway Slope & $\mathrm{O}^{\prime} / 0 \mathrm{~m}$ \\
\hline Ground Roll & $444^{\prime} / 135 \mathrm{~m}=$ \\
\hline *Total to clear & \\
\hline $50^{\prime} / 15 \mathrm{~m}$ obstacle & $929^{\prime} / 283 m$ \\
\hline \multicolumn{2}{|c|}{$\begin{array}{l}\text { *Landing distance from } 50 \mathrm{ft}(15 \mathrm{~m}) \\
\text { above the landing surface. }\end{array}$} \\
\hline
\end{tabular}

Figure 43. Gyronimo 20 Knot Headwind Landing Determination 


\section{Landing Comparison 23: Wet Grass (2-4 inches)}

The default landing ground roll was 624 feet. The default landing distance over a 50-foot obstacle was 1,329 feet. According to the AFM, grass from 2-4 inches in length increases the takeoff ground roll by $15 \%$, and if wet, an additional 10\%. Thus, the AFM ground roll for wet grass was $780 \mathrm{feet}$, and the landing distance over a 50-foot obstacle under the same conditions was 1,485 feet. 


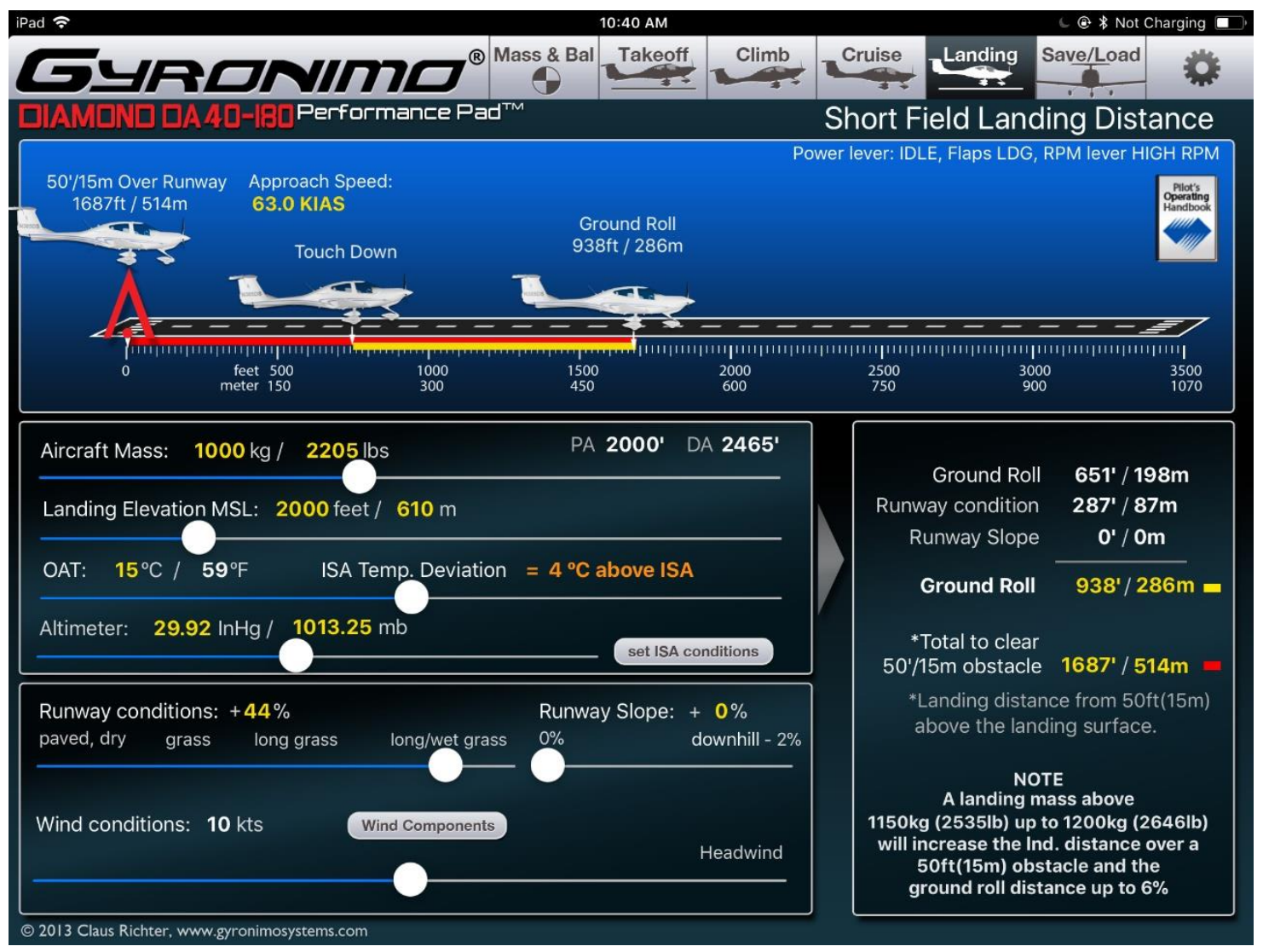

Figure 44. Gyronimo Wet Grass Landing Determination

\section{Landing Comparison 24: 2\% Negative Runway Slope}


The default landing ground roll was 624 feet. The default landing distance over a 50-foot obstacle was 1,329 feet. The AFM states that a $\%$ negative slope upon landing will increase the landing ground distance by $10 \%$, and that this effect upon the ground roll can be greater. A $10 \%$ increase in both values yields a landing ground roll of 686 feet and landing distance over a 50- foot obstacle of 1,462 feet.

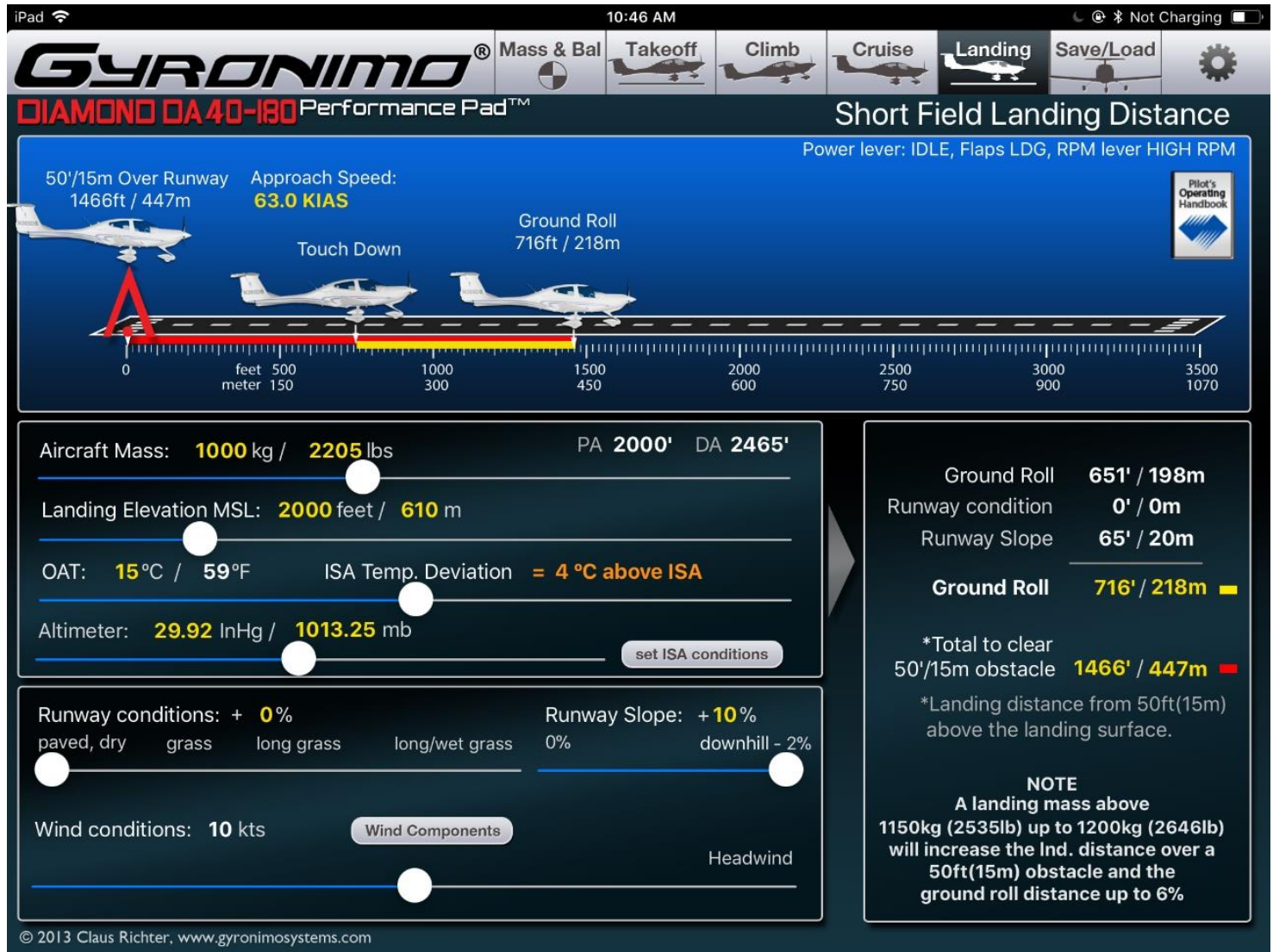

Figure 45. Gyronimo 2\% Negative Runway Slope Landing Determination 